MILANO FELIPE DOS SANTOS FERREIRA MARQUES

PARTICIPAÇÃO DO CANAL DE POTÁSSIO DEPENDENTE DE ATP (KATP) NA RESISTÊNCIA À INSULINA EM MÚSCULO ESQUELÉTICO: CORRELAÇÃO COM O GENE DO GLUT4

Tese apresentada ao Programa de PósGraduação em Fisiologia Humana do Instituto de Ciências Biomédicas da Universidade de São Paulo, para obtenção do Titulo de Doutor em Ciências. 
MILANO FELIPE DOS SANTOS FERREIRA MARQUES

\section{PARTICIPAÇÃO DO CANAL DE POTÁSSIO DEPENDENTE DE ATP (KATP) NA RESISTÊNCIA À INSULINA EM MÚSCULO ESQUELÉTICO: CORRELAÇÃO COM O GENE DO GLUT4}

Tese apresentada ao Programa de PósGraduação em Fisiologia Humana do Instituto de Ciências Biomédicas da Universidade de São Paulo, para obtenção do Titulo de Doutor em Ciências.

Aera de Concentração: Fisiologia Humana

Orientador: Prof. Dr. Ubiratan Fabres Machado

Versão original 
DADOS DE CATALOGAÇÃO NA PUBLICAÇÃO (CIP)

Serviço de Biblioteca e Informação Biomédica do

Instituto de Ciências Biomédicas da Universidade de São Paulo

(c) reprodução total

Marques, Milano Felipe dos Santos Ferreira.

Participação do canal de potássio dependente de ATP (KATP) na resistência à insulina em músculo esquelético: correlação com o gene do GLUT4 / Milano Felipe dos Santos Ferreira Marques. -- São Paulo, 2013.

Orientador: Prof. Dr. Ubiratan Fabres Machado.

Tese (Doutorado) - Universidade de São Paulo. Instituto de Ciências Biomédicas. Departamento de Fisiologia e Biofísica. Área de concentração: Fisiologia Humana. Linha de pesquisa: Transportadores de glicose e resistência à insulina.

Versão do título para o inglês: Participation of ATP-sensitive potassium (KATP) channel in skeletal muscle insulin resistance: correlation with GLUT4 gene.

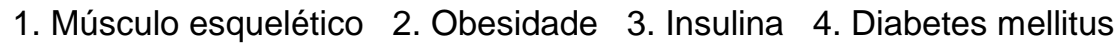
5. Cultura de células correlação com o gene do GLUT4 6. Metabolismo I. Machado, Prof. Dr. Ubiratan Fabres II. Universidade de São Paulo. Instituto de Ciências Biomédicas. Programa de Pós-Graduação em Fisiologia Humana III. Título. 


\section{UNIVERSIDADE DE SÃO PAULO \\ INSTITUTO DE CIÊNCIAS BIOMÉDICAS}

Candidato(a):

Milano Felipe dos Santos Ferreira Marques.

Título da Tese:

Participação do canal de potássio dependente de ATP (KATP) na resistência à insulina em músculo esquelético: correlação com o gene do GLUT4.

Orientador(a):

Prof. Dr. Ubiratan Fabres Machado.

A Comissão Julgadora dos trabalhos de Defesa da Tese de Doutorado, em sessão pública realizada a considerou
( ) Aprovado(a)
( ) Reprovado(a)

\begin{tabular}{|c|c|}
\hline Examinador(a): & $\begin{array}{l}\text { Assinatura: } \\
\text { Nome: ........ } \\
\text { Instituição: }\end{array}$ \\
\hline Examinador(a): & $\begin{array}{l}\text { Assinatura: } \\
\text { Nome: ........ } \\
\text { Instituição: }\end{array}$ \\
\hline Examinador(a): & $\begin{array}{l}\text { Assinatura: } \\
\text { Nome: ........ } \\
\text { Instituição: }\end{array}$ \\
\hline Examinador(a): & $\begin{array}{l}\text { Assinatura: } \\
\text { Nome: ......... } \\
\text { Instituição: . }\end{array}$ \\
\hline Presidente: & $\begin{array}{l}\text { Assinatura: } \\
\text { Nome: ......... } \\
\text { Instituição: . }\end{array}$ \\
\hline
\end{tabular}




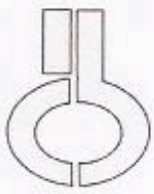

UNIVERSIDADE DE SÃO PAULO

INSTITUTO DE CIÊNCIAS BIOMÉDICAS

Cidade Universitária "Armando de Salles Oliveira"

Av. Prof, Lineu Prestes, 2415 - CEP. 05508 -000 Sào Paulo, SP - Bras

Telefone :(55) (011) $3091.7733-$ telefax : (55) (011) 3091.7438

e-mail: cepegicb.usp.br

\section{Certificado}

Certificamos que o protocolo registrado sob $\mathrm{n}^{\circ} \mathbf{1 1 6}$ nas fls. 62 do livro 02 para uso de animais em experimentaçāo, sob a responsabilidade de Ubiratan Fabres Machado, Coordenador(a) da Linha de pesquisa "Estudo da expressão do canal de potássio dependente de ATP (KATP) na resistência à insulina: Possível correlação com o gene do GLUT4" do qual participou(aram) o(s) alunos Milano Felipe dos Santos Ferreira Marques está de acordo com os Principios Éticos de Experimentação Animal adotado pelo Colégio Brasileiro de Experimentação Animal (COBEA) e foi aprovado pela COMISSÃO DE ÉTICA EM EXPERIMENTAÇ̃̃O ANIMAL (CEEA) em 15.12.08, com validade de 3 anos.

São Paulo, 16 de dezembro de 2008.

\section{Laknon.}

Prof. Dr. Wothan TAVARES DE LIMA Coordenador CEEA - ICB/USP

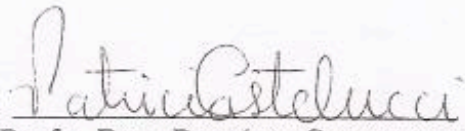

Profa. Dra. PATRICIA CASTELUCCI Secretária CEEA - ICB/USP 


\section{UNIVERSIDADE DE SÃO PAULO}

\section{INSTITUTO DE CIÊNCIAS BIOMÉDICAS}

Cidade Universitária "Armando de Salles Oliveira"

Av. Prof. Lineu Prestes, 2415 - cep. 05508-000 São Paulo, SP - Brasil

Telefone :(55) (011) 3091.7733 e-mail: cep@icb.usp.br

Of.CEUA.001.12

WTL/mogn

São Paulo, 27 de janeiro de 2012.

REF.: Protocolo $n^{0} 116 / 08$.

"Estudo da expressão do canal de potássio dependente de ATP (KATP) na resistência à insulina:

Possivel correlação com o gene do GLUT4"

Prezado Professor,

Informo que a sua licença para uso de animais em experimentação, constante no protocolo em epigrafe, foi prorrogada até 15.12.2014.

Reitero que havendo alteração de metodologia e inserção de novos alunos ao projeto de pesquisa vinculado à referida licença a CEUA/ICB deverá ser informada.

Cordialmente,

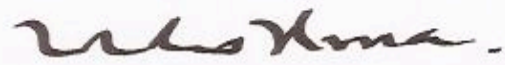

Prof. Dr. WOTHAN TAVARES DE LIMA

Coordenador - CEUA-ICB/ /USP

IImo.Sr.

Prof Dr. UBIRATAN FABRES MACHADO

Departamento de Fisiologia e Biofisica

Instituto de Ciências Biomédicas - USP 
Aos meus pais, Mário e Lúcia, meus irmãos, Murillo e Mário Jr e minha avó Cícera.

Obrigado! 


\section{Há Momentos}

Há momentos na vida em que sentimos tanto a falta de alguém que o que mais queremos é tirar esta pessoa de nossos sonhos e abraçá-la.

Sonhe com aquilo que você quiser.

Seja o que você quer ser, porque você possui apenas uma vida e nela só se tem uma chance de fazer aquilo que se quer.

Tenha felicidade bastante para fazê-la doce.

Dificuldades para fazê-la forte.

Tristeza para fazê-la humana.

E esperança suficiente para fazê-la feliz.

As pessoas mais felizes não têm as melhores coisas.

Elas sabem fazer o melhor das oportunidades que aparecem em seus caminhos.

A felicidade aparece para aqueles que choram. Para aqueles que se machucam.

Para aqueles que buscam e tentam sempre.

$E$ para aqueles que reconhecem a importância das pessoas que passam por suas vidas.

O futuro mais brilhante é baseado num passado intensamente vivido.

Você só terá sucesso na vida quando perdoar os erros e as decepções do passado.

A vida é curta, mas as emoções que podemos deixar duram uma eternidade.

A vida não é de se brincar porque um belo dia se morre.

(Clarice Lispector) 


\section{AGRADECIMENTOS}

Ao meu orientador Prof. Ubiratan, pela sabedoria, dedicação, ética e principalmente pelo amor à ciência, que resultou na construção de um laboratório de pesquisa exemplar. Sempre vou me lembrar da sua luta diária a favor de seus alunos. Obrigado e peço desculpas pelos meus erros e atitudes.

A Dra. Maristela Mitiko Okamoto, uma amiga, uma confidente, nunca poderei agradecer tantos momentos de sufoco em que você me ajudou e os momentos alegres e divertidos durante nossos almoços.

A Dra. Rosana Cristina Tieko Mori, uma amiga que não consigo explicar o meu sentimento, uma mistura de reverência, adoração, amor que tenho por você.

Aos meus amigos do laboratório:
Aline
Ana Cláudia
Paulo
Patrícia
Raquel
Ana Bárbara
Helayne
Thais Poças
Guilherme
Robinson
Dani Furuya
Dani Carioca

A Universidade de São Paulo

A FAPESP e CAPES 


\section{RESUMO}

MARQUES, M. F. S. F. Participação do canal de potássio dependente de ATP (KATP) na resistência à insulina em músculo esquelético: correlação com o gene do Glut4. 2013. 94 f. Tese (Doutorado em Fisiologia Humana) - Instituto de Ciências Biomédicas, Universidade de São Paulo, São Paulo, 2013.

A resistência à insulina foi induzida em ratos Wistar machos, por tratamento com glutamato monossódico (MSG) (4 mg/g/dia, s.c). Aos três meses de idade, ratos controles e obesos foram divididos em grupos não tratados (C e $\mathrm{MSG}$ ) e tratados (CG e $\mathrm{MSG} / \mathrm{G})$ com glimepirida $(0,1 \mathrm{mg} / \mathrm{kg} / \mathrm{dia}$, em água de beber) por 4 semanas. Os animais foram submetidos ao teste de tolerância a insulina (ITT) e amostras de músculo EDL e sóleo foram retirados para quantificação do mRNA e proteína. No ITT, ratos MSG mostraram diminuição significativa do decaimento de glicose em resposta à insulina, o que reverteu com o tratamento com glimepirida. Em músculo sóleo, foi observado aumento de 45\% no mRNA de SUR2A no grupo MSG/G ( $\mathrm{p}<0,01$ vs. MSG e C). Os resultados de mRNA de KIR6.2 resultaram em aumento da expressão em animais $\mathrm{MSG} / \mathrm{G}$ comparados a todos os demais grupos. Semelhantemente, no grupo MSG/G foi encontrado aumento de $103 \%$ da proteína KIR6.2 em membranas plasmáticas (PM), em comparação aos demais grupos. A análise de mRNA Slc2a4, resultou em aumento de $15 \%$ em ratos MSG em relação ao grupo controle, que aumentou ainda mais após o tratamento com glimepirida. Em relação a proteína GLUT4, ratos obesos tratados com glimepirida aumentaram a proteína GLUT4, comparados com controles e obesos não tratados. Não foram encontradas diferenças da expressão de mRNA de MEF2A, MEF2D e HIF1- $\alpha$ em sóleo. Em relação aos resultados em músculo extensor digital longo, (EDL), não houve diferença no mRNA e proteína de SUR2A. O mRNA de Slc2a4 reduziu em 40\% em ratos MSG, e elevou-se após o tratamento com glimepirida, mas não foram encontradas diferenças estatísticas do conteúdo da proteína GLUT4 em EDL nas frações subcelulares analisadas, PM (membranas plasmáticas) e M (microssomas). Em EDL, foi observada uma elevação de mRNA do KIR6.2 no grupo CG, quando comparado aos grupos MSG E MSG/G, a proteína KIR6.2 não teve alteração. Não foram encontradas diferenças da expressão de mRNA MEF2A, MEF2D e HIF1- $\alpha$ em EDL. Em relação aos resultados encontrados em culturas de células musculares L6, geraram dados opostas ao in vivo. Foi observada elevação da expressão de SUR2a do grupo glimepirida em relação ao grupo controle e controle + insulina, diferença também foi encontrada em relação ao grupo glimepirida + insulina. Já os resultados de mRNA de KIR6.2, o grupo controle + insulina obteve redução de KIR6.2 em relação ao controle. O tratamento com glimepirida resultou em aumento da expressão de KIR6.2, em relação ao grupo controle e controle + insulina. A associação de glimepirida + insulina resultou em diminuição de KIR6.2 em relação ao grupo glimepirida. Glimepirida sozinha reduziu a expressão de Slc2a4 em relação ao controle e controle + insulina. A adição de insulina conjuntamente com glimepirida elevou a expressão em relação ao grupo glimepirida. E finalmente, foi observado que insulina provocou redução discreta da expressão de NF-KB no grupo controle + insulina em relação ao controle. A glimepirida elevou a expressão de NF-KB em relação aos grupos controle e controle + insulina. O tratamento conjunto de glimepirida + insulina, gerou redução da expressão de NK-KB em relação ao grupo glimepirida.

Palavras-chave: Músculo esquelético. Resistência à insulina. Canal de potássio dependente de ATP. Fator de transcrição. Receptor de sulfoniluréia. 


\begin{abstract}
MARQUES, M. F. S. F. Participation of ATP-sensitive potassium (KATP) channel in skeletal muscle insulin resistance: correlation with GLUT4 gene. 2013. 94 p. Ph. D. thesis (Human Physiology) - Instituto de Ciências Biomédicas, Universidade de São Paulo, São Paulo, 2013.
\end{abstract}

Insulin resistance was induced in male Wistar rats by neonatal treatment with monosodium glutamate (MSG) $(4 \mathrm{mg} / \mathrm{g} / \mathrm{day}, \mathrm{s.c})$. At the age of three months, both control (C) and MSG treated animals received glimepiride $(0.1 \mathrm{mg} / \mathrm{kg} / \mathrm{day}$, in the drinking water) for 4 weeks, and were divided into non-treated (C and MSG) and glimepiride treated (CG and MSG-G) groups. Animals were submitted to insulin tolerance test (ITT) and samples of glycolytic (EDLextensor digitorium longus) and oxidative (soleus) skeletal muscles were excised for quantification of mRNA expression and protein. In ITT, MSG rats showed significant decrease in glucose decay in response to insulin, which reversed by treatment with glimepiride. In soleus muscle, was observed $45 \%$ increase in mRNA SUR2A in MSG/G group ( $\mathrm{p}<0.01$ vs. MSG and C). Kir6.2 mRNA resulted in increased expression in animals MSG/G compared to all other groups. Similarly, in-group MSG / G was found increase 103\% of Kir6.2 protein in plasma membrane (PM), as compared to other groups. The Slc2a4 mRNA analysis resulted in $15 \%$ increase in MSG rats in relation to control group, which further increased after treatment with glimepiride. Regarding GLUT4 protein, obese rats treated with glimepiride increased GLUT4 protein, compared with controls and obese untreated. There weren't differences in MEF2A, MEF2D and HIF1- $\alpha$ mRNA expression in soleus. Regarding the results in long digital extensor muscle (EDL), there was no difference in mRNA and SUR2A protein. The Slc2a4 mRNA decreased in $40 \%$ in MSG rats, and increased after treatment with glimepiride, but there were no statistical differences in GLUT4 protein content in EDL in subcellular fractions analyzed, PM (plasma membrane) and M (microsomes). In EDL, was observed an increase in Kir6.2 mRNA in CG group compared to groups MSG E MSG/G, Kir6.2 protein did not change. There were not found differences in MEF2A, MEF2D and HIF1- $\alpha$ mRNA expression in EDL. Regarding the results found in cultured L6 muscle cells, generated opposed data to in vivo. Was observed elevated expression of SUR2a glimepiride group compared to control group and control + insulin, difference also was found in relation to glimepiride group + insulin. Already Kir6.2 mRNA results, the control group + insulin obtained a Kir6.2 reduction compared to control. Treatment with glimepiride resulted in increased Kir6.2 expression in the control group and control + insulin. The association of insulin + glimepiride resulted in decrease of Kir6.2 compared to glimepiride group. Glimepiride alone reduced the expression of Slc2a4 in relation to control and control + insulin. The adding of insulin with glimepiride increased expression compared to glimepiride group. And finally, was observed that insulin caused a slight reduction in NF-KB expression in control group + insulin compared to control. Glimepiride increased NF-KB expression in relationship to control and control + insulin. The joint treatment of glimepiride + insulin, generated reduced NK-KB expression compared to the glimepiride group.

Keywords: Skeletal muscle. Insulin resistance. ATP-sensitive potassium channels. Transcription factors. Sulfonylurea receptors. 


\section{SUMÁRIO}

1 INTRODUÇÃ̃

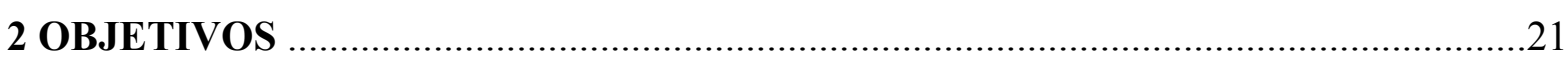

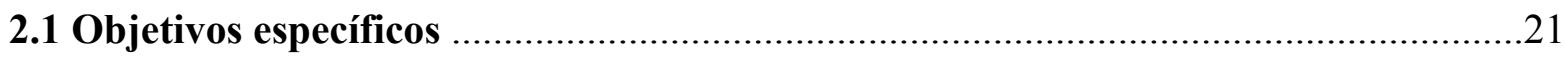

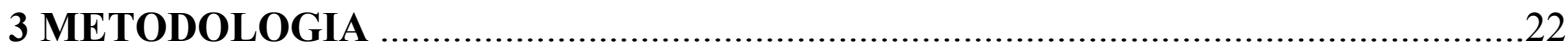

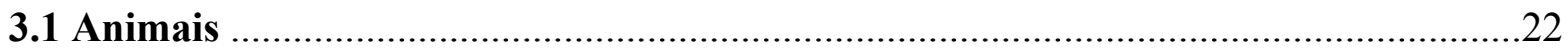

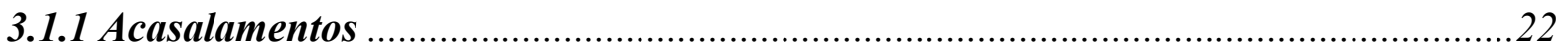

3.1.2 Indução de obesidade pelo glutamato monossódico .................................................22

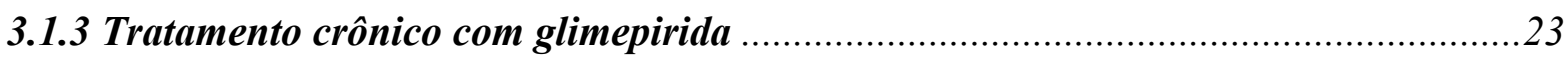

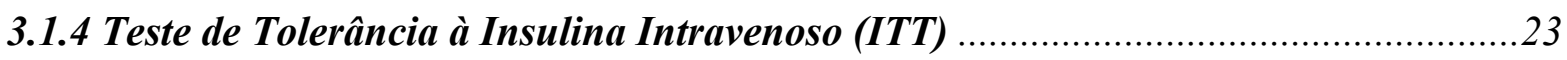

3.1.5 Determinação das concentrações de glicose e insulina. ............................................24

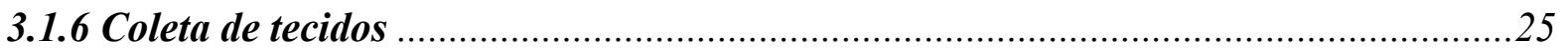

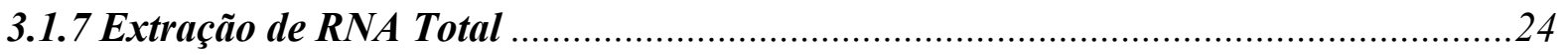

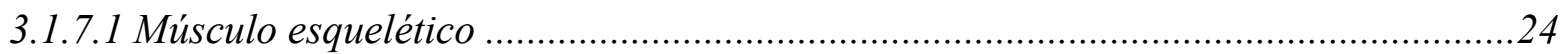

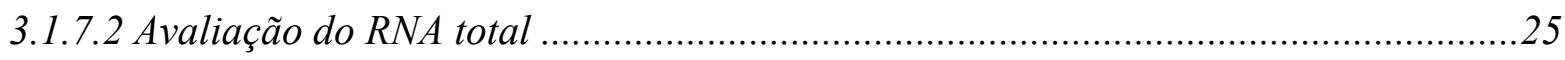

3.1.7.3 Análise da Expressão de mRNA pela RT-PCR em Tempo Real .................................25

3.1.7.4 Análise da expressão das proteínas GLUT4, SUR2a e KIR6.2 .................................29

3.1.7.4.1 Preparação dos tecidos e quantificação das proteínas ............................................29

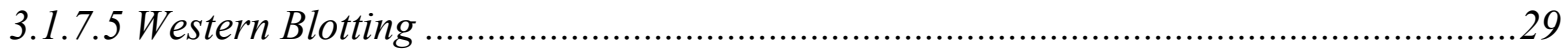

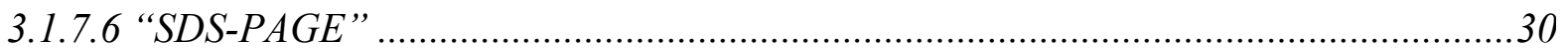

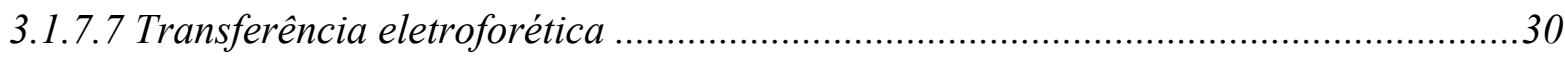

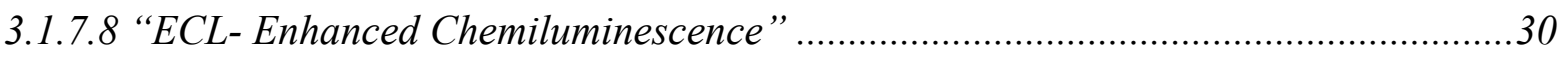

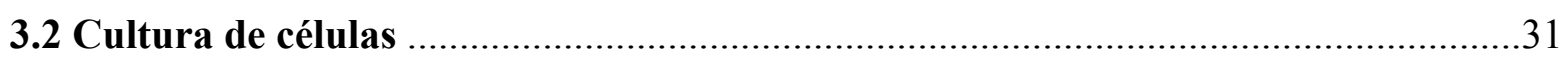

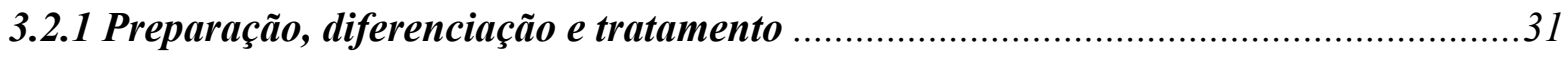

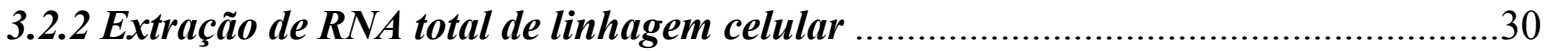

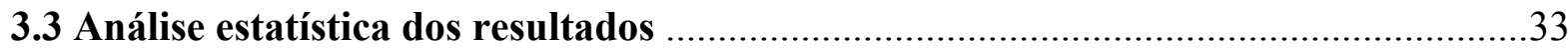

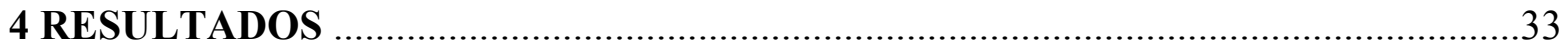

4.1 Parâmetros morfométricos e verificação da presença de obesidade ..........................33

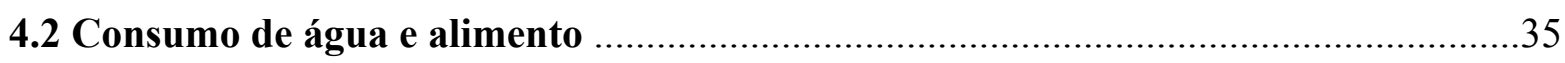

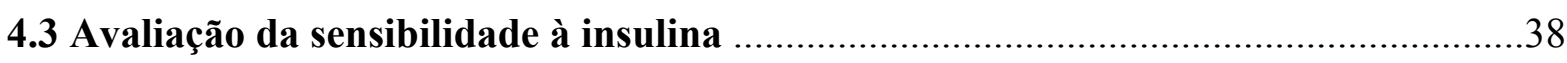

4.4 Qualidade do fracionamento subcelular dos tecidos .................................................40 
4.5 Análise de conteúdo de mRNA dos genes SUR2A, KIR6.2, MEF2A, MEF2D, HIF1a, NF-KB e Slc2a4 e das proteínas SUR2A, KIR6.2 e GLUT4 em músculo esquelético extensor digital longo (EDL) 41

4.5.1 Expressão do mRNA e da proteína SUR2A em EDL .............................................4

4.5.2 Expressão do mRNA e da proteína de KIR6.2 em EDL ..........................................4

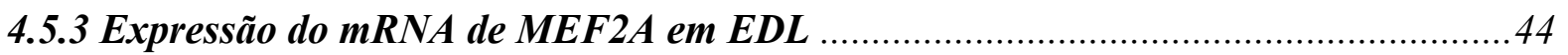

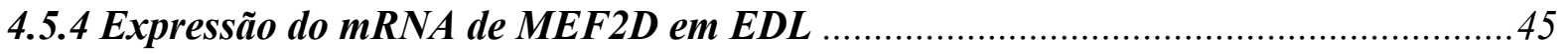

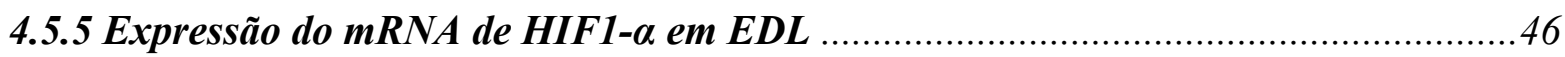

4.5.6 Expressão de Slc2a4 e da proteína GLUT4 em EDL .........................................47

4.6 Análise de conteúdo de mRNA dos genes SUR2A, KIR6.2, MEF2A, MEF2D, HIF-

1a, NF-KB e Slc2a4 e das proteínas SUR2A, KIR6.2 e GLUT4 em músculo sóleo .......49

4.6.1 Expressão do mRNA e proteína de SUR2A em Sóleo ...........................................51

4.6.2 Expressão do mRNA e da proteína KIR6.2 em Sóleo ............................................52

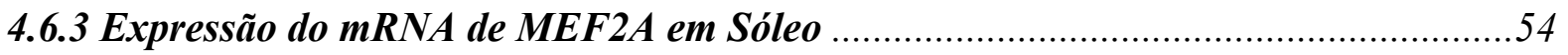

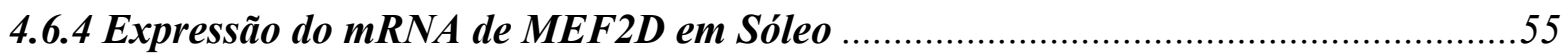

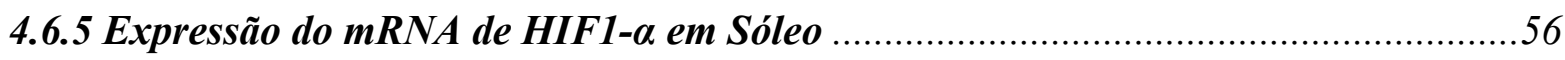

4.6.6 Expressão do mRNA de Slc2a4 e da proteína GLUT4 em Sóleo ................................57

4.7 Análise do conteúdo de mRNA dos genes SUR2A, KIR6.2, MEF2A, MEF2D, HIF-

$1 \alpha$, NF-KB e Slc2a4 em cultura de células musculares L6 ..........................................60

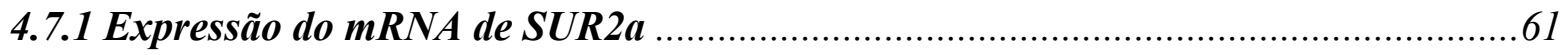

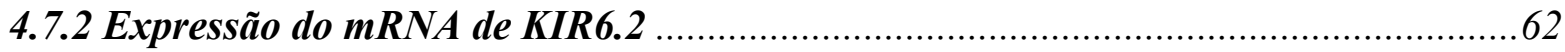

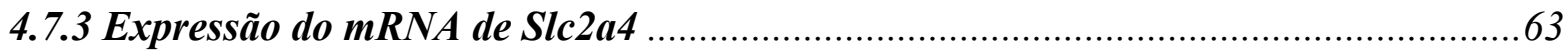

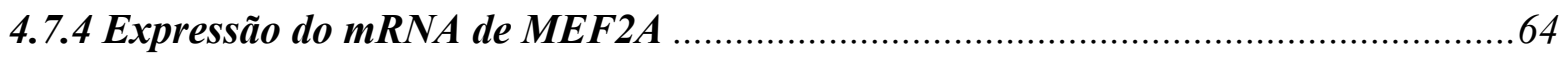

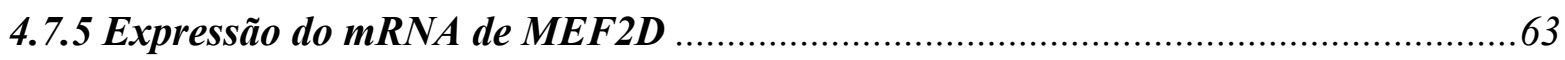

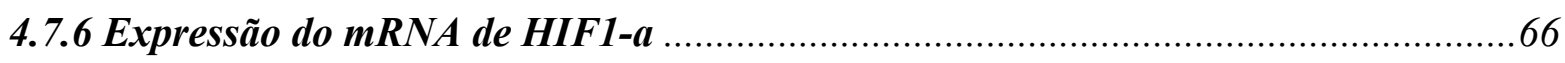

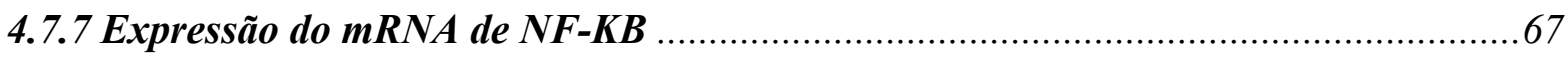

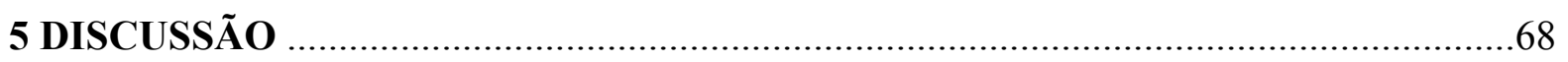

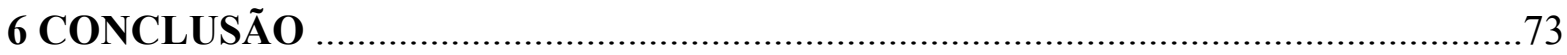

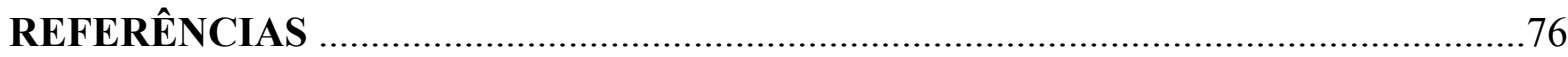

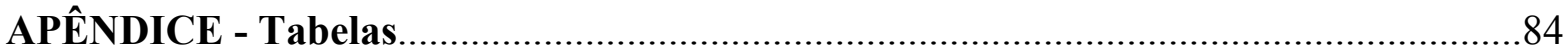




\section{INTRODUÇÃO}

O diabete melito (DM) é a mais comum das doenças metabólicas, sua incidência aumenta em ritmo alarmante, do ano 2000 a 2010, a prevalência de diabéticos aumentou de 121 para 185 milhões, representando 6,4\% da população adulta mundial. Projeções indicam que 366 milhões de indivíduos estarão afetados pela doença em 2030 (BAILEY et al., 2010; WILDING, 2007). Por isso essa enfermidade vem se tornando um dos maiores problemas de saúde pública do século 21. De acordo com a Organização Mundial da Saúde (WHO, 2006), o crescimento dos casos de diabetes está relacionado com alterações no estilo de vida e no perfil socioeconômico destes indivíduos, diminuindo a expectativa de vida desses pacientes em 15 anos. Cerca de dois terços dos indivíduos com diabetes vivem nos países em desenvolvimento, onde a epidemia tem maior intensidade, com crescente proporção de pessoas afetadas em grupos etários mais jovens (MEETOO et al., 2007; WILD et al., 2004).

Na população brasileira entre 30 e 69 anos, a prevalência de DM acomete cerca de 7\% e chega a atingir cifras próximas a $20 \%$ na população acima dos 70 anos. Estima-se que $50 \%$ dos diabéticos ainda não foram diagnosticados e $25 \%$ não fazem nenhum tipo de tratamento (PAIVA et al., 2006). O DM não é uma única doença, mas um grupo heterogêneo de distúrbios metabólicos que apresentam em comum a hiperglicemia. Essa hiperglicemia é o resultado de defeitos na ação da insulina, em sua secreção ou em ambos (SPELLMAN, 2008).

A classificação atual do DM é baseada na etiologia e não no tipo de tratamento. A classificação proposta pela Organização Mundial da Saúde (OMS) e pela Associação Americana de Diabetes (ADA) inclui quatro classes clínicas: DM tipo 1 (DM1), DM tipo 2 (DM2), outros tipos específicos de DM (doenças do pâncreas exócrino, Maturity Onset Diabetes of the Young MODY e endocrinopatias) e diabetes gestacional (SKELLY, 2006).

A obesidade e o ganho de peso estão entre os principais fatores de risco para o DM2, estimando-se que cada quilograma de aumento de peso associa-se a uma elevação de $9 \%$ na prevalência de DM. Mais de 80\% dos pacientes diabéticos do tipo 2 apresentam obesidade ou excesso de peso, agravando a sua situação metabólica, e predispondo a dislipidemias e hipertensão arterial (PILZ; MÄRZ, 2008).

O DM2 caracteriza-se por glicemia inapropriadamente elevada, frequentemente acompanhada de dislipidemia e hipertensão arterial. Muitos indivíduos são assintomáticos, porém a hiperglicemia é em grau suficiente para causar alterações degenerativas a longo prazo (SKELLY, 2006; TIBALDI, 2008). O DM2 é uma desordem metabólica complexa, de causas multifatoriais e poligênicas, apesar de pouco se conhecer sobre os genes envolvidos. A 
síndrome, no entanto, no que se refere à perda do controle glicêmico envolve desarranjo metabólico/funcional em três territórios: tecidos periféricos (adiposo e muscular), ilhotas pancreáticas e tecido hepático. No DM2 os tecidos muscular, adiposo e hepático desenvolvem resistência à ação da insulina, porém nas ilhotas pancreáticas, a secreção de insulina pelas células beta pode estar preservada, gerando um estado relativo de insuficiência de insulina. Com o tempo, a secreção de insulina pode evoluir para uma deficiência absoluta, por exaustão da célula beta, causando maior deterioração na homeostasia (HICKMAN; MACDONALD, 2007).

Quando tecidos sensíveis à ação da insulina, quanto ao transporte de glicose, têm a capacidade de captar glicose reduzida, caracteriza-se o estado de resistência à insulina. Esta desordem metabólica contribui no estabelecimento de quadros de hipertensão, dislipidemia e doença cardiovascular aterosclerótica, que associados à obesidade e/ou DM2 compõem a Síndrome Metabólica (REAVEN, 1988). A resistência insulínica torna-se mais intensa, o que pode ser associado à carga genética e/ou condições adquiridas como obesidade, sedentarismo e envelhecimento; e então, começa a diminuir a secreção de insulina (SPELLMAN, 2007). Estudos recentes comprovam que uma das vias de deterioração da função das células beta ocorre por exposição crônica a elevados níveis de ácidos graxos livres (AGL), associados à obesidade e aos estados de resistência insulínica (PRATO et al., 2007). A lipotoxicidade está associada ao acúmulo de gordura intracelular causando disfunção da secreção pancreática de insulina e a diminuição da função das células beta. De acordo com esta hipótese, a exposição crônica aos AGL levaria a ativação de vias que causam aumento do estresse oxidativo e ativação de vias inflamatórias ocasionando apoptose das células beta pancreáticas (MARCHETTI et al., 2008).

O músculo esquelético é o maior território de utilização de glicose, sendo responsável no organismo por $85 \%$ da captação de glicose estimulada por insulina (DEFRONZO et al., 1981) no período pós-prandial.

O transporte de glicose é fundamental para o metabolismo energético celular. A rota glicolítica é empregada por todos os tecidos para degradação de glicose e fornecimento de energia (na forma de ATP) e intermediários para outras rotas metabólicas. Para acessar o intracelular, a glicose não pode solubilizar-se na membrana, devido ao caráter polar da molécula, e, para tanto, existem dois mecanismos de transporte de glicose através da membrana celular: difusão facilitada, mediada por transportadores da família GLUT; e co- 
transporte com o íon sódio, mediado por transportadores da família SGLT (SCHEEPERS et al., 2004).

A família GLUT é composta por 14 membros que são numerados pela ordem cronológica de seu descobrimento. São proteínas de 45-60 kDa com $12 \alpha$-hélices transmembrânicas e hidrofóbicas, interligadas por alças hidrofílicas, distribuídas de forma que a porção C-terminal e a N-terminal fiquem do lado citoplasmático (JOOST et al., 2001).

O GLUT4 é o transportador insulino-dependente mais abundante nas membranas celulares do músculo esquelético, cardíaco e tecido adiposo. A insulina, na musculatura esquelética estimula a captação de glicose e a síntese de glicogênio, e no tecido adiposo estimula a captação de glicose e redução na degradação com aumento na síntese de triglicerídeos. Embora sejam vários os eventos intracelulares envolvidos na captação de glicose estimulada pela insulina, o fenômeno culmina com a translocação de vesículas ricas em GLUT4 do intracelular para a membrana plasmática, aumentando a densidade de transportador na membrana, e consequentemente aumentando a difusão da glicose para o intracelular (MACHADO, 1998). Qualquer defeito em alguma destas etapas pode determinar resistência ao estimulo da insulina, podendo levar ao desenvolvimento de diabetes tipo 2 (HUANG; CZECH, 2007).

Resistência insulínica no músculo esquelético é defeito primário em indivíduos portadores de DM2. A sensibilidade insulínica decai drasticamente, embora a tolerância à glicose possa se deteriorar minimamente, enquanto houver hiperinsulinemia compensatória (GULLI et al., 1992; PRATIPANAWATR et al., 2001)

No músculo esquelético, o GLUT4, codificado pelo gene Solute Carrier 2A4 (Slc2a4), apresenta-se em maior quantidade em fibras do tipo I e IIa, quando comparado com as fibras do tipo IIb (MARETTE et al., 1992). No estado quiescente, uma boa quantidade de proteína GLUT4 permanece estocada em vesículas intracelulares, porém frente a um estímulo realizado pela insulina ou pela contração muscular, as vesículas são rapidamente translocadas para a membrana plasmática e para os túbulos $\mathrm{T}$, aumentando drasticamente a captação de glicose (CORTRIGHT; DOHM, 1997).

Adicionalmente a esta regulação aguda na distribuição subcelular, a expressão de Slc2a4 está sob controle dinâmico e complexo. Em estados de deficiência insulínica tais como jejum e diabetes insulino privo, ambos conteúdos de mRNA e proteína GLUT4 estão reduzidos no tecido adiposo e músculos cardíaco e esquelético (CAMPS et al., 1992; DEPRE et al., 2000; NEUFER et, al., 1993). Porém, em estados de diabetes tipo 2, a resistência à 
insulina também se acompanha de redução de GLUT4, apesar da presença de hiperinsulinemia (MACHADO et al., 1993, MACHADO et al., 1994).

A região promotora do gene do Slc2a4 apresenta sítios específicos (elementos responsivos) que ancoram proteínas (fatores de transcrição) que atuam como ativadores ou repressores da transcrição gênica. Um fator de transcrição apresenta domínios que se ligam ao DNA (no elemento responsivo) e outros que podem recrutar co-ativadores ou co-repressores, os quais contribuem na estimulação ou repressão da transcrição do gene-alvo pela RNAPolimerase tipo II. Portanto, o controle da expressão gênica é modulado pela interação de uma série de fatores de transcrição, além de sua capacidade de ativarem co-ativadores ou coinibidores (BRIAVANOU; DORNELL, 2002).

O fator transcricional MEF2 (Myocyte Enhancer Factor 2), importante na regulação do gene $S l c 2 a 4$, tem papel central na proliferação, diferenciação, morfogênese, sobrevivência e apoptose da célula muscular. Os fatores MEF2 pertencem à família MADS Box (MCM1Agamous-Deficiens-Serum response factor) e foram descritos pela primeira vez como fatores de transcrição que se ligam a sequências de DNA ricas em $\mathrm{A} / \mathrm{T}$ nos promotores de vários genes músculo-específicos. Existem 4 genes da família MEF2 que foram identificados em vertebrados: mef2a, $b, c$ e $d$ que são expressos de forma distinta, mas em padrões de sobreposição durante a embriogênese e nos tecidos adultos. Eles possuem domínios de ligação ao DNA quase idênticos na extremidade N-terminal, com alta homologia no domínio MADS Box (aminoácidos 1-57). Este domínio é responsável pela ligação ao DNA e dimerização das proteínas, permitindo que os fatores MEF2 se liguem como homo ou heterodímeros a um elemento cis com a sequência (C/T)TA(A/T)TATATATA(G/A). Um domínio adjacente ao MADS Box chamado domínio MEF2 (aminoácidos 58-86), que é característico da família, influencia a afinidade de ligação ao DNA assim como a interação com co-fatores. A região $\mathrm{C}$ terminal apresenta o domínio de transativação. Nessa região, também ocorrem processos complexos de splicing alternativo, com certos exons presentes em todos os tipos celulares, enquanto outros são limitados a tipos celulares específicos (BLACK; OLSON, 1998; JANSON et al., 2001).

Os fatores da família MEF2 podem ser ativados por $\mathrm{Ca}++$, Calcineurina, MAP quinases p38, ERK5 e CaM quinase. Além disso, os fatores MEF2 também são regulados pela associação com desacetilases de histonas da classe II (HDAC-II) no núcleo. Neste caso, a sinalização pelo $\mathrm{Ca}++$, através da ativação de CaM-quinase leva à fosforilação de HDAC-II, 
que se transloca para o citosol, permitindo a ativação dos fatores MEF2 (BLACK; OLSON, 2006).

O elemento responsivo aos MEF2s, na região promotora do gene Slc2a4 de camundongo, está localizado entre os pares de bases 466-457 (LIU et al., 1994), e ancora os fatores MEF2A, B, C e D, e o MyoD, que atuam como ativadores da transcrição do Slc2a4 (MORENO et al., 2003).

Outro regulador do gene Slc2a4 é o fator induzido por hipóxia (HIF). Este é um fator de transcrição gênica heterodimérico, em geral composto de duas proteínas basic helix-loophelix (bHLH): HIF-A e HIF-B. Existem três isoformas de HIF-A que são estruturalmente semelhantes. A isoforma HIF-3A, ao contrário das isoformas HIF-1A e HIF-2A, está associada à regulação negativa da transcrição gênica induzida pelo HIF (WANG et al., 1993; WANG et al., 1995).

As duas subunidades (HIF-A e HIF-B) são constitutivamente expressas, entretanto, enquanto a subunidade B é estável tanto em normóxia quanto em hipóxia, a A é rapidamente degradada se o ambiente for de normóxia (MAXWELL et al., 1999; WANG et al., 1995a). O HIF-1A já foi descrito como ativador da transcrição dos genes Slc2al e Slc2a3, e como inibidor da transcrição do gene do Slc2a2 (ERBET et al., 1996). Royer e colaboradores (2000) verificaram o aumento do GLUT4 na hipóxia, e estudos do nosso laboratório demostraram fortes evidências de que HIF1-A esteja envolvido na ativação do gene Slc2a4 em músculo esquelético (LIMA et al., 2009; SILVA et al., 2005).

NF-אB (do inglês, nuclear factor kappa $B$ ) também é proposto como um regulador do gene Slc2a4. A família do NF-кB é composta por cinco membros denominados, RelA (p65),

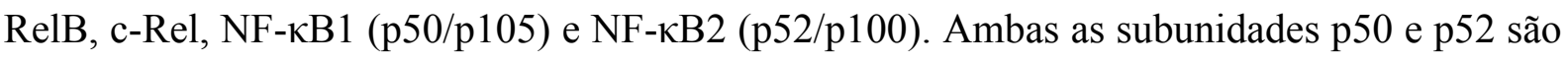
sintetizadas a partir de proteínas precursoras longas, p105 e p100. Em geral, a forma ativa de

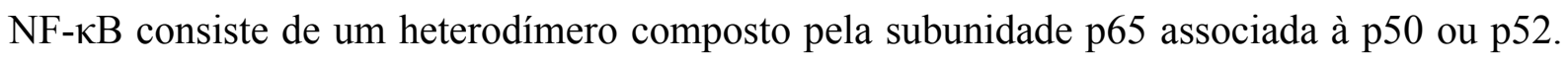
$\mathrm{Na}$ maioria das células, este heterodímero reside no citosol associado a um inibidor protéico,

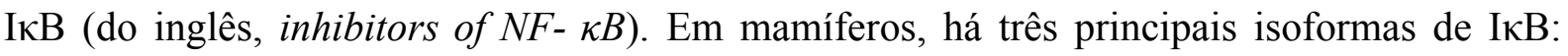

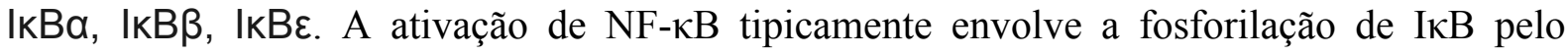
complexo I $\kappa$ B cinase (do inglês, I $\kappa B$ quinase), composto por IKK $\alpha, \operatorname{IKK} \beta$ e IKK $\gamma$ (NEMO).

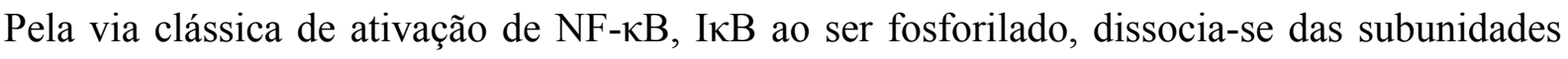
heterodiméricas de NF-אB sendo direcionado à degradação proteosomal. Como consequência

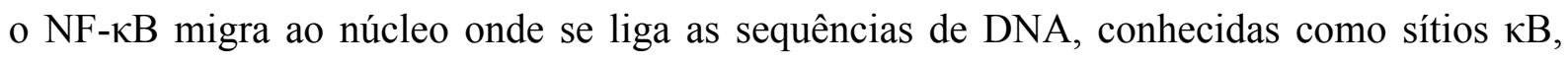
localizadas nas regiões promotoras de genes relacionados a apoptose, adesão celular, resposta 
imune, inflamação, estresse celular e remodelamento tecidual. É importante ressaltar que a expressão desses genes é também dependente da ação de outras vias de sinalização e fatores

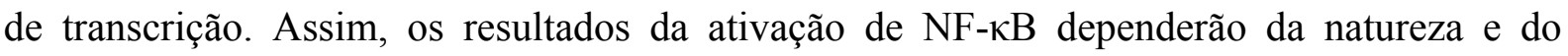
contexto da célula (PERKINS, 2007).

A atuação de NF-kB na regulação do gene Slc2a4 foi sugerida em meados de 2002 (RUAN et al., 2002). Posteriormente, Silva et al. (2005) relacionaram o aumento do mRNA do NFKB e da sua atividade de ligação ao DNA, com a diminuição na expressão gênica de GLUT4 em amostras de músculo solear de ratos jejuados. Além disto, a repressão na expressão do gene Slc2a4 já foi relacionada com aumento no conteúdo de IL-6 do (inglês, interleucin 6) devido ativação da via $\mathrm{PKC} / \mathrm{NF}-\kappa \mathrm{B}$ por palmitato, em células musculares C2C12 (JOVÉ et al., 2005). Adicionalmente, alguns estudos de nosso laboratório reforçaram o papel inibitório do NFkB na expressão do Slc2a4 também em célula adiposa (FURUYA et al., 2010; FURUYA et al., 2012). Finalmente, um recente estudo do nosso grupo demonstrou definitivamente o efeito repressor do NFkB sobre a transcrição do Slc2a4, apontando 2 sítios de ligação presentes no promotor do gene (FURUYA et al., in press).

Além da regulação por meio de fatores transcrionais, em algumas situações fisiopatológicas, especialmente obesidade e DM2, a resistência insulínica pode estar ligada a ativação dos canais de potássio dependentes de ATP, os quais funcionam como sensor energético e metabólico.

Os canais de potássio dependentes de ATP (KATP) são proteínas de membrana com permeabilidade seletiva ao potássio, e representam a maior e mais diversa família de canais iônicos identificada. O receptor de sulfoniluréia 1 (SUR1), membro da super família ATPbinding cassette (ABC) encontra-se na região regulatória do KATP e foi assim denominado por ser sítio de ligação das sulfoniluréias, classe de fármacos utilizada no tratamento de DM2. O canal iônico KIR6.2, denominado de Potassium inwardly-rectifying channel, está localizado na região formadora de poros (ASHCROFT, 2006; BRYAN et al., 2004). Acreditase que o SUR seja o sensor da relação ATP/ADP, importante na atividade do canal. Os genes KIR 6.2 e SURl estão localizados conjuntamente no cromossomo 11 (11p 15.1) e estão sob regulação de um promotor comum, regulado por um único fator de transcrição, porém desconhecido, isso permite que as expressões de ambos os genes estejam intrinsecamente associadas (SMITH et al., 2007).

O papel deste canal está bem definido em células beta pancreáticas, onde participa ativamente do processo de secreção de insulina em resposta à glicose; os mecanismos 
envolvidos incluem: 1) transporte da glicose para o interior as células pelo transportador GLUT2; 2) metabolização intracelular da glicose gerando ATP; 3) aumento intracelular da razão ATP/ADP; 4) fechamento dos canais de potássio dependentes de ATP ( $\left.\mathrm{K}_{\mathrm{ATP}}\right)$; 5) aumento de $\mathrm{K}^{+}$intracelular; 6) despolarização de membrana da célula beta; 7) abertura do canal de $\mathrm{Ca}^{2+}$ voltagem dependente; 8) influxo de $\mathrm{Ca}^{2+}$ e aumento de sua concentração citoplasmática e 9) exocitose dos grânulos secretores contendo insulina (ASHCROFT, 2006; SMITH, 2007).

A participação do KATP na regulação da secreção da insulina foi evidenciada após a descoberta de que mutações nos genes codificadores das subunidades SUR1 e KIR6.2 são responsáveis pela doença conhecida como hipoglicemia hiperinsulinêmica persistente neonatal (HHPN), anteriormente conhecida como nesidioblastose (THOMAS et al., 1995). O conhecimento sobre o $\mathrm{K}_{\mathrm{ATP}}$ está bem desenvolvido na célula beta pancreática, devido ao seu importante papel na secreção de insulina, entretanto, sua função em outros territórios ainda é praticamente desconhecida.

O canal KATP está presente em vários outros tecidos; incluindo tecido cardíaco, adiposo, vascular, cerebral e muscular liso. Existem várias combinações KIR 6.X / SUR, que se expressam seletivamente em vários tecidos, e que determinam diferenças bioquímicas e farmacológicas. Duas isoformas de KIR6 (KIR 6.1 e KIR 6.2) e duas proteínas SUR (SUR1 e SUR2) foram identificadas em seres humanos. As proteínas SUR2A e SUR2B são formadas por splicing alternativo do RNA primário, e conferem propriedades fisiológicas e farmacológicas distintas sobre a complexidade do canal, sendo que a isoforma SUR2A é predominantemente encontrada em músculo esquelético e cardíaco. (FLAGG et al., 2010). Assim, no tecido muscular, a combinação das proteínas identificada é KIR6.2 / SUR2A (NAGASHIMA et al., 2004; SOLBACH et al., 2006), cuja função é desconhecida, embora haja indícios de que participe no processo de captação de glicose (SEINO; MIKI, 2003). Canais de KATP estão entre os canais mais expressos em sarcolema do musculo esquelético. A função do canal de KATP no músculo esquelético tem sido pouco estudada, em comparação ao músculo cardíaco.

Estudos de camundongos geneticamente modificados revelaram que os canais KATP também estão envolvidos na proteção contra isquemia neuronal, cerebral, alterações cardíacas, regulação da musculatura lisa vascular e na captação de glicose no músculo esquelético (SEINO; MIKI, 2003). Estas propriedades derivam da sua capacidade de alterar o metabolismo celular, por meio da atividade elétrica e/ou por sensoriamento nas mudanças dos 
níveis de ATP e MgADP citosólicos. Estes nucleotídeos têm ações antagônicas sobre o canal, o MgADP abre enquanto o ATP fecha o canal (CAMPBELL et al., 2003).

As sulfoniluréias exercem o seu efeito de liberar insulina principalmente através da inibição do canal de potássio dependente de ATP. No presente estudo, utilizamos a glimepirida, uma droga do grupo das sulfoniluréias, que são secretagogos de insulina e, por isso, indicados apenas para pacientes que tenham reserva pancreática do hormônio. As sulfoniluréias recebem esta denominação por apresentarem na sua estrutura química, um grupamento composto por ácido sulfônico e uréia (KECSKEMETI et al., 2002). Por seu potente efeito sobre a secreção de insulina, induzem aumento da insulinemia e, algumas vezes, hipoglicemia prolongada (RAPTIS; DIMITRIADIS, 2001).

A glimepirida é uma sulfoniluréia cujos efeitos vão além do estímulo à secreção de insulina. Dados de literatura sugerem que esta droga pode apresentar efeitos extrapancreáticos importantes, levando a um aumento da sensibilidade à insulina. Há estudos que demostraram que a glimepirida aumenta a captação de glicose e a taxa de translocação de GLUT4 em músculo esquelético (MORI et al., 2008; MULLER; GEISEN, 1996) e a expressão da proteína GLUT4 em músculo cardíaco (BAHR et al., 1995).

Em relação à homeostasia glicêmica, no músculo esquelético, o papel dos canais KATP ainda é completamente desconhecido, embora já tenha sido discutida a possibilidade de estarem envolvidos na captação de glicose (MINAMI et al., 2004). Além disso, recentemente, nosso grupo demonstrou que o tratamento de ratos resistentes à insulina com glimepirida, restaura a homeostasia glicêmica, aumentado a captação de glicose em músculo sóleo, por aumentar a expressão e a translocação do GLUT4 no tecido (MORI et al., 2008).

O músculo esquelético é o principal sítio de captação de glicose sob estímulo insulínico (ZORZANO; PALACIN; GUMÁ, 2005). Uma vez que os KATP possam desempenhar um papel importante na capacidade do músculo esquelético captar glicose, por exemplo, modulando a expressão do gene Slc2a4, as proteínas constituintes do canal passariam a representar um importante alvo para desenvolvimento de novas abordagens preventivas ou terapêuticas para a resistência à insulina e o diabetes mellitus. 


\section{OBJETIVOS}

Investigar a possível correlação entre a expressão do canal de potássio dependente de ATP (KIR6.2 e SUR2A), a expressão do Slc2a4/GLUT4 em músculo esquelético e a resistência à insulina.

\subsection{Estratégias experimentais}

- Investigar in vivo em músculo esquelético a expressão gênica de KIR6.2, SUR2A e Slc2a 4 em ratos com resistência à insulina (obesos) e submetidos a tratamento para aumento da sensibilidade à insulina (glimepirida).

- Investigar in vitro em célula muscular L6 a expressão gênica de KIR6.2, SUR2A e Slc2a4, MEF2A, MEF2D, HIF1- $\alpha$ e NF-KB em resposta a concentrações de glicose e de insulina altas, verificando também o efeito da glimepirida.

- Investigar se as alterações de expressão gênica observadas se refletem em alterações nos conteúdos das proteínas KIR6.2, SUR2A e GLUT4.

- Investigar possíveis alterações de expressão dos fatores transcricionais MEF2A, MEF2D, HIF1- $\alpha$ em músculo esquelético de ratos obesos tratados com glimepirida e em célula muscular L6. 


\section{METODOLOGIAS}

\subsection{Animais}

\subsubsection{Acasalamentos}

Os experimentos foram realizados em ratos da linhagem Wistar. Animais de três a cinco meses de idade, obtidos do biotério central do Instituto de Ciências Biomédicas da Universidade de São Paulo, foram acasalados no Biotério de Experimentação do Departamento de Biofísica e Fisiologia desta universidade. As fêmeas prenhas foram mantidas em gaiolas individuais do $15^{\circ} \sim 17^{\circ}$ dia de gestação até o desmame das ninhadas.

\subsubsection{Indução de obesidade pelo glutamato monossódico}

Há diversos modelos experimentais de obesidade, com o objetivo de representar o quadro de desordem metabólica característico de resistência à insulina. Em ratos, a obesidade pode ser conseguida por meio da administração subcutânea de glutamato monossódico (MSG), um aminoácido neuroexcitatório lesivo ao sistema nervoso central (KIZER et al., 1978). Já foi demonstrado que a administração subcutânea dessa substância em ratos no período neonatal, quando a barreira hematoencefálica não está totalmente desenvolvida, resulta uma degeneração aguda do núcleo arqueado do hipotálamo, levando à obesidade na vida adulta, que pode se acompanhar de outras disfunções endócrinas (DAWSON; ANNAU, 1983; KIZER et al., 1978). Este modelo experimental tem sido utilizado para a investigação de mecanismos moleculares envolvidos na resistência à insulina e DM2, assim como para avaliar potenciais abordagens terapêuticas.

Do $2^{\circ}$ ao $8^{\circ}$ dia de vida, metade dos filhotes machos receberam injeções subcutâneas de glutamato monossódico (Sigma-Aldrich Chemicals, Steinhein, H.T., Alemanha), na dose de $4,0 \mathrm{mg} / \mathrm{g} / \mathrm{dia}$, enquanto a outra metade recebeu volume equivalente de salina $0,9 \%$. Após o desmame, os animais foram mantidos em gaiolas coletivas, com livre acesso à água e alimento, em ambiente com ciclo de luz controlado de 12 horas claro/ 12horas escuro e temperatura constante de $23 \pm 2{ }^{\circ} \mathrm{C}$. Aos três meses de idade, foram divididos em grupos experimentais conforme descritos a seguir: 
1. Controle (C);

2. Controle tratado com glimepirida (CG);

3. Obeso (MSG);

4. Obeso tratado com glimepirida (MSG/G).

A presença de obesidade foi verificada através da análise as características morfométricas e pelo calculo de índice de Lee $\left(\left[{ }^{3} \sqrt{ }\right.\right.$ peso $(\mathrm{g}) \div$ comprimento naso-anal $\left.(\mathrm{cm})\right] \mathrm{X}$ 100), um parâmetro semelhante ao índice massa corpórea, utilizado para expressar o grau de obesidade em animais.

\subsubsection{Tratamento crônico com glimepirida}

Animais controles e obesos foram tratados por quatro semanas com glimepirida (Amaryl ${ }^{\circledR}$, Aventis Pharma, Scoppito, Itália) na dose de $0,1 \mathrm{mg} / \mathrm{kg}$ de peso corpóreo/ dia, misturada à água de beber. Esta dose, conforme dados da literatura, seria a mínima necessária para inibir a elevação da glicose plasmática após uma sobrecarga oral de glicose (ELREYANI et al., 1999).

Na semana anterior ao início do tratamento, foi medida ingestão hídrica média diária de cada grupo, para calcular a quantidade da droga a ser diluída na água, conforme o volume ingerido. A ingestão ao longo das quatro semanas de tratamento foi acompanhada, assegurando a preservação da dose de $0,1 \mathrm{mg} / \mathrm{kg} / \mathrm{dia}$, durante todo o período. A quantidade de alimento ingerida pelos diferentes grupos durante o tratamento também foi medida.

Ao final do tratamento, os animais foram utilizados para as avaliações descritas a seguir.

\subsubsection{Teste de Tolerância à Insulina Intravenoso (ITT)}

Amostras de sangue foram coletadas por punção caudal dos animais anestesiados (pentobarbital sódico, $60 \mathrm{mg} / \mathrm{Kg}$ de peso corpóreo), as coletas foram realizadas antes e aos 4 , 8, 12 e 16 minutos após a sobrecarga intravenosa de insulina regular humana (Biobrás, Montes Claros, M.G., Brasil), 0,75 U/Kg de peso corpóreo, pela veia peniana. Para a determinação da glicemia, utilizou-se um glicosímetro (Precision Q.I.R, Medisense, São Paulo, S.P., Brasil). A constante de decaimento da glicose (KITT) foi calculada a partir da 
regressão linear do logaritmo neperiano dos valores glicêmicos obtidos no teste (BONORA et al., 1989).

\subsubsection{Determinação das concentrações de glicose e insulina.}

Amostras de sangue foram coletadas da veia cava inferior. O plasma, separado por centrifugação a $2000 \mathrm{rpm}$, foi estocado a $-20^{\circ} \mathrm{C}$, em alíquotas para dosagem da concentração de glicose e insulina.

A concentração de glicose plasmática foi determinada pelo método enzimáticocolorimétrico de glicose-oxidase (kit glicose E enzimática, CELM, São Paulo, S.P., Brasil). A insulina plasmática foi determinada por radioimunoensaio (RIE) de fase sólida (kit Coat - $a$ Count $^{\circledR}$ Insulin, DPC ${ }^{\circledR}$, Los Angeles, USA)

\subsubsection{Coleta de tecidos}

Os músculos esqueléticos sóleo (SOL - músculo de fibras vermelhas, oxidativas) e extensor digital longo (EDL - fibras brancas, glicolíticas) foram retirados após anestesia, pesados, e submetidos a análises de proteínas por Western Blotting, e de mRNA por PCR em Tempo Real.

\subsubsection{Extração de RNA Total}

\subsubsection{Músculo esquelético}

Foi utilizado 1,0 $\mathrm{mL}$ de TRIZOL Reagent (Invitrogen Life Technologies, Gaithersburg, N.Y., USA) para homogeneização de 0,1g de tecido no Polytron PT 300 KINEMATICA (Brinkman, Bohemia, N.Y., EUA) a 25.000 rpm. Após a incubação de 5 minutos em temperatura ambiente (TA), e centrifugação a $10.000 \mathrm{~g}\left(15 \mathrm{~min}, 4^{\circ} \mathrm{C}\right)$, clorofórmio foi adicionado ao sobrenadante. Após $10 \mathrm{~min}$ em temperatura ambiente, a amostra foi centrifugada a $10.000 \mathrm{~g},\left(15 \mathrm{~min}, 4{ }^{\circ} \mathrm{C}\right)$ e a fase superior, acrescida de isopropanol, foi incubada (10 min., TA) e centrifugada a $10.000 \mathrm{~g}\left(15 \mathrm{~min}, 4{ }^{\circ} \mathrm{C}\right)$. O precipitado foi lavado em etanol $70 \%$ e centrifugado a $10.000 \mathrm{~g}\left(15 \mathrm{~min}, 4^{\circ} \mathrm{C}\right)$. Removido o sobrenadante, secou-se o precipitado, que foi solubilizado em água DEPC (dietil 
pirocarbonato), em banho-maria a $65^{\circ} \mathrm{C}$ por 10 minutos. O RNA extraído foi armazenado a $70{ }^{\circ} \mathrm{C}$.

\subsubsection{Avaliação do RNA total}

A integridade do RNA extraído foi avaliada pela visualização das bandas 28 e 18S, sob luz ultravioleta após corrida em gel desnaturante com agarose a 1,0\%.

\subsubsection{Análise da Expressão de mRNA pela RT-PCR em Tempo Real}

A quantificação da expressão de mRNA dos genes foi realizada por transcrição reversa do mRNA seguida de PCR (RT-PCR) em tempo real. Para os genes SUR2A, KIR6.2, Slc2a4 e GAPDH foi utilizado o sistema de amplificação TaqMan Two Step RT-PCR (Applied Biosystems, Foster City, C.A., EUA) e para os genes MEF2A, MEF2D, HIF1- $\alpha$ e GAPDH2 foi utilizado o sistema SYBER ${ }^{\circledR}$ Green RT-PCR (Agilent, Santa Clara, C.A., EUA).

Após extração de RNA total, as amostras foram submetidos a tratamento prévio com DNase I para remover possível contaminação por DNA genômico antes da transcrição reversa para obtenção do cDNA a partir de RNA. Adicionou-se 1 U de DNase I, Amplification Grade (Invitrogen-Life Technologies, Carlsbad, C.A., EUA), 200 U de tampão 10x (Invitrogen-Life Technologies, Carlsbad, C.A., EUA), completando o volume para $10 \mu \mathrm{L}$, com água esterilizada tratada com (DEPC) (Sigma Aldrich, St. Louis, M.O., EUA), incubado por $25^{\circ}$ por 15 min no termociclador, após isso, foi adicionado $25 \mathrm{mM}$ de EDTA para inibir a ação da DNase I.

A transcrição reversa para síntese de cDNA, foi realizada a partir de $1 \mu \mathrm{g}$ de RNA total utilizando o kit ImProm-II ${ }^{\mathrm{TM}}$ Reverse Transcriptase (Promega, Sant Louis, C.A., EUA), Random primers (Invitrogen, EUA), nucleotídeos 100mM dNTP Set, PCR Grade (Invitrogen, Grand Island, N.Y., EUA) e água deionizada 0,01\%. Os cDNAs sintetizados foram armazenados a $-20^{\circ} \mathrm{C}$.

O cDNA proveniente de RNA total de músculo esquelético, de cada gene foi amplificado pela PCR em tempo real, foram selecionados iniciadores e sondas marcadas com fluoróforo FAM para os genes SUR2A, KIR6.2, Slc2a4 e fluoróforo VIC para GAPDH1 (Quadro 1). A escolha foi possível com o auxílio do programa Primer Express ${ }^{\circledR}$ (Applied 
Biosystems, Foster City, C.A., EUA), para o gene GAPDH1 foi usado o sistema TaqMan ${ }^{\circledR}$ Gene Expression Assays. Iniciadores e sondas foram selecionados de acordo com a sequência disponível [número de acesso D83598 (SUR2A), NM_031358 (KIR6.2), NM_012751.1 (GLUT4) NM_017008.3 (GAPDH 1 e 2), MEF2D (NM_133665.3), MEF2A (NM_001014035.1) e HIF1- $\alpha$ (NM_024359.1) no Banco de genes (GenBank) do National Institute of Health (NIH) (www.ncbi.nlm.nih.gov).

Quadro 1 - Iniciadores e sondas utilizados nas PCR em Tempo Real.

\begin{tabular}{|c|c|c|}
\hline Genes & Iniciadores & Fragmento \\
\hline$S U R 2 A$ & $\begin{array}{l}\text { 5' ACATGGCCACGGAAAACATT 3', } \\
\text { 5' ACTCCACTAAAATACCCTCAGAAAAGA 3' } \\
\text { 5' FAM CCATAGCTCACCGTGTCT MGB3' }\end{array}$ & $141 \mathrm{bp}$ \\
\hline KIR6.2 & $\begin{array}{l}\text { 5' CTCATCATCTACCACGTCATCGA 3', } \\
\text { 5' GGGTGGTAATGCCTGTGGTT 3' } \\
\text { 5' FAM CTGGCTCCTAGTGACCTG MGB3', }\end{array}$ & $133 \mathrm{bp}$ \\
\hline GLUT4 & $\begin{array}{l}\text { 5' GGCTGTGCCATCTTGATGAC 3', } \\
\text { 5' CACGATGGACACATAACTCATGGAT 3' } \\
\text { 5' FAM AACCCGCTCCAGCAGC MGB3' }\end{array}$ & $75 \mathrm{bp}$ \\
\hline$G A P D$ & Sequência não fornecida pela Applied Biosystems & $87 \mathrm{bp}$ \\
\hline$M E F 2 A$ & $\begin{array}{l}\text { 5' CCAATGGGAATGCCAAAGACAATG 3' } \\
\text { 5' TCC GAC TGT TCA TTC CAA CA } 3\end{array}$ & $103 \mathrm{bp}$ \\
\hline$M E F 2 D$ & $\begin{array}{l}\text { 5' CCACTGCCTACAACACAGATTACC 3' } \\
\text { 5' CCCTGCAGGTGAGCTGAAG 3' }\end{array}$ & $109 \mathrm{bp}$ \\
\hline$H I F 1-\alpha$ & $\begin{array}{l}\text { 5'CGAAGAACTCTCAGCCAC 3' } \\
\text { 5' AGCTCGTGTCCTCAGATTCC }\end{array}$ & $94 \mathrm{bp}$ \\
\hline GAPDH & $\begin{array}{l}\text { 5'GAACATCATCCCTGCATCC 3' } \\
\text { 5'CCTGCTTCACCACСТTCTT3 }\end{array}$ & $97 \mathrm{bp}$ \\
\hline
\end{tabular}


O programa de PCR em tempo real foi constituído de: (1) um ciclo 2 min a $50{ }^{\circ} \mathrm{C}$, (ativação da UNG); (2) um ciclo de 10 min a $95^{\circ} \mathrm{C}$, (inativação da UNG); (3) 40 ciclos de 15 s a $95^{\circ} \mathrm{C}$ (desnaturação) e 1 min a $60{ }^{\circ} \mathrm{C}$ (hibridização e extensão).

Os sinais de fluorescência emitidos pelos fluoróforos das sondas TaqMan foram detectados pelo equipamento ABI Prism 7500 (Applied Biosystems, Foster City, C.A., EUA). Os dados foram analisados utilizando-se o programa 7500 System SDS Software (Applied Biosystems, Foster City, C.A., EUA). Para o sistema de amplificação SYBER® Green foi utilizado o equipamento Stratagene (Agilent, Santa Clara, C.A., EUA). Os equipamentos geraram curvas semi-logaritímicas dos sinais de amplificação. A análise fornece o parâmetro ciclo em que o sinal de fluorescência é significativo, denominado ciclo treshold $\left(\mathrm{C}_{\mathrm{t}}\right)$ (BUSTIN, 2000; LIVA; SCHMITTGEN, 2001). Para cada amostra cDNA, o Ct de cada gene é registrado e comparado com o do gene da gliceraldeído desidrogenase $(G A P D)$ que é utilizado como controle endógeno.

A quantidade de cDNA utilizada nos ensaios foi otimizada a partir de curvapadrão que permite avaliar a linearidade da amplificação bem como a eficiência da mesma. Para essa finalidade, foram utilizadas diluições seriadas (1:2, 1:4, 1:8 e 1:16) de cDNA de amostras usadas apenas para teste nos ensaios de PCR em tempo real. As diluições de cDNA e os respectivos valores de $\mathrm{Ct}$ foram colocados em gráfico que permite verificar a relação entre essas duas variáveis ( $\mathrm{Ct} \times \log$ da diluição de cDNA). Após otimização, as concentrações de sondas escolhidas foram de $200 \mathrm{nM}$ e dos iniciadores de 200 nM, para ambos os genes SUR2A, KIR6.2 e GLUT4, para GAPD, foi utilizado a quantidade recomendada pelo fabricante, $900 \mathrm{nM}$ de sonda e $900 \mathrm{nM}$ de iniciadores. Para os genes MEF2A, MEF2D, HIF1- $\alpha$ e GAPDH2 foram utilizados $300 \mathrm{nM}$ de iniciadores.

A eficiência da reação foi calculada de acordo com a inclinação da curva gerada pela seguinte fórmula: $\mathbf{E}=\mathbf{1 0}^{-1 / a}-1 \times 100$, onde $a$ é a inclinação da curva (PFAFFL, 2001). Segundo LIVAK e SCHMITTGEN, 2001, para um ensaio de PCR em tempo real ter alta eficiência $(90 \%$ a $110 \%$ ), a inclinação (slope) da curva-padrão deve ser próximo de -3,3. No Quadro 2 são apresentados os resultados de inclinações (slopes) das curvas e as respectivas eficiências dos ensaios 
Quadro 2 - Valores de inclinação da curva e eficiência das RT-PCR em tempo real.

\begin{tabular}{|lcc|}
\hline Gene & Inclinação da curva & Eficiência \\
\hline SUR2A & $-3,32$ & $101 \%$ \\
SIR6.2 & $-3,29$ & $100 \%$ \\
GAPDH1 & $-3,18$ & $103 \%$ \\
MEF2A & $-3,43$ & $96 \%$ \\
MEF2D & $-3,25$ & $102 \%$ \\
NF-KB & $-3,32$ & $101 \%$ \\
HIF- $\alpha$ & $-3,33$ & $102 \%$ \\
GAPDH2 & $-3,31$ & $100 \%$ \\
\hline
\end{tabular}

Os valores de $\mathrm{Ct}$ obtidos nesses ensaios foram utilizados para o calculo da expressão relativa de mRNA de cada gene alvo em relação à do GAPDH (controle endógeno). Essa relação é denominada Delta $\mathrm{Ct}(\Delta \mathrm{Ct})$ e é calculada pela fórmula:

$$
\mathrm{DCt}=\left(\mathrm{Ct}_{\text {gene alvo }}-\mathrm{Ct}_{\text {controle endógeno }}\right)
$$

Com objetivo de avaliar a variação de expressão entre os grupos foi utilizado o parâmetro Delta Delta $\mathrm{Ct}(\mathrm{DDCt})$ que é calculado utilizando o Delta $\mathrm{Ct}$ da média dos controles não tratados, usando a seguinte fórmula:

$$
\mathrm{DDCt}=\left(\mathrm{DCt}_{\text {controle não tratado }}-\mathrm{DCt}_{\text {amostra }}\right)
$$

Os dados de $\Delta \Delta \mathrm{Ct}$ foram transformados em escala logarítmica $(2 \Delta \Delta \mathrm{Ct})$ para comparar dados entre os grupos. A expressão é interpretada pelo seu aumento ou diminuição após o tratamento. 


\subsection{Preparação dos tecidos e quantificação das proteínas}

As amostras de tecidos musculares foram processadas para extração proteica fracionada conforme Mitsumoto e Klip (1992). Após homogeneização em Polytron PT 3000 KINEMATICA (Brinkman, Bohemia, N.Y., EUA) a 20.000 rpm, em tampão de homogeneização (Tris $\mathrm{HCl} 10 \mathrm{mM}$; EDTA 1,0 mM; sacarose $250 \mathrm{mM}$ ) numa proporção de 1:6 (peso: volume), as amostras foram centrifugadas a $760 \mathrm{~g}\left(10 \mathrm{~min}, 4{ }^{\circ} \mathrm{C}\right) . \mathrm{O}$ sobrenadante foi separado e centrifugado a $31.000 \mathrm{~g}\left(60 \mathrm{~min}, 4^{\circ} \mathrm{C}\right)$, sendo o pellet resuspendido em tampão de homogeneização, correspondente à fração de membrana plasmática (PM). O sobrenadante, após ultracentrifugação a $190.000 \mathrm{~g}\left(60 \mathrm{~min}, 4{ }^{\circ} \mathrm{C}\right)$, produziu o pellet correspondente à fração microssomal (M).

\subsubsection{Western Blotting}

Os experimentos para análise do conteúdo das proteínas GLUT4, KIR6.2 e SUR2A foram avaliados conforme as etapas a seguir:

\subsubsection{6 "SDS-PAGE"}

Foi utilizado o método desenvolvido por Laemmli e modificado por Garfin (GARFIN, 1990), que envolve um sistema descontínuo de dois géis contíguos:

a - gel de empacotamento ("stacking gel") $6 \% \mathrm{~T} ; 2,7 \% \mathrm{C}$

b - gel de separação (“resolving gel”) 10\% T; 2,7\% C (para GLUT4 e KIR6.2)

Antes da aplicação, as amostras foram fervidas por $5 \mathrm{~min}$. A eletroforese começou com a corrida no gel de empacotamento sob voltagem constante em $40 \mathrm{~V}$ até que ocorre-se o empacotamento da amostra, o que foi observado na transição dos géis. Posteriormente, foi aplicada uma corrente constante de $55 \mathrm{~mA}$ para a corrida no gel de separação por 3 horas. 


\subsubsection{Transferência eletroforética}

Após a separação das frações proteicas no gel de poliacrilamida foi realizada a sua transferência eletroforética para uma membrana de nitrocelulose Trans-Blot (Bio-Rad, Hercules, C.A., EUA), sob corrente constante de $35 \mathrm{~mA}$, por 16 horas, a $4{ }^{\circ} \mathrm{C}$, em tampão Tris $\mathrm{HCl}(12,5 \mathrm{mM})$, glicina (95 mM), metanol 20\%, pH 8,3.

A qualidade da transferência foi verificada corando-se o gel com azul brilhante de coomasie.

\subsubsection{7 "ECL-Enhanced Chemiluminescence"}

Após a transferência eletroforética, foi iniciado o processo de ECL para detecção das proteínas:

1) Bloqueio inespecífico da membrana em leite desnatado $2 \%$ diluído em PBS $1 \mathrm{X}$ pH 7,2 $\left[\mathrm{NaCl} 0,8 \%(0,140 \mathrm{M}) ; \mathrm{Na}_{2} \mathrm{HPO}_{4} \cdot\left(12 \mathrm{H}_{2} \mathrm{O}\right) \quad 0,115 \%(0,008 \mathrm{M}) ; \mathrm{KCl} 0,02 \%(0,003 \mathrm{M})\right.$; $\left.\mathrm{KH}_{2} \mathrm{PO}_{4} 0,02 \%(0,0015 \mathrm{M})\right]$ por 2 horas;

2) Para proteína GLUT4, incubou com anticorpo (rabbit anti-GLUT4 polyclonal antibody, Millipore, CA, USA) primário (1:4000) em PBS 1X (BSA 8\%) por 3 horas a $37^{\circ} \mathrm{C}$, sob agitação e para a proteína KIR6.2, incubou com anticorpo (rabbit anti-KIR6.2 polyclonal antibody, Milliopore, C.A., USA) primário (1:200) em TBS-T (BSA 5\%) por 4 a temperatura ambiente.

3) Lavagens: 2 lavagens rápidas com $10 \mathrm{~mL}$ de solução de lavagem TBS -T (Tris- $\mathrm{HCl}$ 1\% $(0,01 \mathrm{M}), \mathrm{NaCL} 3 \%(0,05 \mathrm{M})$, Tween 20 0,05\%); 1 lavagem de 15 minutos com solução de lavagem, sobre o agitador; 3 lavagens com solução de lavagem, 5 minutos cada.

4) Para GLUT4, incubou-se com anticorpo secundário com HRP (Amershan ECL Antirabbit IgG, GE Healthcare, Pittsburgh, P.A., EUA), conjugado coma enzima peroxidaseHRP (1:10.000) em TBS-T + leite desnatado 1\%, por 1 hora, sob agitação e temperatura ambiente, em relação a proteína KIR6.2, incubou-se com anticorpo secundário com HRP (donkey anti-goat GE Healthcare, Pittsburgh, P.A., EUA) em TBS-T + leite desnatado 1\%, por 1 hora, sob agitação e temperatura ambiente 
5) Lavagens: 2 lavagens rápidas com solução de lavagem; 1 lavagem com solução de lavagem por 15 minutos; 4 lavagens de 5 minutos cada com solução de lavagem.

6) Detecção: Incubação da membrana $\left(0,125 \mathrm{~mL} / \mathrm{cm}^{2}\right)$ com as soluções de detecção A e B $\left(\mathrm{ECL}^{\mathrm{TM}}\right.$ Western Blotting Analysis System, RPN 2108) na proporção 1:1 por 2 minutos.

7) Autorradiografia: a membrana foi exposta a filme de RX (Hyperfilm - Amersham, Buckinghamshire, UK), por um tempo variável de 15 segundos a 30 minutos. Após esse período o filme foi revelado com solução reveladora e reforçadora GBX e solução fixadora e reforçadora GBX (Kodak Brasileira, São Paulo, S.P., Brasil).

\subsection{Cultura de células}

Foram utilizadas células musculares da linhagem L6, provenientes do banco mundial de células ATCC (American Type Culture Collection).

\subsubsection{Propagação, diferenciação e tratamento das células}

Alíquotas de células musculares da linhagem L6 foram descongeladas e cultivadas conforme sugerido pelo fornecedor. Desta forma, a propagação e a diferenciação foram realizadas utilizando Meio Dulbecco MEM (DMEM) Vitrocell Embriolife - $4.500 \mathrm{mg} / \mathrm{L}$ de glicose (Vitrocell, Campinas, S.P., Brasil) suplementado com 10\% de Soro Fetal Bovino-SFB (v/v) (Vitrocell, Campinas, S.P., Brasil) e 1\% de antibiótico (penicilina/ estreptomicina) (v/v) (Sigma-aldrich, St. Louis, M.O., EUA). Permaneceram em incubadora Nuaire a 5\% de $\mathrm{CO}_{2}$, $37{ }^{\circ} \mathrm{C}$ até atingirem confluência de cerca de $70 \%$. Neste ponto, o meio de propagação foi substituído por meio de diferenciação contendo, Meio Dulbecco MEM Vitrocell Embriolife $4.500 \mathrm{mg} / \mathrm{L}$ de glicose (Vitrocell, Campinas, S.P., Brasil) suplementado com 2\% de Soro Fetal Bovino-SFB (v/v) (Vitrocell, Campinas, S.P., Brasil) e 1\% de antibiótico (penicilina/ estreptomicina) (v/v) (Sigma-aldrich, St. Louis, M.O., EUA).

Após sete dias de diferenciação (YONEMITSU et al., 2001), o meio contendo 2\% de SFB foi substituído por Meio Dulbecco MEM (DMEM), (Vitrocell Embriolife - $1.000 \mathrm{mg} / \mathrm{L}$ de glicose, BR) (HOMMELBERG et al., 2009) e de antibiótico (v/v) (Sigma-Aldrich Chemicals, Steinhein, Alemanha) por 6 horas. 
Em seguida, o tratamento por 24 horas foi iniciado, em Meio Dulbecco 16,7 mM de D-Glicose (DMEM) (Vitrocell, Campinas, S.P., Brasil). No primeiro grupo denominado de Controle, foi adicionado 0,03\% de DMSO (Sigma-Aldrich Chemicals, Steinhein, Germany), DMSO é o solvente da glimepirida. No segundo grupo Controle + Insulina composto por $100 \mathrm{nM}$ de insulina (Sigma-Aldrich Chemicals, Steinhein, Alemanha) e 0,03\% de DMSO. No terceiro grupo, Glimepirida, as células foram tratadas por $100 \mathrm{uM}$ de glimepirida (SigmaAldrich Chemicals, Steinhein, Alemanha), e no quarto e último grupo, denominado de Glimepirida + Insulina, foi adicionado $100 \mathrm{uM}$ de glimepirida e $120 \mathrm{nM}$ de insulina ((Sigma-Aldrich Chemicals, Steinhein, Alemanha).

\subsubsection{Extração de RNA total de linhagem celular}

Amostras de células musculares L6 cultivadas em placas com 6 poços foram inicialmente acrescidas de PBS1X, para retirar o excesso de meio de cultura, e posteriormente destinadas a extração de RNA total, com reagente Trizol (Invitrogen Life Technologies, Boemia, N.Y., EUA), conforme instruções do fabricante. Após esta etapa, a concentração de RNA total das amostras e o grau de pureza destas, determinado pela razão $A_{260 n m} / A_{280 n m}$, foi avaliado por espectrofotometria (Gene Quant II, Pharmacia Biotech, Londres, UK). A integridade do RNA extraído foi avaliada pela visualização das bandas 28 e 18S, sob luz ultravioleta após corrida em gel de agarose (1\%). Posteriormente foi realizado a transcrição reversa e PCR em Tempo Real, mesma metodologia utilizada em musculo esquelético, descrita anteriormente.

\subsection{Análise estatística dos resultados}

A associação entre as variáveis mensuradas e os fatores de interesse será verificada utilizando-se a Análise de Variância com múltiplos fatores (ANOVA). Para comparações entre os parâmetros avaliados ao longo do tempo será utilizado ANOVA one way e two-way para medidas repetidas. Serão considerados estatisticamente significantes os resultados cujos níveis descritivos (valores de $P$ ) forem inferiores a 0,05 . 


\section{RESULTADOS}

\subsection{Parâmetros morfométricos e verificação da presença de obesidade}

As tabelas 1 e 2 mostram os parâmetros morfométricos dos animais controles e obesos (C e MSG), tratados e não tratados com glimepirida (CG e MSG/G). Observou-se que os animais obesos apresentaram pesos absolutos dos músculos esqueléticos sóleo (SOL) e extensor digital longo (EDL) significativamente menores em relação aos controles (tabela 1a). Analisando-se o peso destes tecidos relativamente ao peso corpóreo, não houve diferença entre ratos controles e obesos, demonstrando que o menor peso absoluto dos músculos dos obesos foi devido ao prejuízo no crescimento/desenvolvimento, sendo mantida a proporção de massa magra relativa à massa corporal (tabela $1 \mathrm{~b}$ ).

Os animais obesos mostraram menor peso corpóreo, associado à diminuição do comprimento naso-anal (tabela 2), de tal forma que a obesidade confirmou-se pelo índice de Lee, que demonstrou que os animais MSG e MSG/G apresentaram maior peso em relação ao comprimento que seus respectivos controles $\mathrm{C}$ e CG respectivamente (tabela 2).

O tratamento com a glimepirida não afetou nenhuma das características morfométricas analisadas (tabela 1a, $1 \mathrm{~b}$ e 2 ).

Tabela 1a - Peso absoluto dos tecidos de animais controles e obesos, tratados (CG e MSG/G) e não tratados (C e MSG) com glimepirida por 4 semanas.

\begin{tabular}{lcc}
\hline Tecido & SOL (mg) & EDL (mg) \\
Grupo & $169 \pm 4,5$ & $162 \pm 4,6$ \\
\hline $\mathbf{C ~ ( n = 1 3 )}$ & $173 \pm 8,5$ & $154 \pm 4,2$ \\
$\mathbf{C G}(\mathbf{n}=\mathbf{1 2})$ & $104 \pm 6,5^{* * *}$ & $103 \pm 7,1^{* * * \wedge \wedge \wedge}$ \\
$\mathbf{M S G}(\mathbf{n}=\mathbf{1 2})$ & $108 \pm 10,1^{* * * \wedge \wedge \wedge}$ & $118 \pm 4,5^{* * * \wedge \wedge \wedge}$ \\
\hline $\mathbf{M S G} / \mathbf{G}(\mathbf{n}=\mathbf{1 5})$ &
\end{tabular}

SOL = músculo sóleo; EDL = músculo Extensor Digital Longo

Valores expressos como média \pm EPM e comparados por análise de variância de 1 via, para dados independentes.

${ }^{* *} \mathrm{p}<0,01$ vs. $\mathrm{C} ;{ }^{* * *} \mathrm{p}<0,001$ vs. $\mathrm{C} ;{ }^{\wedge \wedge \wedge} \mathrm{p}<0,001$ vs. $\mathrm{C} / \mathrm{G}$ 
Tabela 1b - Peso relativo a 100 gramas de peso corpóreo dos tecidos de animais controles e obesos, tratados (CG e MSG/G) e não tratados (C e MSG) com glimepirida por 4 semanas.

\begin{tabular}{lcc}
\hline \multicolumn{1}{c}{ Tecido } & SOL $(\mathbf{m g} / \mathbf{1 0 0} \mathbf{g})$ & EDL (mg/100 g) \\
\hline Grupo & & \\
\hline CG (n=13) $(\mathbf{1 2})$ & $43 \pm 2$ & $42 \pm 1$ \\
MSG (n=12) & $44 \pm 3$ & $41 \pm 2$ \\
MSG/G (n=15) & $28 \pm 2$ & $30 \pm 4$ \\
\hline
\end{tabular}

$\mathrm{SOL}=$ músculo sóleo; EDL = músculo Extensor Digital Longo

Valores expressos como média \pm EPM e comparados por análise de variância de 1 via, para dados independentes.

Tabela 2 - Índice de Lee, peso corpóreo e comprimento naso-anal de ratos controles e obesos, tratados (CG e MSG/G) e não tratados (C e MSG) com glimepirida durante quatro semanas.

\begin{tabular}{|c|c|c|c|c|}
\hline Grupo & Peso & (g) & Comprimento $(\mathrm{cm})$ & $\begin{array}{c}\text { Índice de Lee } \\
\qquad\left(\mathrm{g}^{1 / 3} / \mathrm{cm}\right)\end{array}$ \\
\hline$C(n=13)$ & $402 \pm 7,3$ & & $24,3 \pm 0,19$ & $30,9 \pm 0,41$ \\
\hline$C G(n=12)$ & $398 \pm 4,5$ & & $24,4 \pm 0,3$ & $30,1 \pm 0,33$ \\
\hline MSG $(n=12)$ & $310 \pm 5,5^{* * * \wedge}$ & & $21,1 \pm 0,34 * * * \wedge \wedge$ & $31,7 \pm 0,65^{* \wedge \wedge}$ \\
\hline MSG/G $(n=15)$ & $313 \pm 8,2 * * * \wedge$ & & $21,3 \pm 0,56^{* * * \wedge \wedge \wedge}$ & $32,4 \pm 0,34^{* \wedge \wedge}$ \\
\hline
\end{tabular}

ÍNDICE DE LEE $=([\sqrt[3]{\text { peso }(\mathrm{g}) \div \text { comprimento naso-anal }(\mathrm{cm})] \mathrm{X} 100)}$

Valores expressos como média \pm EPM, comparados por Análise de variância de 1 via, para dados independentes.

${ }^{\wedge} \mathrm{p}<0,05$ vs. CG; $\quad{ }^{* * *} \mathrm{p}<0,001$ vs. $\mathrm{C} ; \quad{ }^{\wedge} \mathrm{p}<0,01 \quad$ vs. $\quad \mathrm{CG} ; \quad{ }^{*} \mathrm{p}<0,05 \quad$ vs. $\quad \mathrm{C}$; 


\subsection{Consumo de água e alimento}

Os consumos de água e ração dos diferentes grupos experimentais foram medidos antes e durante as 4 semanas de tratamento com glimepirida, pelo menos 2 vezes por semana.

As tabelas 3A e 3B mostram, respectivamente, o consumo médio de ração e de água, antes do início da administração da glimepirida e ao final do período de tratamento. Durante este período, os consumos tanto de alimento como de água se mantiveram constantes dentro de cada grupo, não havendo diferença significativa entre o consumo inicial e consumo final, após 4 semanas.

Comparados aos animais controles, os obesos (tratados ou não com glimepirida) apresentaram consumo absoluto significativamente mais baixo, tanto de alimento quanto de água, o que se iguala aos controles quando normalizado por $100 \mathrm{~g}$ de peso corporal. A glimepirida não alterou o consumo, pois os grupos CG e MSG/G apresentaram ingestão semelhante aos grupos C e MSG, respectivamente. 
Tabela 3a - Consumo alimentar diário de ratos controles e obesos, tratados (CG e MSG/G) e não tratados (C e MSG) com glimepirida, expresso em valores absolutos $(\mathrm{g}) \mathrm{e}$ relativos a $100 \mathrm{~g}$ de peso corpóreo $(\mathrm{g} / 100 \mathrm{~g})$.

Grupo

Absoluto

Absoluto

Consumo Alimentar

Inicial: média dos dois dias anteriores ao inicio do tratamento com glimepirida; Final: média dos dois últimos dias antes do sacrifício. Resultados expressos como média \pm EPM, calculada a partir do consumo médio de 4 ou 5 gaiolas, contendo 3-4 animais.

$* * * p<0,001$ vs. $\mathrm{C} ;{ }^{\wedge \wedge \wedge} \mathrm{p}<0,001$ vs. $\mathrm{CG}$ 
Tabela 3b - Consumo hídrico diário de ratos controles e obesos, tratados (CG e MSG/G) e não tratados (C e MSG) com glimepirida, expresso em valores absolutos $(\mathrm{mL})$ e relativos a $100 \mathrm{~g}$ de peso corpóreo $(\mathrm{mL} / 100 \mathrm{~g})$.

Grupo

Absoluto

\section{Consumo hídrico}

\section{Relativo}

\section{Inicial (mL) $\quad$ Final $(\mathrm{mL}) \quad$ Inicial $(\mathrm{mL} / 100 \mathrm{~g}) \quad$ Final $(\mathrm{mL} / 100 \mathrm{~g})$}
C (4)
$41,2 \pm 2,52$
$42,3 \pm 1,08$
$11,3 \pm 0,45$
$10,4 \pm 0,45$

CG (4)

$39,9 \pm 0,97$

$40,9 \pm 0,56$

$10,5 \pm 0,56$

$11,9 \pm 0,39$

MSG (4)

$31,3 \pm 1,0 * * \wedge \wedge$

$33,4 \pm 0,65 * * \wedge \wedge$

$9,5 \pm 0,39$

$9,9 \pm 0,45$

MSG/G (5)

$$
33,1 \pm 1,98 * * \wedge \wedge
$$

$33,4 \pm 0,16^{* * \wedge \wedge}$

$11,6 \pm 0,53$

$11 \pm 0,34$

Inicial = média dos dois dias anteriores ao inicio do tratamento com glimepirida; Final = média dois últimos dias antes do sacrifício. Resultados expressos como média \pm EPM, calculada a partir do consumo médio de 4 ou 5 gaiolas, contendo 3-4 animais.

$* * \mathrm{p}<0,01$ vs. $\mathrm{C} ;{ }^{\wedge \wedge} \mathrm{p}<0,01$ vs. $\mathrm{CG}$ 


\subsection{Avaliação da sensibilidade à insulina}

$\mathrm{Na}$ tabela 4, observa-se que a glimepirida elevou a insulinemia tanto nos ratos controles $(p<0,05)$ quanto nos obesos $(p<0,01)$. Mesmo com as insulinemias elevadas, os animais tratados não apresentaram variações glicêmicas importantes. Comparando-se C e MSG, não houve diferença significativa entre as insulinemias, embora os obesos tendessem a apresentar uma elevação, o que indica que estes animais foram avaliados numa fase do desenvolvimento em que as alterações metabólicas da obesidade ainda não se encontravam totalmente estabelecidas.

Com objetivo de confirmar a presença de resistência insulínica no grupo MSG, utilizamos o teste de tolerância à insulina. A figura 1 mostra as constantes de decaimento da glicose (kITT) obtidas a partir dos valores de glicemia de 0 a 16 minutos após sobrecarga venosa de insulina, $\mathrm{O}$ grupo MSG apresentou decaimento da glicose significativamente menor que os grupos $\mathrm{C}, \mathrm{CG}$ e $\mathrm{MSG} / \mathrm{G}$. 
Tabela 4 - Parâmetros metabólicos de ratos controles e obesos, tratados (CG e MSG/G) e não tratados (C e MSG) com glimepirida, durante quatro semanas.

\begin{tabular}{lcl}
\hline Grupo & Glicemia (mg/dl) & Insulinemia (uU/mL) \\
\hline C (7) & $139,8 \pm 4,9$ & $19,6 \pm 3,0$ \\
CG (6) & $143,6 \pm 4,7$ & $26,5 \pm 2,9 *$ \\
MSG (4) & $145,7 \pm 5,7$ & $22,3 \pm 2,0$ \\
MSG/G (7) & $143,3 \pm 3,5$ & $37,9 \pm 3,3 * * * \# \#$ \\
\hline
\end{tabular}

Amostras coletadas sem restrição alimentar prévia. Resultados expressos como média \pm EPM, comparados por Análise de Variância de 1 via, para dados independentes. $* \mathrm{p}<0,05$ vs. $\mathrm{C},{ }^{* * *} \mathrm{p}<0,001$ vs. C, \#\# p<0,01 vs. MSG

Figura 1 - Constante de decaimento de glicose (kITT) de ratos controles e obesos, tratados (CG e MSG/G) e não tratados (C e MSG) com glimepirida por 4 semanas.

\section{ITT}

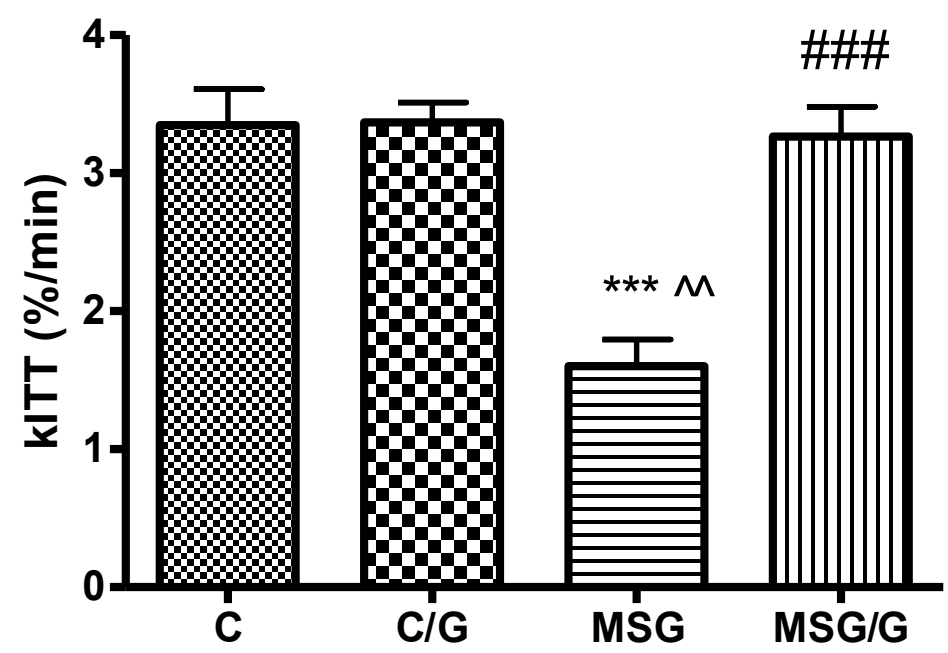

Os resultados foram obtidos em 4-6 animais por grupo, sendo as médias comparadas por análise de variância de 1 via para dados independentes, seguida do teste de Student Newman-Kewls (SNK):

***p $<0,001$ vs. $\mathrm{C} ;{ }^{\wedge \wedge} \mathrm{p}<0,01$ vs. $\mathrm{CG} ; \# \# \# \mathrm{p}<0,001$ vs. MSG. 


\subsection{Qualidade do fracionamento subcelular dos tecidos}

Na tabela 5 estão mostrados os valores de recuperação proteica total para SOLEO e EDL. Em cada fração (PM e M), nenhuma diferença significativa foi observada entre os grupos.

Tabela 5 - Recuperação proteica total por grama de tecido nas diferenças frações dos tecidos de ratos controles e obesos (CG e $\mathrm{MSG} / \mathrm{G}$ ) e não tratados (C e $\mathrm{MSG}$ ) com glimepirida, por 4 semanas.

\begin{tabular}{|c|c|c|c|c|}
\hline SOLEO & $C(n=7)$ & $C / G(n=6)$ & $\operatorname{MSG}(n=5)$ & MSG/G $(n=8)$ \\
\hline PM (mg/g) & $4,27 \pm 0,9$ & $4,70 \pm 1,53$ & $4,43 \pm 1,73$ & $6,73 \pm 2,08$ \\
\hline M (mg/g) & $1,93 \pm 0,21$ & $2,11 \pm 0,32$ & $2,41 \pm 0,40$ & $2,45 \pm 0,35$ \\
\hline EDL & $C(n=7)$ & $C / G(n=6)$ & $\operatorname{MSG}(n=7)$ & MSG/G $(n=8)$ \\
\hline PM (mg/g) & $4,53 \pm 0,9$ & $4,78 \pm 1,74$ & $5,99 \pm 1,7$ & $5,97 \pm 1,62$ \\
\hline M (mg/g) & $2,12 \pm 0,23$ & $3,2 \pm 0,45$ & $2,33 \pm 0,23$ & $2,94 \pm 0,69$ \\
\hline
\end{tabular}

EDL, músculo Extensor Digital Longo; PM, fração de membranas plasmáticas; $M$, fração de membranas microssomais. Resultados expressos como média \pm EPM e comparações estatísticas apenas entre os grupos, para uma mesma fração de cada tecido (ANOVA de 1 via, para dados independentes) 


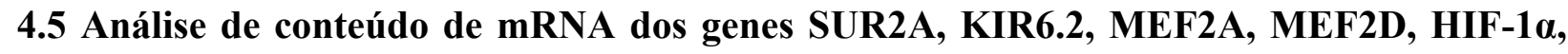
NF-KB e Slc2a4 e das proteínas SUR2A, KIR6.2 e GLUT4 em músculo esquelético extensor digital longo (EDL)

As tabelas contendo média e desvio padrão são apresentadas no item apêndice.

\subsubsection{Expressão do mRNA e da proteína SUR2A em EDL}

Não foram observadas diferenças significativas na expressão do mRNA e da proteína de SUR2A entre os diferentes grupos analisados, em músculo esquelético extensor digital longo (EDL) (figura 2). 
Figura 2 - Análise do mRNA de SUR2A (A) e da proteína SUR2A (B) em músculo extensor digital longo de ratos controles e obesos, tratados $(\mathrm{CG}$ e $\mathrm{MSG} / \mathrm{G})$ e não tratados (C e MSG) com glimepirida por 4 semanas.

\section{mRNA SUR2A EDL}
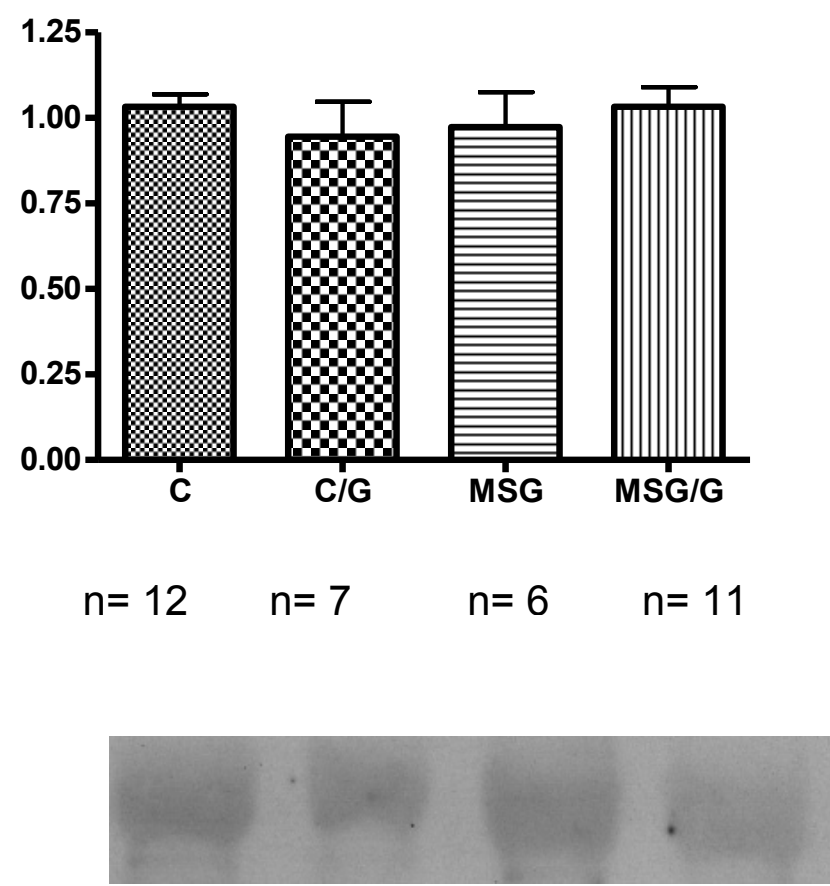

Proteína SUR2A EDL

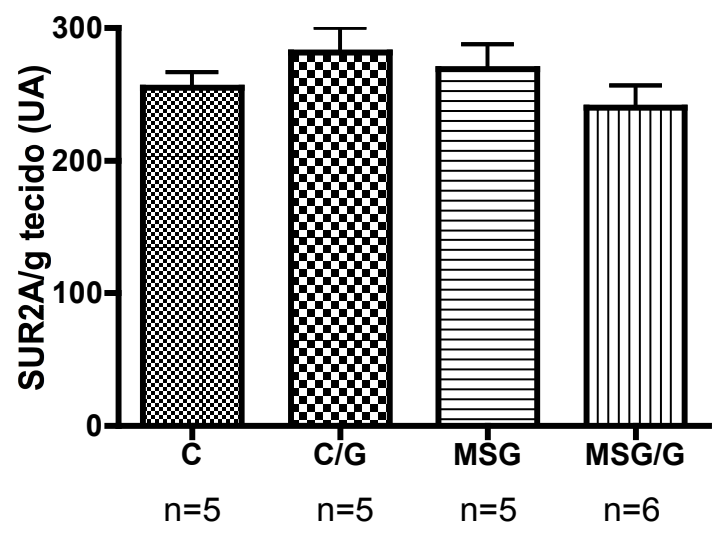

Em A: conteúdos dos mRNAs do SUR2A, normalizados por GAPD. Os resultados são média \pm EPM de 3 experimentos distintos. Em B: conteúdo da proteína (UA/g tecido) em membranas plasmáticas (PM). Abaixo: Autorradiografia típica de membranas plasmáticas (PM). Os resultados são média \pm EPM. Anova de 1 via para dados independentes/SNK: 


\subsubsection{Expressão do mRNA e da proteína de KIR6.2 em EDL}

Foi observada uma elevação de 23,9 \% no mRNA do KIR6.2 no grupo controle tratado, (CG vs. $\mathrm{C}, \mathrm{p}<0,01)$. Este aumento também foi observado no grupo $\mathrm{CG}$ em relação aos grupos MSG e MSG/G (33,3 \% e 23,1\%; $<<0,01$, respectivamente). Os animais obesos (MSG) não mostraram alteração da expressão de KIR6.2 em relação ao controle (C). Após tratamento com glimepirida, grupo $\mathrm{MSG} / \mathrm{G}$, resultou em uma discreta elevação da expressão de KIR6.2, mas não foi significativa em relação ao obeso não tratado (MSG).

Não houve diferenças significativas do conteúdo da proteína KIR6.2 em membranas plasmáticas (PM). 
Figura 3 - Análise do mRNA de KIR6.2 (A) e da proteína KIR6.2 (B) em músculo extensor digital longo de ratos controles e obesos, tratados $(\mathrm{CG}$ e $\mathrm{MSG} / \mathrm{G})$ e não tratados $(\mathrm{C}$ e MSG) com glimepirida por 4 semanas.
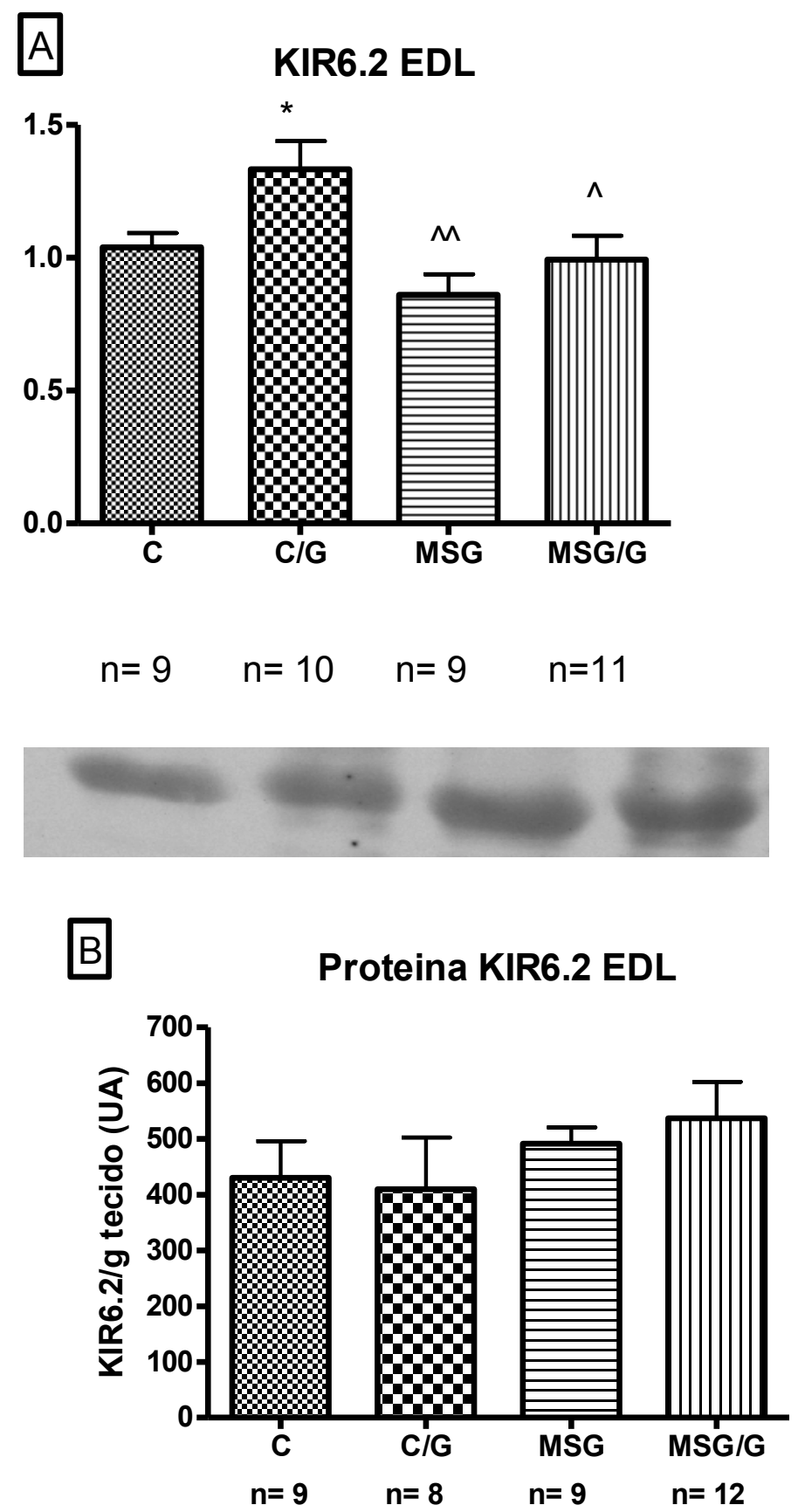

Em A: conteúdos dos mRNAs do KIR6.2, normalizados por GAPD. Os resultados são média \pm EPM de 3 experimentos distintos. Em B: conteúdo da proteína (UA/g tecido) em membranas plasmáticas (PM). Abaixo: Autorradiografia típica de membranas plasmáticas (PM). Os resultados são média \pm EPM. Anova de 1 via para dados independentes/SNK:

*p $<0,05$ vs. $\mathrm{C} ;{ }^{\wedge} \wedge 0,01$ vs. $\mathrm{CG} ;{ }^{\wedge} 0,05$ vs. $\mathrm{CG}$ 
Não foram observadas diferenças significativas na expressão do mRNA de MEF2A no EDL dos diferentes grupos analisados (figura 4).

Figura 4 - Análise do mRNA de MEF2A em músculo EDL de ratos controles e obesos, tratados ( $\mathrm{CG}$ e $\mathrm{MSG} / \mathrm{G})$ e não tratados (C e $\mathrm{MSG}$ ) com glimepirida por 4 semanas.

\section{MEF2A}

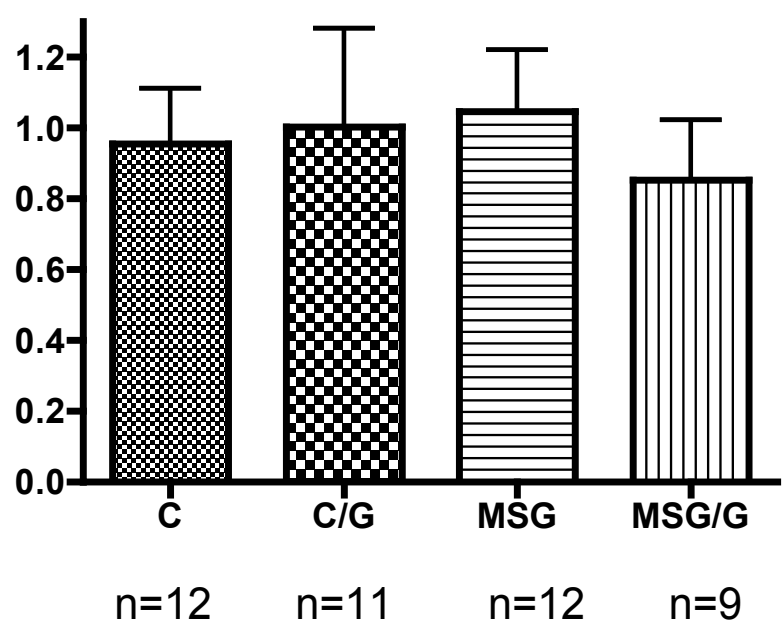

Conteúdos dos mRNAs de MEF2A, normalizados por GAPDH2. Os resultados são média \pm EPM. Anova de 1 via para dados independentes/SNK: 
4.5.4 Expressão do mRNA de MEF2D em EDL

Não foram observadas (figura 5) diferenças significativas na expressão do mRNA do MEF2D no EDL dos diferentes grupos analisados.

Figura 5 - Análise do mRNA de MEF2D em músculo EDL de ratos controles e obesos, tratados (CG e MSG/G) e não tratados (C e MSG) com glimepirida por 4 semanas.

\section{MEF2D}

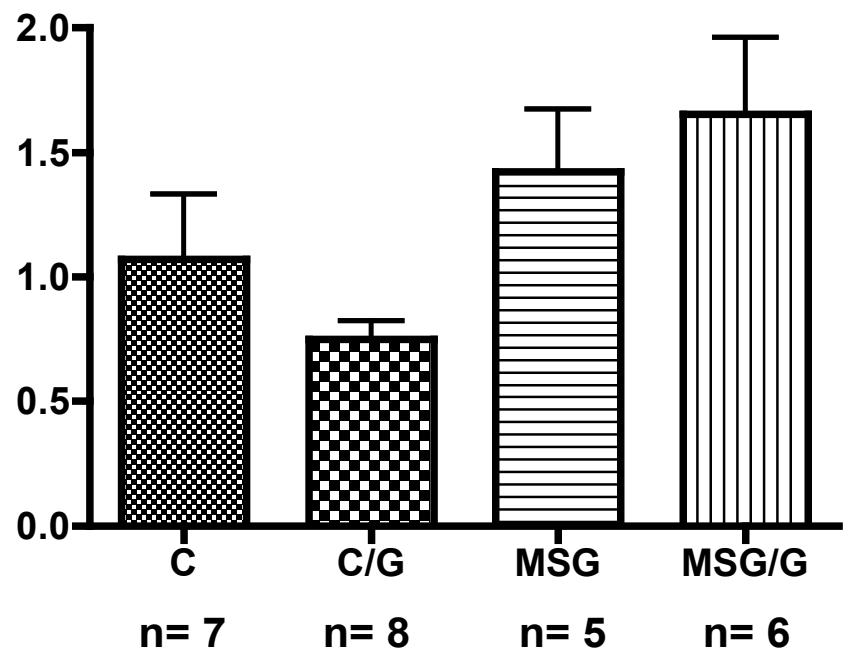

Conteúdos dos mRNAs de MEF2D, normalizados por GAPDH2. Os resultados são média \pm EPM. Anova de 1 via para dados independentes/SNK: 


\subsubsection{Expressã̃o mRNA de HIF1- $\alpha$ em EDL}

Não foram observadas (figura 6) diferenças significativas na expressão do mRNA do HIF1- $\alpha$ em EDL dos diferentes grupos analisados).

Figura 6 - Análise do mRNA de HIF1- $\alpha$ em músculo EDL de ratos controles e obesos, tratados (CG e MSG/G) e não tratados (C e MSG) com glimepirida por 4 semanas.

\section{HIF $1-\alpha$}

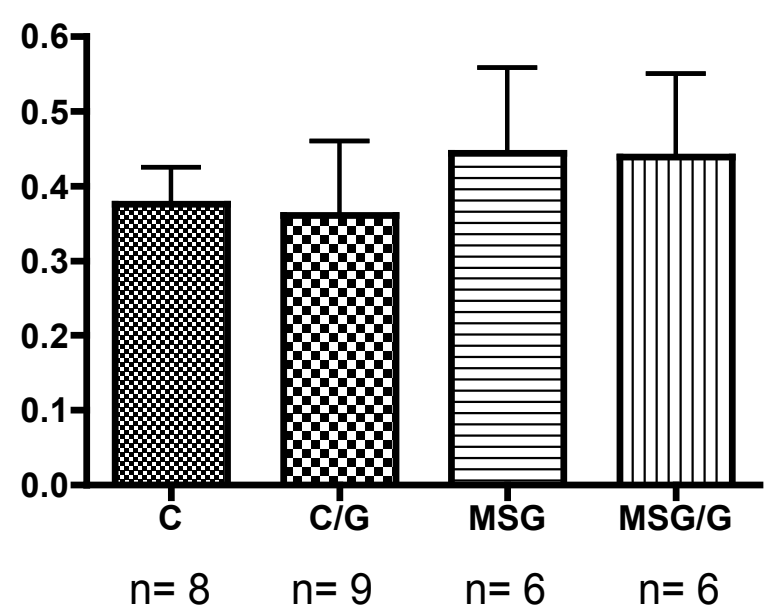

Conteúdos dos mRNAs de HIF1- $\alpha$, normalizados por GAPDH2. Os resultados são média \pm EPM. Anova de 1 via para dados independentes/SNK: 


\subsubsection{Expressão de Slc2a4 e da proteína GLUT4 em EDL}

No grupo obeso não tratado, houve uma redução de $40 \%$ da expressão de Slc $2 a 4$ (MSG vs. C, p<0,01). Após o tratamento de 4 semanas com glimepirida, o conteúdo de mRNA de Slc2a4 aumentou em 42\% nos obesos (MSG/G vs. $\mathrm{MSG}, \mathrm{p}<0,01$ ), retornando a valores semelhantes aos do controle. A glimepirida não alterou a expressão de $S l c 2 a 4$ nos animais controles.

Em relação à proteína, não foram encontradas diferenças significativas no conteúdo total $(\mathrm{PM}+\mathrm{M})$ e nem nas frações subcelulares de GLUT4. 
Figura 7 - Análise do mRNA Slc2a4 (A) e da proteína GLUT4 (B) em músculo extensor digital longo de ratos controles e obesos, tratados (CG e $\mathrm{MSG} / \mathrm{G})$ e não tratados (C e MSG) com glimepirida por 4 semanas.
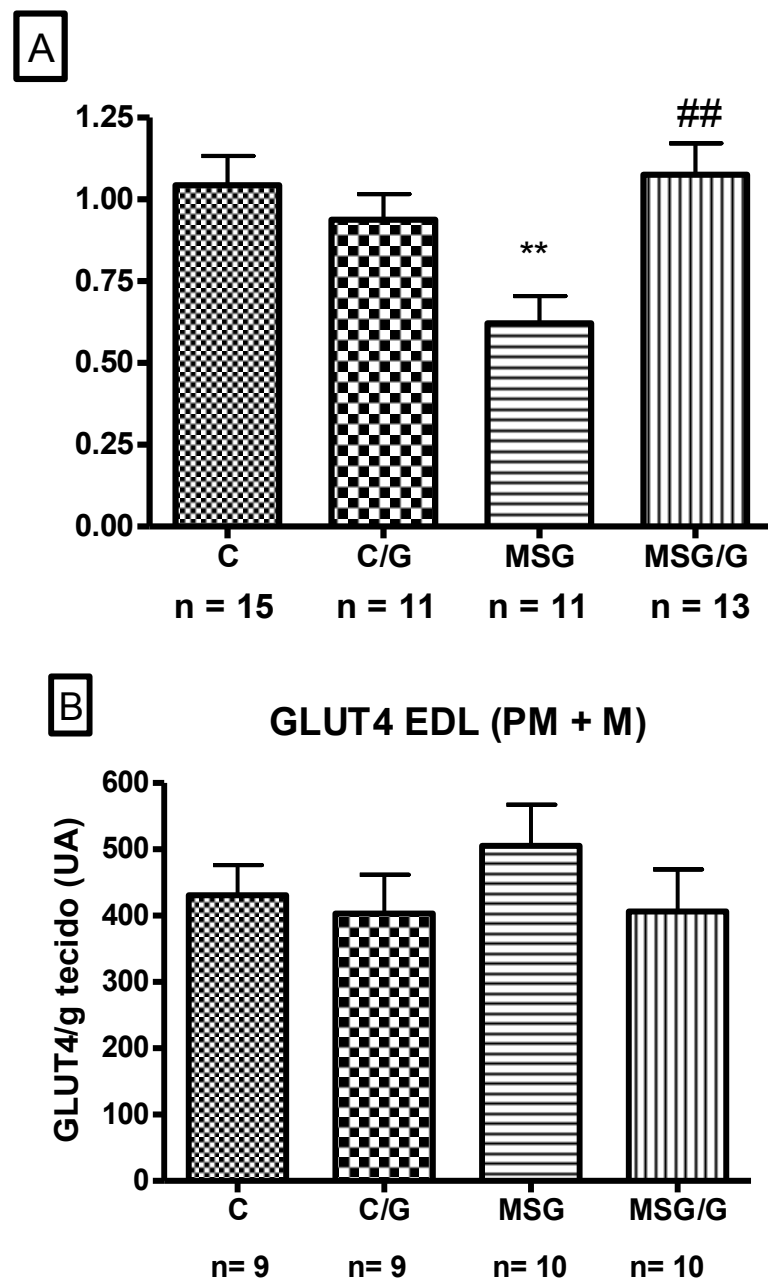

Em A: conteúdos dos mRNAs de Slc2a4, normalizados por GAPD. Os resultados são média \pm EPM de 3 experimentos distintos. Em B: conteúdo da proteína (UA/g tecido) em membranas totais $(\mathrm{PM}+\mathrm{M})$. Os resultados são média \pm EPM. Anova de 1 via para dados independentes/SNK: ${ }^{* *} \mathrm{p}<0,01$ vs. $\mathrm{C}^{\wedge}{ }^{\wedge}$ $\mathrm{p}<0,05$ vs. CG; \#\# $\mathrm{p}<0,01$ vs. MSG 
Figura 8 - Análise da proteína GLUT4 em membranas de frações subcelulares do músculo extensor digital longo de ratos controles e obesos, tratados (CG e MSG/G) e não tratados (C e MSG) com glimepirida por 4 semanas.

GLUT EDL (PM)
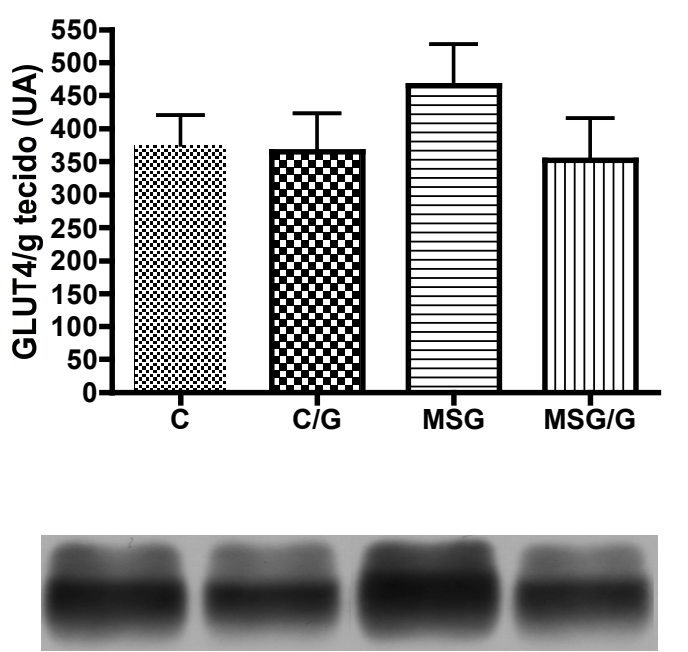

GLUT4 EDL (M)
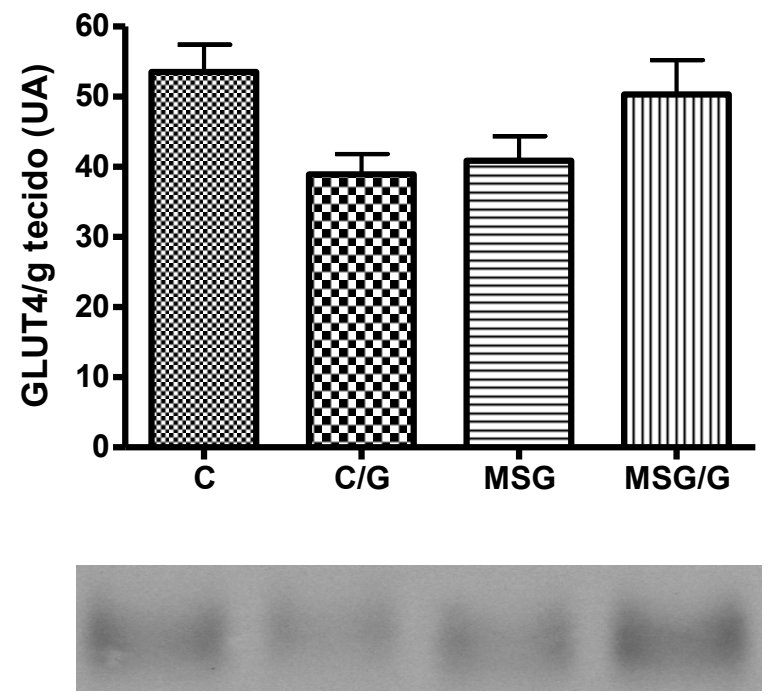

À esquerda: Conteúdo de GLUT4 em membranas plasmáticas (PM), contido numa mesma quantidade de proteínas totais (40ug) submetidas à eletroforese. À direita: Conteúdo de GLUT4 em microssomas (M), contido numa mesma quantidade de proteínas totais (40ug) submetidas à eletroforese. Abaixo: Autorradiografias típicas das frações PM e M. Os resultados são média \pm EPM, expressos em UA por grama de tecido.

4.6 Análise de expressão do conteúdo de mRNA dos genes SUR2A, KIR6.2, MEF2A, MEF2D, HIF1- $\alpha$, NF-KB e Slc2a4, e do conteúdo de proteína de KIR6.2 e GLUT4 em músculo esquelético sóleo

As tabelas contendo média e desvio padrão são apresentadas no item apêndice. 
4.6.1 Expressão mRNA e proteína de SUR2A em Sóleo

Alterações foram claramente observadas da expressão de mRNA de SUR2A (Figura 9) em músculo sóleo de animais obesos tratados por 4 semanas com glimepirida (aumento de $\sim 45 \%$ em relação a todos os demais grupos $\mathrm{p}<0,01$ ).

Figura 9 - Análise do mRNA de SUR2a em músculo sóleo de ratos controles e obesos, tratados (CG e $\mathrm{MSG} / \mathrm{G})$ e não tratados (C e $\mathrm{MSG}$ ) com glimepirida por 4 semanas.

\section{mRNA SUR2a SOLEO}

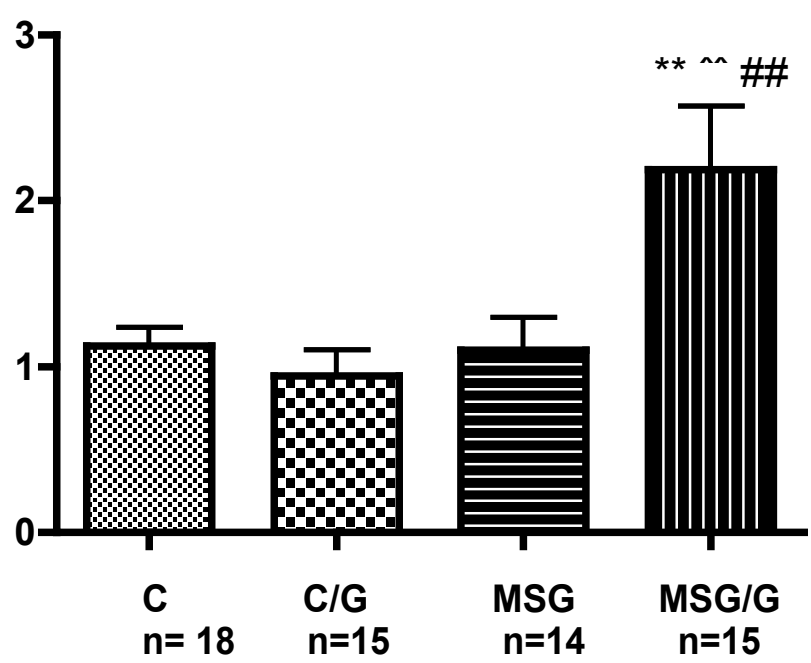

Conteúdos dos mRNAs do SUR2A, normalizados por GAPD. Os resultados são média \pm EPM. Anova de 1 via para dados independentes/SNK:

** $\mathrm{p}<0,01$ vs. $\mathrm{C} ;{ }^{\wedge \wedge} \mathrm{p}<0,01$ vs. $\mathrm{CG}$; \#\# $\mathrm{p}<0,01$ vs. MSG 


\subsubsection{Expressão mRNA e da proteína KIR6.2 em Sóleo}

Aumento evidente foi observado (figura 10) na expressão de mRNA de KIR6.2 em músculo sóleo de animais obesos tratados com glimepirida, em relação aos demais grupos $(\sim 76 \%, \mathrm{p}<0,05$ a $\mathrm{p}<0,01)$. O mesmo efeito da glimepirida foi observado em relação ao conteúdo da proteína KIR6.2 em membrana plasmática (PM) que aumentou $\sim 100 \%$ no grupo MSG/G. 
Figura 10 - Análise do mRNA de KIR6.2 (A) e da proteína KIR6.2 (B) em músculo sóleo de ratos controles e obesos, tratados ( $\mathrm{CG}$ e $\mathrm{MSG} / \mathrm{G})$ e não tratados $(\mathrm{C}$ e $\mathrm{MSG}) \mathrm{com}$ glimepirida por 4 semanas.
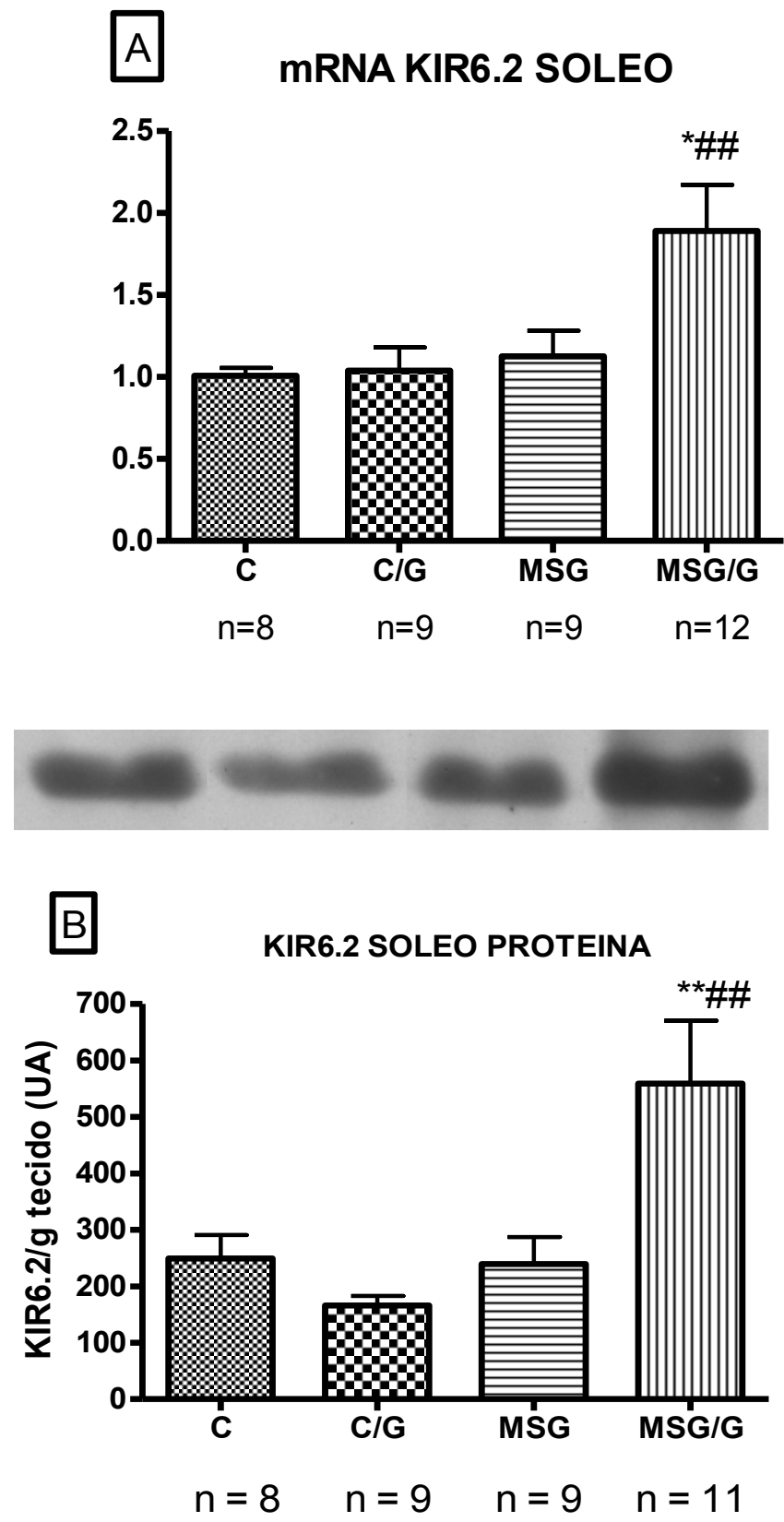

Em A: conteúdos dos mRNAs do KIR6.2, normalizados por GAPD. Os resultados são média \pm EPM. Em B: conteúdo da proteína (UA/g tecido) em membranas plasmáticas (PM). Abaixo: Autorradiografia típica da fração de membranas plasmáticas (PM). Os resultados são média \pm EPM. Anova de 1 via para dados independentes/SNK:

* $\mathrm{p}<0,05$ vs. $\mathrm{C} ; \wedge$ p $<0,05$ vs. CG; \#\# $\mathrm{p}<0,01$ vs. MSG; \# $\mathrm{p}<0,05$ vs. MSG. 
Não foram observadas (Figura 11) diferenças significativas na expressão do mRNA do MEF2A entre os diferentes grupos analisados.

Figura 11 - Análise do mRNA de MEF2A em músculo sóleo de ratos controles e obesos, tratados (CG e $\mathrm{MSG} / \mathrm{G})$ e não tratados (C e $\mathrm{MSG})$ com glimepirida por 4 semanas.

\section{MEF2A}

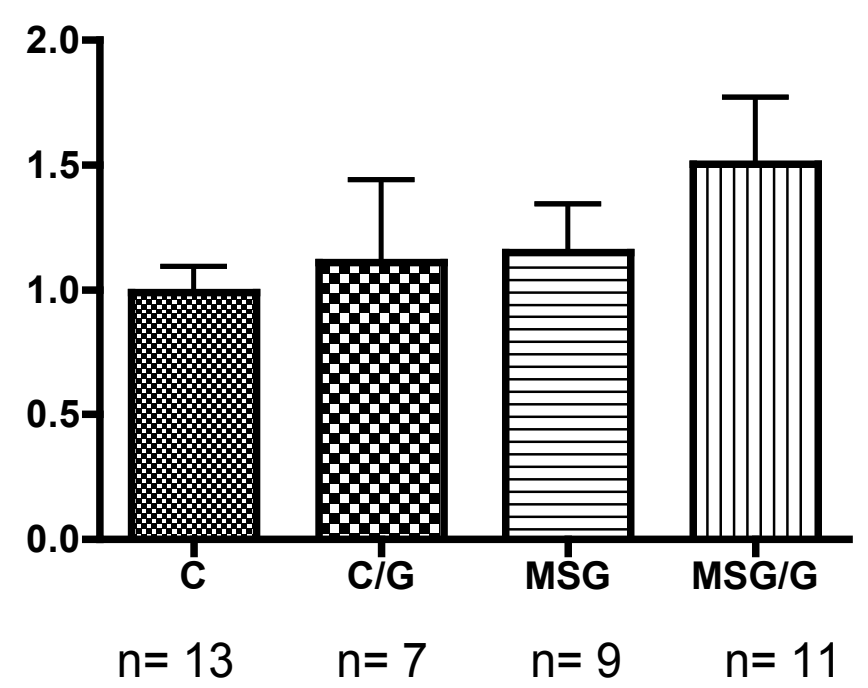

Conteúdos dos mRNAs de MEF2A, normalizados por GAPDH2. Os resultados são média \pm EPM. Anova de 1 via para dados independentes/SNK: 
Não foram observadas (figura 12) diferenças significativas na expressão do mRNA do MEF2D entre os diferentes grupos analisados.

Figura 12 - Análise do mRNA de MEF2D em músculo sóleo de ratos controles e obesos, tratados (CG e MSG/G) e não tratados (C e MSG) com glimepirida por 4 semanas.

\section{MEF2D}

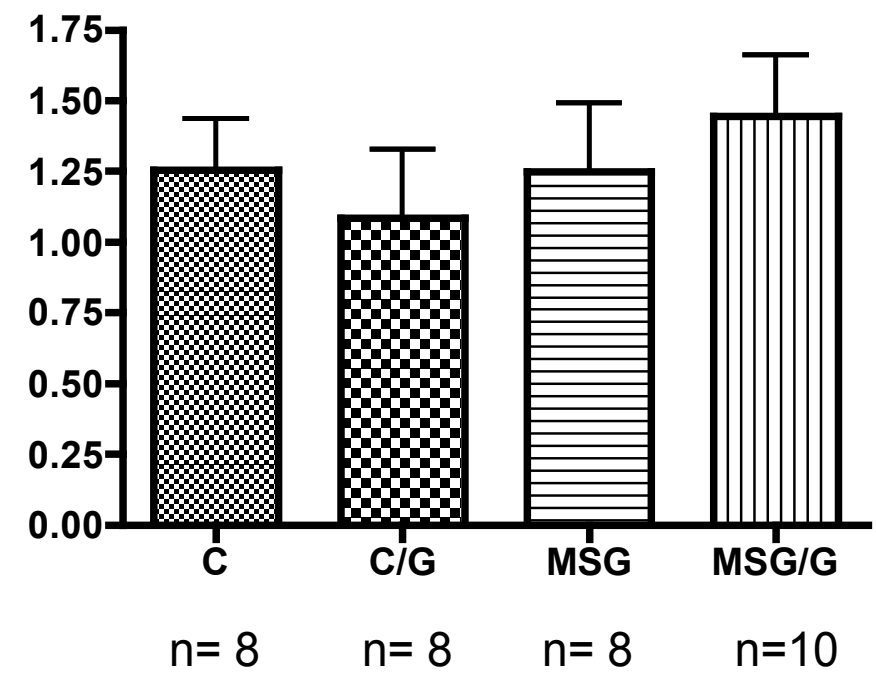

Conteúdos dos mRNAs de MEF2D, normalizados por GAPDH2. Os resultados são média \pm EPM. Anova de 1 via para dados independentes/SNK: 
Não foram observadas (Figura 13) diferenças significativas na expressão do mRNA do HIF1- $\alpha$ entre os diferentes grupos analisados.

Figura 13 - Análise do mRNA de HIF1Aem músculo sóleo de ratos controles e obesos, tratados (CG e MSG/G) e não tratados (C e MSG) com glimepirida por 4 semanas.

\section{HIF1- $\alpha$}

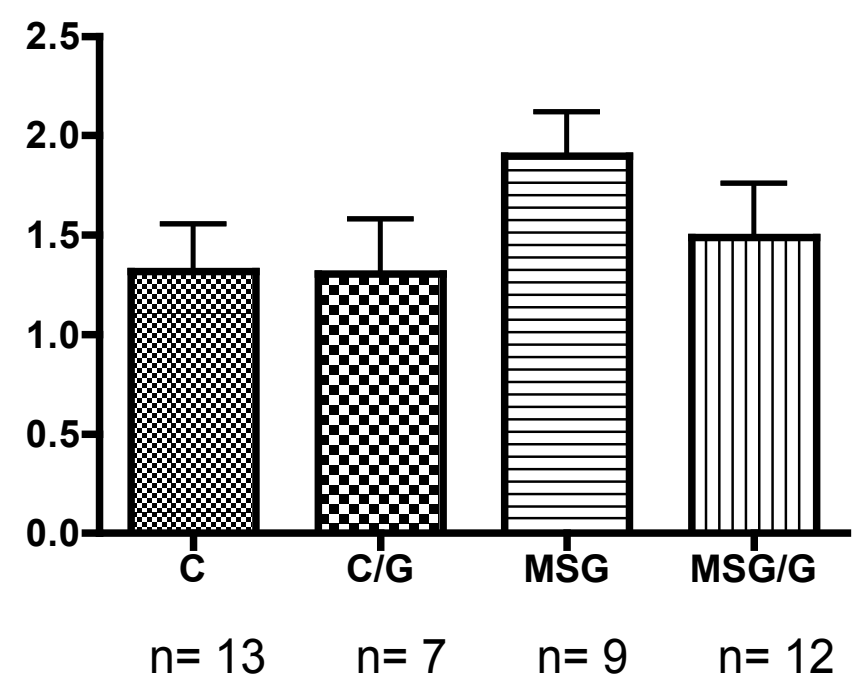

Conteúdos dos mRNAs de HIF1- $\alpha$, normalizados por GAPDH2. Os resultados são média \pm EPM. Anova de 1 via para dados independentes/SNK: 
4.6.6 Expressão mRNA de Slc2a4 e da proteína GLUT4 em Sóleo

Os resultados obtidos neste tecido estão representados nas figuras 14 e 15 .

Após tratamento com glimepirida, a expressão de $S l c 2 a 4$ elevou-se em relação ao grupo controle $(\mathrm{p}<0,05)$. Resultado semelhante foi observado na proteína GLUT4, com a diferença de que o aumento observado em animais MSG/G foi estatisticamente significativo em relação a todos os demais grupos. 
Figura 14 - Análise do mRNA de $S l c 2 a 4$ (A) e da proteína GLUT4 (B) em músculo sóleo de ratos controles e obesos, tratados ( $\mathrm{CG}$ e $\mathrm{MSG} / \mathrm{G})$ e não tratados $(\mathrm{C}$ e $\mathrm{MSG}) \mathrm{com}$ glimepirida por 4 semanas.
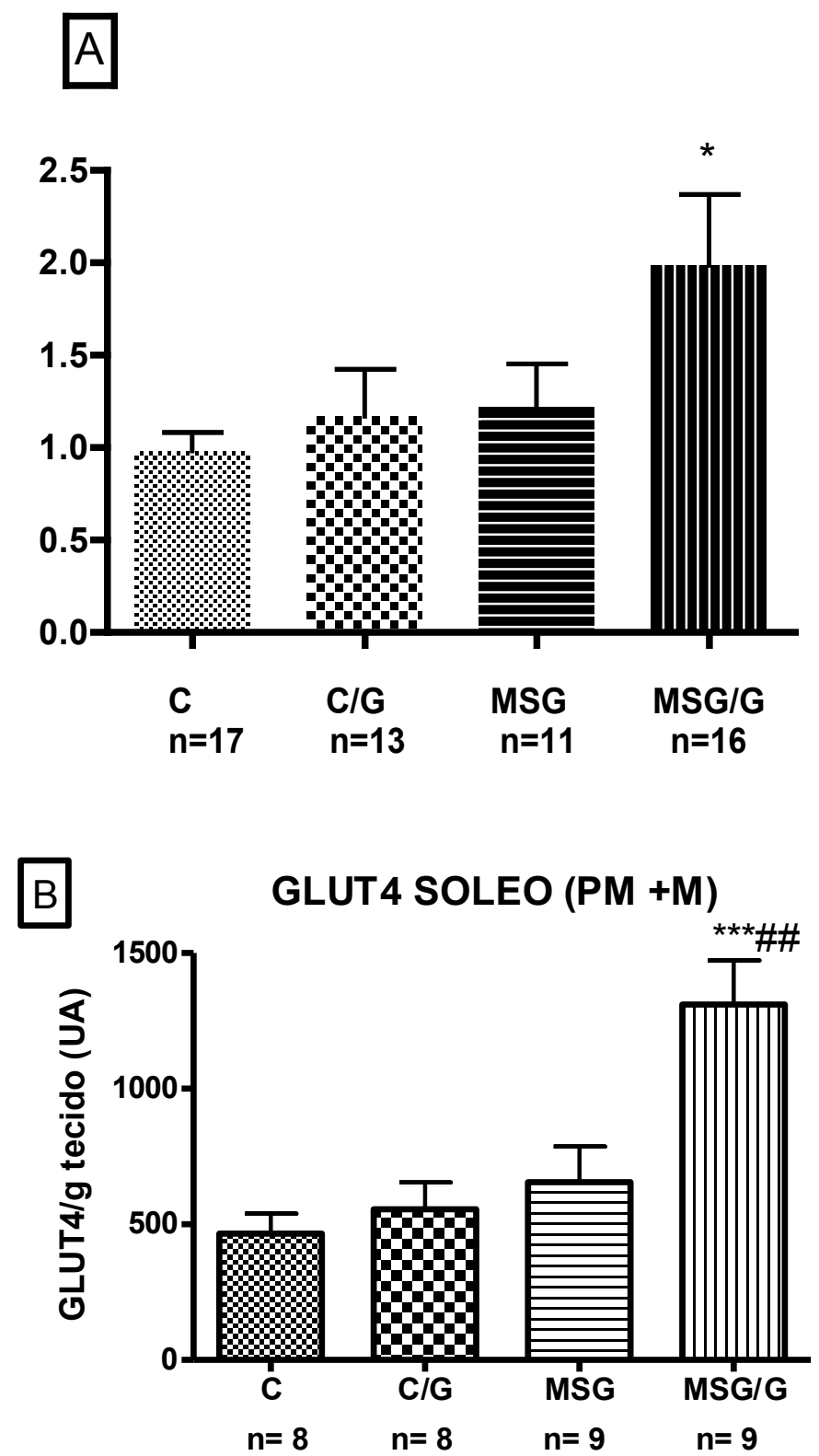

Em A: conteúdos dos mRNAs do Slc2a4, normalizados por GAPD. Os resultados são média \pm EPM. Em B: conteúdo da proteína (UA/g tecido) em membranas totais $(\mathrm{PM}+\mathrm{M})$. Os resultados são média \pm EPM. Anova de 1 via para dados independentes/SNK:

${ }^{*} \mathrm{p}<0,05$ vs. $\mathrm{C} ; * * * \mathrm{p}<0,001$ vs. $\mathrm{C} ; \# \# \mathrm{p}<0,01$ vs. MSG 
Figura 15 - Análise da proteína GLUT4 em membranas de frações subcelulares do músculo sóleo de ratos controles e obesos, tratados ( $\mathrm{CG}$ e $\mathrm{MSG} / \mathrm{G})$ e não tratados ( $\mathrm{C}$ e MSG) com glimepirida por 4 semanas.
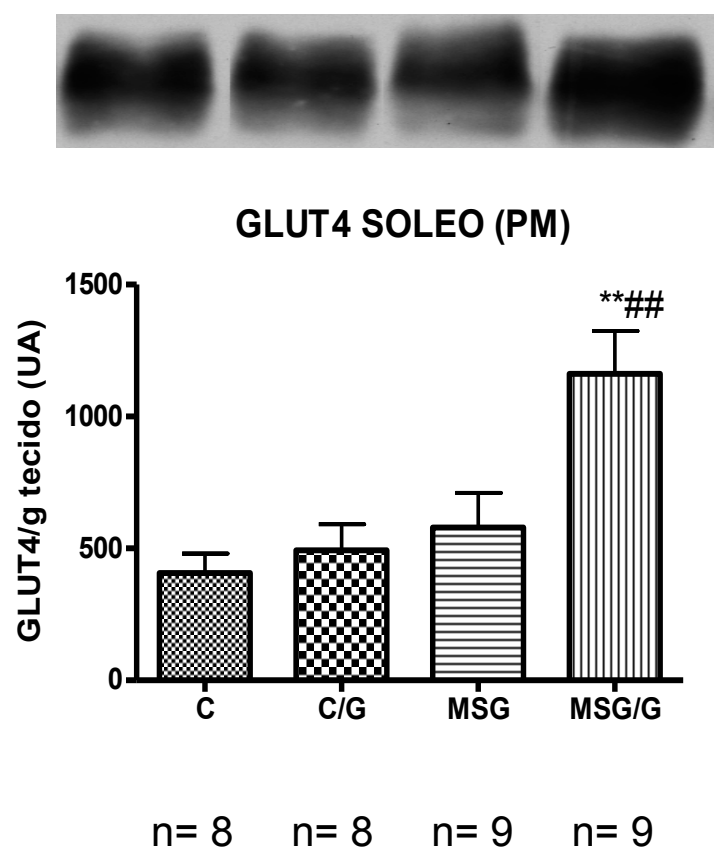

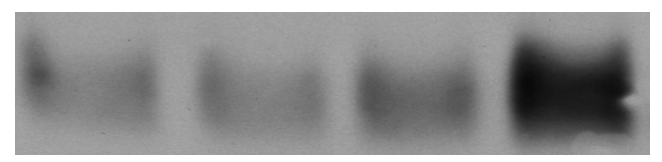

GLUT4 SOLEO (M)

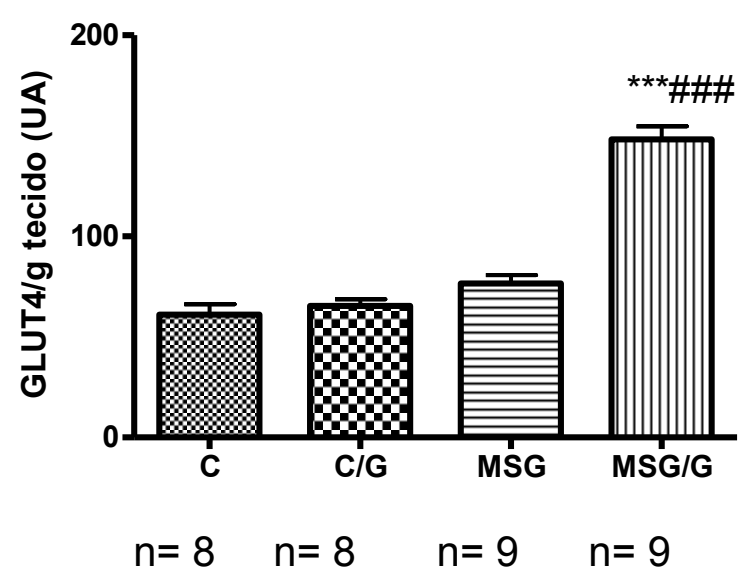

À esquerda: Conteúdo de GLUT4 em membranas plasmáticas (PM), contido numa mesma quantidade de proteínas totais (40ug) submetidas à eletroforese. À direita: Conteúdo de GLUT4 em microssomas (M), contido numa mesma quantidade de proteínas totais (40ug) submetidas à eletroforese. Abaixo: Autorradiografias típicas das frações PM e M. Os resultados são média \pm EPM, expressos em UA por grama de tecido.

**p $<0,01$ vs. $C$; \#\#p<0,01 vs. MSG; ***p<0,001 vs. C; \#\#\#p<0,001 vs. MSG

Na tabela 6 são mostrados os resultados da análise de correlação entre as médias de expressão de mRNA de Slc2a4, SUR2a, KIR6.2 e de proteína GLUT4, SUR2a e KIR6.2 em músculo sóleo. Em relação à expressão dos mRNAs observou-se correlação positiva do Slc2a4, com SUR2a e KIR6.2, assim como do SUR2a com o KIR6.2. Também houve correlação positiva entre a proteína GLUT4 e a proteína KIR6.2. Para concluir, também houve correlação positiva entre as variações dos mRNAs com as proteínas, destacando-se que a correlação entre o mRNA do Slc2a4 e a proteína KIR6.2 apresentou uma significância marginal $(\mathrm{P}=0.0662)$. 
Tabela 6 - Análise da correlação entre as médias de expressão de mRNA de Slc2a4, SUR2A, KIR6.2 e de proteína GLUT4, SUR2A e KIR6.2. em músculo sóleo de ratos controles e obesos, tratados (CG e $\mathrm{MSG} / \mathrm{G})$ e não tratados (C e $\mathrm{MSG}$ ) com glimepirida.

\begin{tabular}{ccc}
\hline \multicolumn{1}{c}{$r$} & $\boldsymbol{P}$ \\
\hline $\boldsymbol{m} \boldsymbol{R} \boldsymbol{A} \boldsymbol{}$ & & \\
Slc2a4 vs. SUR2a & 0,9928 & 0,0472 \\
Slc2a4 vs. KIR6.2 & 0,9896 & 0,0104 \\
KIR6.2 vs. SUR2a & 0,9842 & 0,0158 \\
Proteína & & \\
GLUT4 vs. KIR6.2 & 0,9527 & 0,0473 \\
mRNA vs. Proteína & & 0,0662 \\
Slc2a4 vs. SUR2A & 0,9338 & 0,0036 \\
Slc2a4 vs. KIR6.2 & 0,9964 & 0,0333 \\
KIR6.2 vs. GLUT4 & 0,9667 & 0,0028 \\
SUR2a vs. GLUT4 & 0,9972 & \\
\hline
\end{tabular}

$r=$ coeficiente de correlação de Pearson

4.7 Análise do conteúdo de mRNA dos genes SUR2A, KIR6.2, MEF2A, MEF2D, HIF1a, NF-KB e Slc2a4 em cultura de células musculares L6.

As tabelas contendo média e desvio padrão são apresentadas no item apêndice. 


\subsubsection{Expressão mRNA de SUR2A}

Foi observada elevação da expressão de SUR2a no grupo glimepirida, em relação ao grupo controle e controle + insulina $(p<0,01 ; p<0,001$, respectivamente). $O$ grupo glimepirida também diferiu do grupo glimepirida + insulina $(p>0,01)$.

Figura 16 - Análise do mRNA de cultura de células musculares L6. Grupos: controle, controle + insulina, glimepirida e glimepirida + insulina. Conteúdos dos mRNAs de SUR2A, normalizados por GAPDH2.

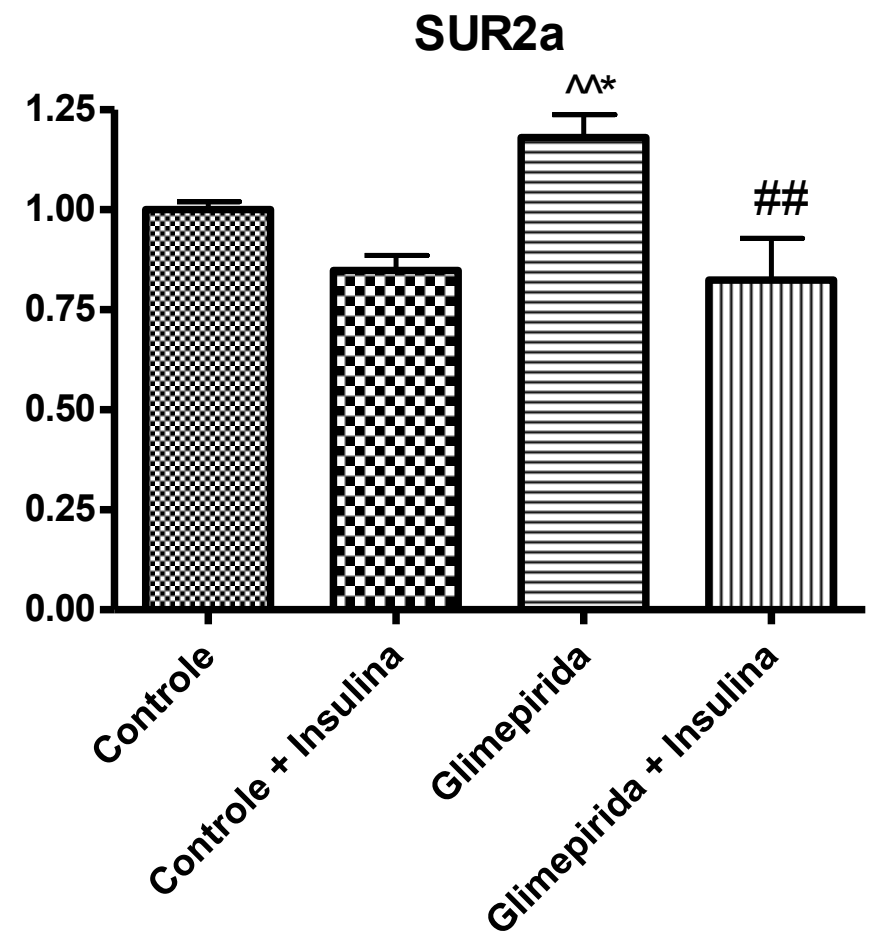

Os resultados são média \pm EPM. Anova de 1 via para dados independentes/SNK: * $\mathrm{p}<0,001$ vs. Controle; ${ }^{\wedge}$ p $<0,01$ vs. Controle + Insulina; \#\# p <0,01 vs. Glimepirida 


\subsubsection{Expressã̃o mRNA de KIR6.2}

O grupo controle + insulina reduziu a expressão de mRNA de KIR6.2 em relação ao controle $(p<0,05)$. O tratamento com glimepirida resultou em aumento da expressão de KIR6.2, em relação ao grupo controle $(p<0,001)$ e controle + insulina $(p<0,001)$. A associação de glimepirida + insulina resultou em diminuição de KIR6.2 em relação ao grupo glimepirida $(\mathrm{p}<0,01)$.

Figura 17 - Análise do mRNA de cultura de células musculares L6. Grupos: controle, controle + insulina, glimepirida e glimepirida + insulina.

\section{KIR6.2}

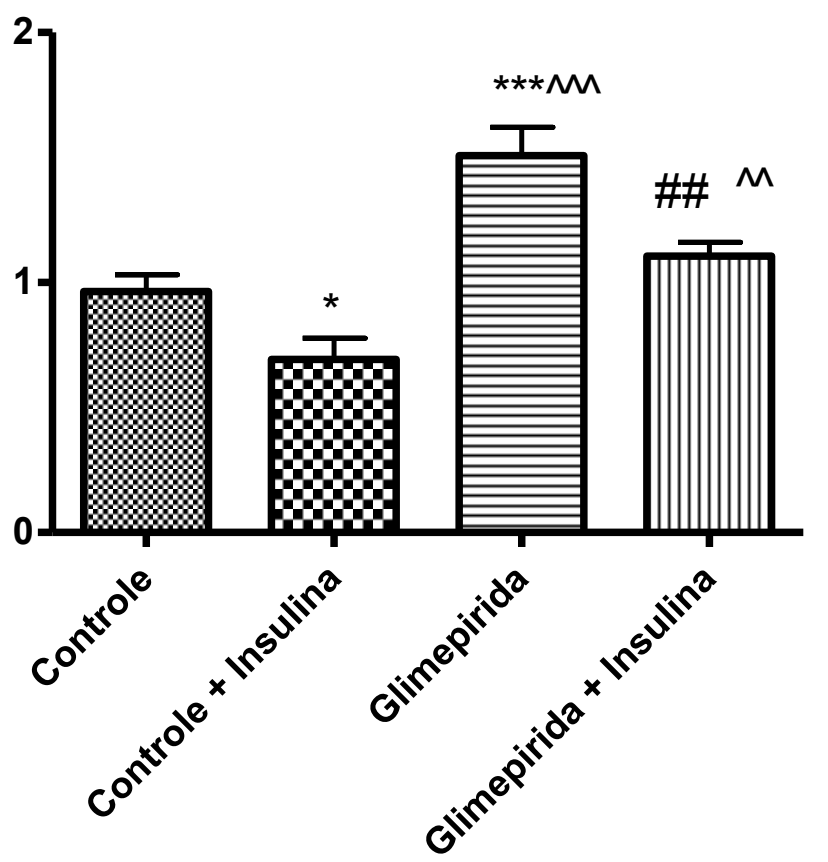

Conteúdos dos mRNAs de KIR6.2, normalizados por GAPDH2. Os resultados são média \pm EPM. Anova de 1 via para dados independentes/SNK: ${ }^{*} \mathrm{p}<0,01$ vs. Controle; ${ }^{\wedge \wedge} \mathrm{p}<0,01$ vs. Controle + Insulina; \#\# $\mathrm{p}<0,01$ vs. Glimepirida; ${ }^{\wedge} \mathrm{p}<0,01$ vs. Controle + Insulina. 


\subsubsection{Expressão mRNA de Slc2a4}

No grupo glimepirida foi observado redução da expressão de $S l c 2 a 4$ em relação ao grupo controle e controle + insulina $(\mathrm{p}<0,001)$. A adição de insulina conjuntamente com glimepirida elevou a expressão em relação ao grupo glimepirida $(p<0,01)$.

Figura 18 - Análise do mRNA de cultura de células musculares L6. Grupos: controle, controle + insulina, glimepirida e glimepirida + insulina.

\section{SIc2a4}

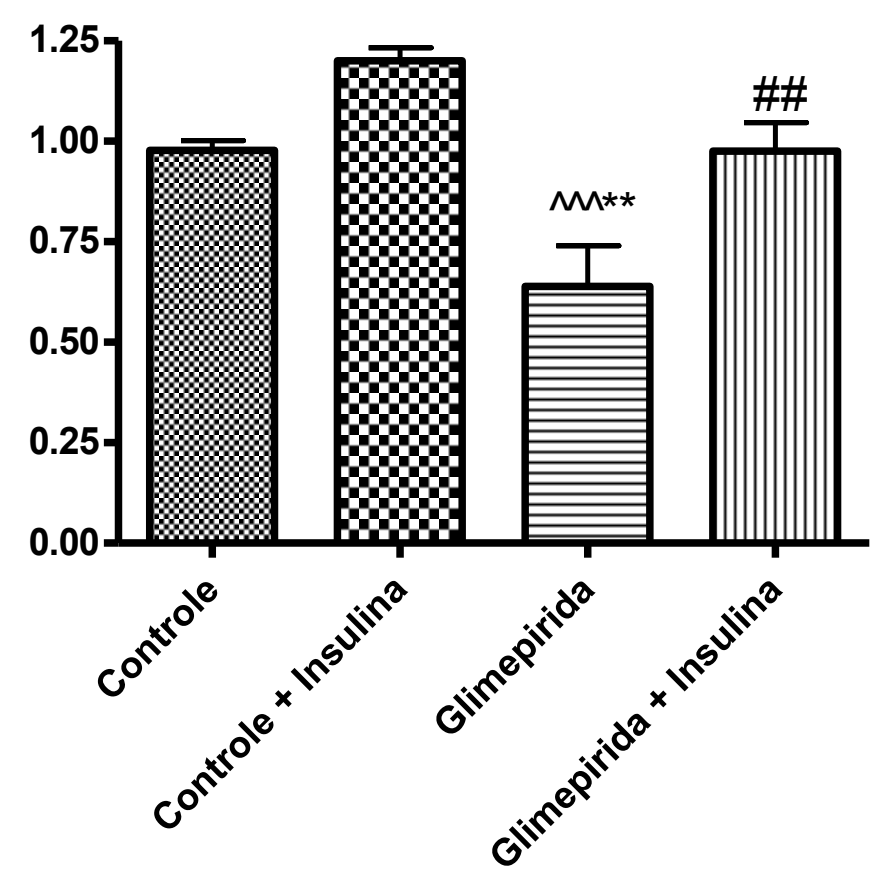

Conteúdos dos mRNAs de Slc2a4, normalizados por GAPDH2. Os resultados são média \pm EPM. Anova de 1 via para dados independentes/SNK: ${ }^{* *} \mathrm{p}<0,001$ vs. Controle; ${ }^{\wedge \wedge} \mathrm{p}<0,001$ vs. Controle + Insulina; \#\# p<0,01 vs. Glimepirida 
4.7.4 Expressão $m R N A$ de $M E F 2 A$

Não foram observadas (Figura 19) diferenças significativas na expressão do mRNA do MEF2A entre os diferentes grupos analisados.

Figura 19 - Análise do mRNA de cultura de células musculares L6. Grupos: controle, controle + insulina, glimepirida e glimepirida + insulina.

\section{MEF2A}

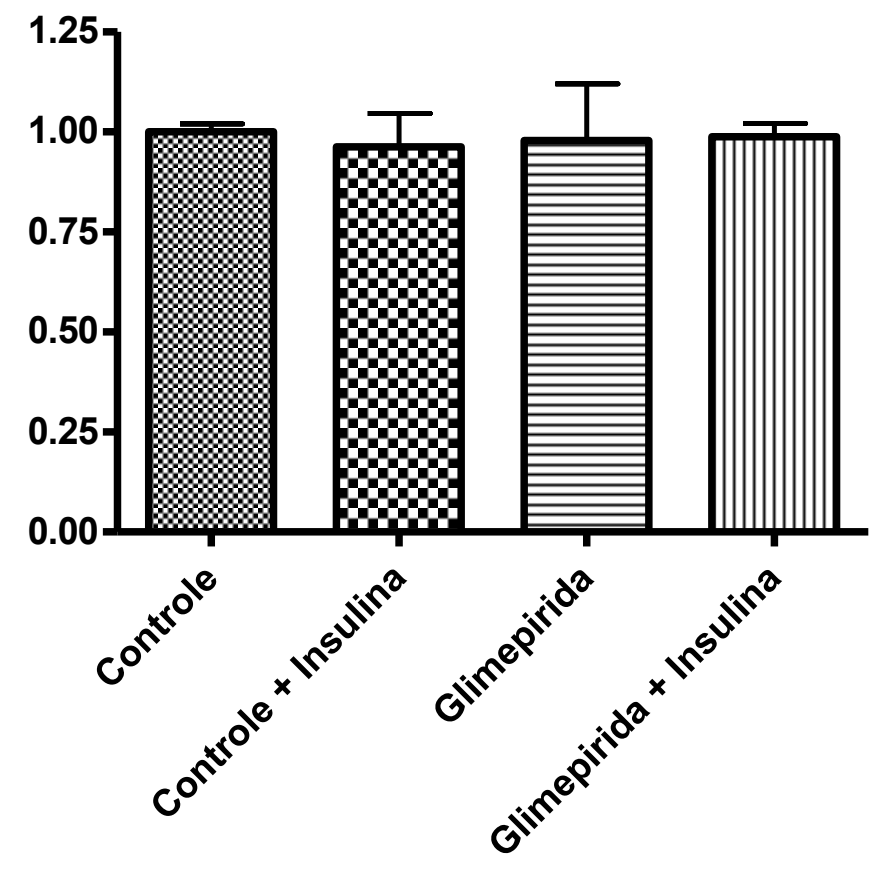

Conteúdos dos mRNAs de MEF2A, normalizados por GAPDH2. Os resultados são média \pm EPM. Anova de 1 via para dados independentes/SNK: 


\subsubsection{Expressão mRNA de MEF2D}

Não foram observadas (Figura 20) diferenças significativas na expressão do mRNA do MEF2D entre os diferentes grupos analisados.

Figura 20 - Análise do mRNA de cultura de células musculares L6. Grupos: controle, controle + insulina, glimepirida e glimepirida + insulina.

\section{MEF2D}

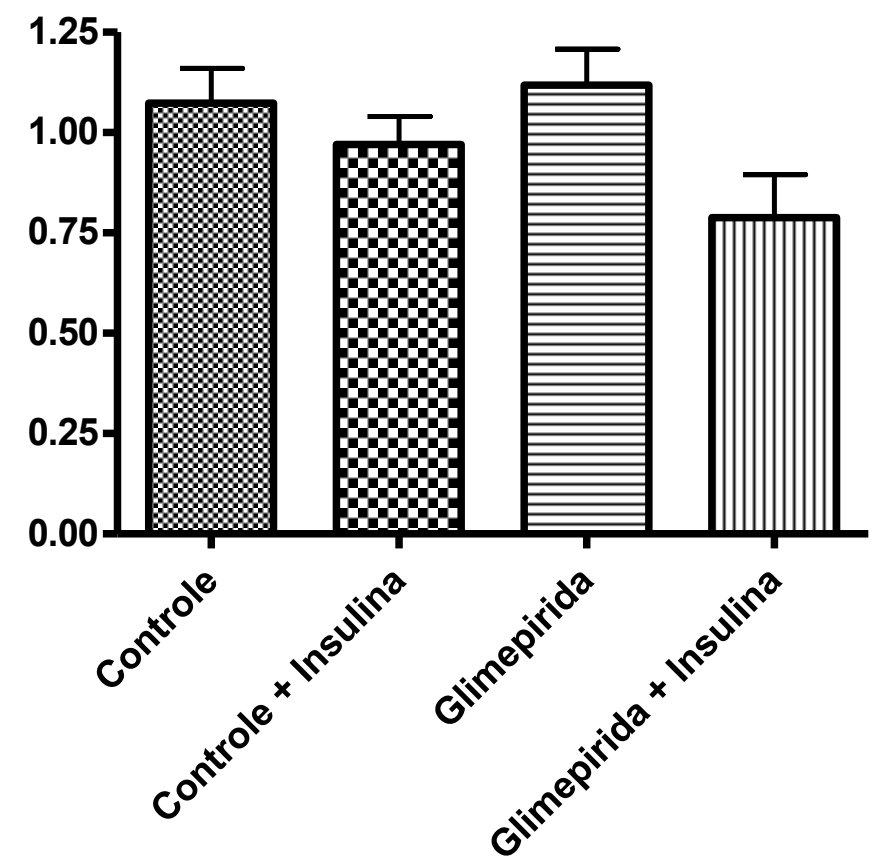

Conteúdos dos mRNAs de MEF2D, normalizados por GAPDH2. Os resultados são média \pm EPM. Anova de 1 via para dados independentes/SNK: 


\subsubsection{Expressão mRNA de HIF1a}

Não foram observadas (Figura 21) diferenças significativas na expressão do mRNA do HIF-1a entre os diferentes grupos analisados.

Figura 21 - Análise do mRNA de cultura de células musculares L6. Grupos: controle, controle + insulina, glimepirida e glimepirida + insulina.

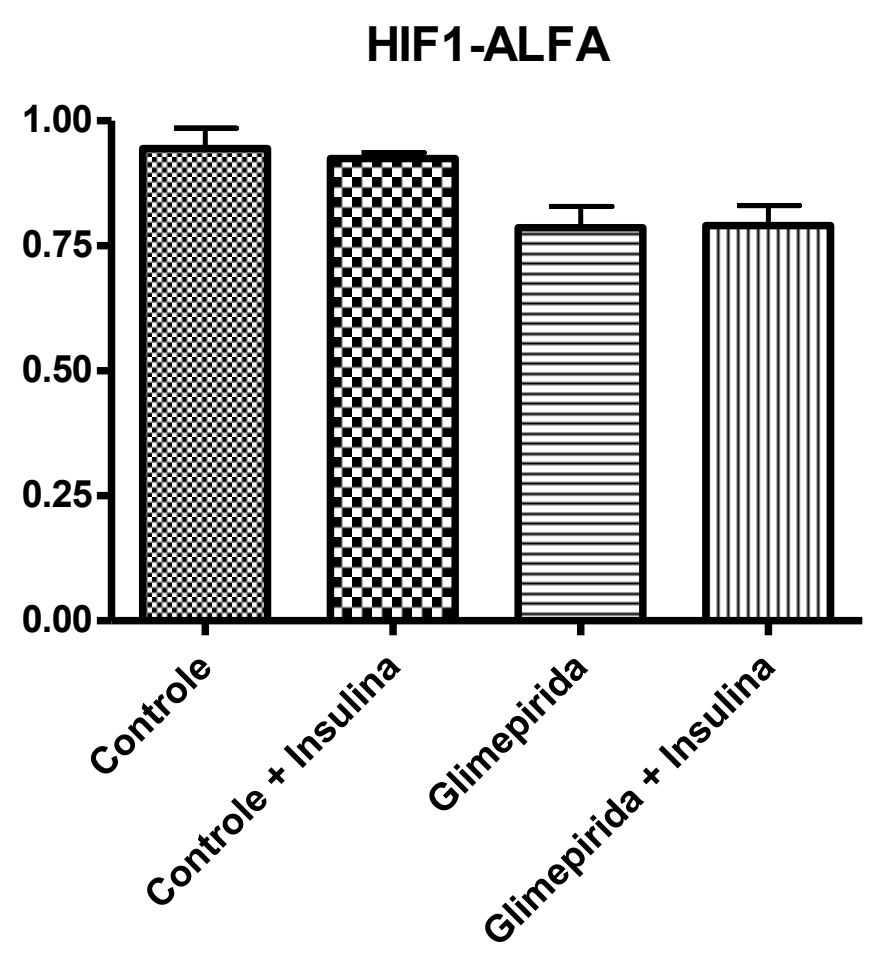

Conteúdos dos mRNAs de HIF1- $\alpha$, normalizados por GAPDH2. Os resultados são média \pm EPM. Anova de 1 via para dados independentes/SNK: 


\subsubsection{Expressão $m R N A$ de NF-KB}

Foi observado que insulina provocou redução discreta da expressão de NF-KB no grupo controle + insulina em relação ao controle $(p<0,05)$. A glimepirida elevou a expressão de NF-KB em relação aos grupos controle e controle + insulina $(p<0,01)$. A insulina junto com a glimepirida foi suficiente para reduzir o aumento da expressão de NFKB induzido pela glimepirida $(\mathrm{p}<0,01)$.

Figura 22 - Análise do mRNA de cultura de células musculares L6. Grupos: controle, controle + insulina, glimepirida e glimepirida + insulina.

\section{NFKB}

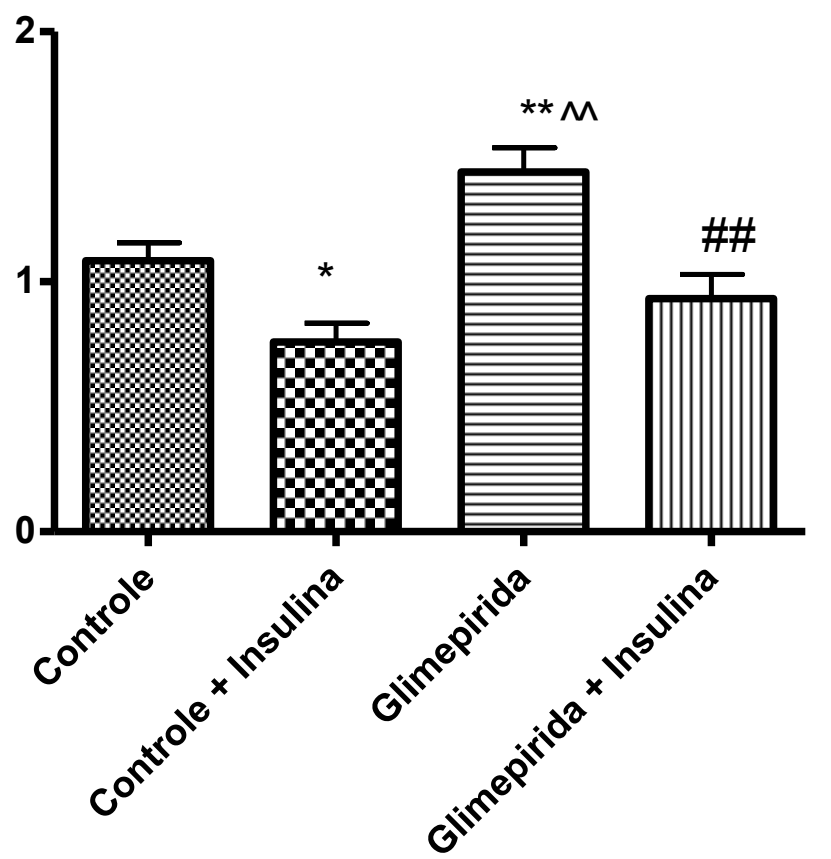

Conteúdos dos mRNAs de NF-KB, normalizados por GAPDH2. Os resultados são média \pm EPM. Anova de 1 via para dados independentes/SNK: ${ }^{* *} \mathrm{p}<0,001$ vs. $\mathrm{C} ;{ }^{\wedge} \wedge \mathrm{p}<0,01$ vs. Controle +Insulina; \#\# $\mathrm{p}<0,01$ vs. Glimepirida 


\section{DISCUSSÃO}

No presente estudo investigaram-se alterações da expressão de Slc2a4/GLUT4 e dos genes Sur2a e Kir6.2, que codificam as proteínas que compõem o KATP, em um modelo de animal obeso, pois espera-se que o maior conhecimento da fisiopatologia da obesidade possa trazer benefícios tanto para o tratamento como para a prevenção desta alteração.

A administração neonatal de glutamato monossódico (MSG) produz necrose neuronal seletiva na eminência média e nos núcleos pré-óptico e arqueado do hipotálamo. A área postrema, órgão subfornical e neurônios do hipocampo rostral também são danificados após injeção neonatal de MSG. Ocorre desenvolvimento de várias alterações neuro-endócrinas que incluem obesidade, déficite de crescimento, hipogonadismo, esterilidade e hipercorticoesteronemia (MACHO et al., 1999; NAKAJIMA et al., 1995), de maneira tempo e dose dependentes. O comprometimento de vários sistemas neuro/endócrinos neste quadro de obesidade está de acordo com o observado em humanos obesos, nos quais alterações no GH e nos eixos hipotálamo-hipófise-gônada e hipotálamo-hipófise-adrenal já foram descritas (MORTON et al., 2004).

Alguns fatores têm sido apontados como responsáveis pela obesidade em animais tratados com MSG, tais como:

1. deficiência do hormônio do crescimento $(\mathrm{GH})$. Esta poderia ser uma causa para o crescimento anormal, além do acúmulo de gordura, já que este hormônio possui atividade lipolítica e a redução do mesmo favorece elevada lipogênese (MAITER et al., 1991; NAKAI et al., 1996; NEMOROFF et al., 1977).

2. reduzida atividade termogênica do tecido adiposo marrom (TAM) (HIMMSHAGEN, 1989);

3. hipercorticosteronemia (LORDEN; CAUDLE, 1986; NAKAJIMA et al., 1985).

Adicionalmente, os animais MSG são hiperinsulinêmicos e resistentes à insulina, e a elevação da glicemia pode alcançar níveis suficientes para diagnóstico de diabetes tipo 2 (MACHADO; SHIMIZU; SAITO, 1993; PAPA; SERAPHIM; MACHADO, 1997).

A obesidade nem sempre está associada com elevado peso corporal e por isso, índices de massa adiposa devem ser utilizados como critérios de identificação da obesidade. Rogers e Webb (1980) fizeram a correlação de vários parâmetros (índice de Lee, densidade, conteúdo de água corpórea e peso relativo do tecido adiposo gonadal) com a porcentagem da massa gordurosa corpórea e verificaram que em uma população de camundongos normais e obesos 
(macho e fêmeas) todos os quatro parâmetros citados acima se correlacionam significativamente com a massa gordurosa.

Resultados obtidos no presente estudo demostraram que ratos tratados com MSG no período neonatal apresentaram-se claramente obesos, conforme esperado. Os animais apresentaram peso corpóreo absoluto e peso dos músculos significativamente menores do que os animais controle. Porém, o menor peso dos tecidos musculares foi reflexo do prejuízo no crescimento, provavelmente relacionado à menor secreção de GH (KOVACS et al., 2000; MARMO et al., 1994). Quando se avaliou o índice de Lee, que correlaciona a massa corporal com o volume corporal, observou-se que os animais MSG tornaram-se obesos. Quanto maior este valor, maior foi a incorporação em massa em relação ao ganho em comprimento do animal.

Neste estudo, animais obesos apresentaram menor consumo absoluto de ração e água, mas o consumo relativo não se alterou, de modo que podemos considerá-los hipo ou normofágicos. Morris e colaboradores (1998) demostraram que estes ratos MSG acumulam gordura, apesar da ingestão calórica ser normal ou reduzida, pelo fato de que apresentam menor gasto energético. Considerando-se que a obesidade decorre do desequilíbrio energético em que o aporte energético é maior que o gasto energético, compreende-se o desenvolvimento de obesidade na vigência de normofagia.

Alterações da homeostase glicídica decorrentes do tratamento neonatal com glutamato monossódico já foram amplamente relatadas (CAMERON et al., 1978; OLNEY et al., 1969; TOKUYAMA; HIMMS-HAGEN, 1996).

No presente estudo, a insulinemia e glicemia dos animais MSG não apresentaram diferenças quando comparadas a dos ratos controles, diferentemente do que já foi descrito na literatura em ratos Sprague-Dawley (MACHO et al., 2000) e em camundongos (FURUYA et al., 2009). As células $\beta$-pancreáticas são capazes de aumentar a secreção de insulina na tentativa de contrabalancear a resistência à insulina, resultando em um estado de hiperinsulinemia, comumente encontrado na obesidade (JEANRENAUD, 1978; PAPA et al., 1997). Entretanto, a presença da resistência insulínica em nossos ratos MSG somente foi confirmada pelo teste de tolerância à insulina (ITT), o que já havia sido relatado em estudo anterior de nosso laboratório (MORI et al., 2008). A presença de normoinsulinemia na vigência de resistência à insulina pode indicar um estado inicial de desenvolvimento da resistência, no qual o distúrbio glicêmico ainda não é suficiente para acionar hiperinsulinemia detectável. Considerando que os animais MSG, quando desafiados com o secretagogo de 
insulina, foram capazes de aumentar significativamente a insulinemia, podemos concluir que, no presente estudo, os animais obesos estavam em estágio precoce de desenvolvimento da resistência à insulina, ainda com boa reserva pancreática.

Em resumo, as características dos animais MSG estão de acordo com o esperado para um estado de obesidade acompanhada por resistência insulínica ainda em desenvolvimento. Como já foi comentado acima, quadros graves de obesidade induzida por MSG em camundongos já foram demonstrados, nos quais ocorre hiperglicemia suficiente para diagnóstico de DM2SG (MACHADO, 1993).

No presente estudo, utilizamos a glimepirida, uma droga do grupo das sulfoniluréias, que são secretagogos de insulina e, por isso, indicados apenas para pacientes que tenham reserva pancreática do hormônio. A glimepirida, embora tenha alta afinidade pelas células beta, apresenta efeito antihiperglicemiante superior ao de outras sulfoniluréias, o que sugeriu um efeito de aumentar a sensibilidade à insulina (KRAMER et al., 1996; MORI et al., 2008; MULLER; GEISEN, 1996).

Conforme descrito na metodologia, a glimepirida foi administrada aos animais na água de beber, e não deve ter alterado a palatabilidade da água, pois não afetou a ingestão hídrica. Também não se alteraram as características morfométricas dos animais tratados, indicando que os efeitos da droga não decorreram de emagrecimento, por exemplo. A dose diária de 0,1 $\mathrm{mL} / \mathrm{kg}$ de peso foi determinada com base em dados da literatura (EL-REYANI et al., 1999, MORI et al., 2008) e como observado no teste de tolerância à insulina, esta dose foi eficiente na reversão da resistência insulínica. Em relação à glicemia, não foram encontradas diferenças significativas apos o tratamento com glimepirida, porém a insulina elevou-se significativamente. A explicação para este estado homeostásico em que na vigência de maior insulinemia a glicemia permanece inalterada, a despeito de maior sensibilidade ao hormônio, ainda é difícil de ser encontrada, e mereceria estudos adicionais.

Estudo anterior de nosso laboratório já havia demonstrado que a glimepirida aumentava a sensibilidade insulínica de animais obesos por MSG, efeito este que envolveu maior capacidade do músculo oxidativo captar glicose. Assim, no presente estudo passou-se a investigar mecanismos moleculares acionados no músculo esquelético, que poderiam explicar o efeito sensibilizador da glimepirida.

Foram selecionados dois diferentes tipos de tecidos musculares esqueléticos: o músculo sóleo, composto predominantemente por fibras vermelhas, oxidativas, e o extensor digital longo (EDL), músculo predominantemente branco, glicolítico, com a finalidade de 
estudar a regulação da expressão de GLUT4, proteína chave para a captação de glicose estimulada por insulina. A regulação da expressão de Slc2a4 é variável de acordo com as diferenças na composição das fibras, sendo as fibras oxidativas (vermelhas) mais sensíveis à ação da insulina, com maior conteúdo de GLUT4 e taxa de transporte máximo de glicose mais alta (RICHARDSON et al., 1991). Nossos resultados reforçam a importância do sóleo na homeostasia, pois importantes efeitos foram observados neste músculo, enquanto mínimas alterações foram observadas no EDL.

O conteúdo de GLUT4 em músculo esquelético na obesidade tem sido amplamente estudado, no entanto os resultados descritos são variados. Acredita-se que as diferenças sejam decorrentes do modelo experimental, do estado metabólico e ou do tipo de fibra muscular utilizados. Os primeiros estudos de GLUT4 em animais obesos por MSG foram realizados em camundongos com alto nível de resistência à insulina, já com alterações glicêmicas compatíveis com diabetes tipo 2 (MACHADO et al., 1993; MACHADO et al., 1994; PAPA et al., 1997); nestes animais, redução importante no conteúdo de proteína GLUT4 foi detectada em músculo misto gastrocnemius. Interessantemente, de Carvalho Papa (2002) demonstrou que a alteração (redução) do GLUT4 no gastrocnemius de camundongos MSG é um efeito tardio durante a evolução da obesidade dos ratos. Analisando animais de 2, 4 e 7 meses de idade, foi demonstrado que o GLUT4, no músculo, mostrou-se inalterado aos 2 e 4 meses, sendo que aos 4 meses de idade já havia resistência à insulina. Somente aos 7 meses de idade é que a resistência se agravo, e o GLUT4 mostrou-se reduzido no músculo (DE CARVALHO PAPA et al., 2002). Semelhantemente ao demonstrado nos camundongos MSG de 4 meses, Mori e colaboradores (2008) não observaram alteração da proteína GLUT4 em músculo sóleo de ratos obesos por MSG, já com resistência à insulina.

No presente estudo, a obesidade por MSG não induziu alterações no mRNA do Slc2a4 no sóleo, somente após tratamento por glimepirida, mas diminuiu no EDL, o que não se refletiu em alterações importantes no conteúdo total da proteína. Estes resultados estão de acordo com o descrito por Mori e colaboradores (2008), e sugerem um estágio ainda inicial no desenvolvimento da obesidade, o qual deverá culminar com redução no GLUT4

Apesar do GLUT4 inalterado neste estágio, isto não exclui a participação do músculo esquelético na determinação da resistência à insulina do animal obeso. De fato, Mori e colaboradores (2008) já demonstraram que a captação de glicose pelo sóleo de animais MSG está reduzida, mesmo com GLUT4 ainda inalterado. Isto pode decorrer de aumento de gordura intramiocelular, o qual está associado com resistência à insulina seja por induzir 
defeito na sinalização desse hormônio, e consequente translocação do GLUT4, seja por alterar o gradiente de difusão da glicose (VIRKAMAKI et al., 2001).

Conforme já apresentado, estudo anterior demonstrou que a glimepirida era capaz de aumentar a sensibilidade à insulina em ratos MSG, por aumentar a captação de glicose em músculo sóleo, o que envolveria aumento na expressão do GLUT4 (MORI et al., 2008). No presente estudo, o tratamento dos animais obesos com glimepirida também induziu no músculo sóleo um aumento do Slc2a4, o qual se refletiu em aumento importante da proteína, o que deve contribuído para melhorar a captação de glicose neste tecido, e consequentemente contribuir para recuperar a homeostasia glicêmica. Considerando que a glimepirida ativa o receptor SUR2A, associado a KIR6.2, procurou-se correlacionar esses potenciais efetores da ação da droga com expressão do GLUT4, principalmente em sóleo.

Foi observado, que ratos obesos tratados com glimepirida por 4 semanas, aumentaram a expressão de mRNA de SUR2a e KIR6.2 em sóleo, assim como aumentaram as proteínas SUR2A e KIR6.2. Estas observações indicam que a glimepirida deve alterar o KATP dos animais obesos, pelo menos no sóleo, podendo induzir alterações metabólicas que se relacionem com a melhora da homeostasia glicêmica.

Embora ambos os grupos tratados com glimepirida (CG e MSG/G) tenham apresentado insulinemias elevadas, não podemos atribuir à insulina o aumento do GLUT4, pois este efeito não foi observado no grupo controle tratado com a droga (grupo CG). Por outro lado, hiperinsulinemia crônica tem sido correlacionada com repressão da expressão do Slc2a4 (MACHADO et al., 1993; PAPA et al., 1997). Portanto, isto reforça um efeito próprio da glimepirida em aumentar a expressão do GLUT4, independente do concomitante efeito repressor da hiperinsulinemia.

MEF2A e MEF2D são fatores transcricionais que têm sido frequentemente relacionados a aumento da expressão do gene Slc2a4 induzido por contração muscular (SILVA et al., 2005). Além disso, Thai e colaboradores (1998) demostraram que em músculo de camundongo diabético há redução da expressão e da atividade de MEF2A e MEF2D, o que pode estar relacionado à redução da expressão do Slc2a4 observada nesta condição. Entretanto, nossos resultados não detectaram alterações de expressão de mRNA dos fatores transcricionais MEF2A e MEF2D, o que sugere que estes não estejam participando do aumento de expressão observado. Entretanto, o mRNA inalterado dos MEF2A e D não exclui a possibilidade de que estes fatores estejam se ligando mais ativamente ao promotor do gene Slc2a4. 
Sabe-se que em condição de normóxia, o HIF-1 $\alpha$ é rapidamente degradado pela via proteossomal da ubiquitina, sendo praticamente inexistente na célula (HUANG et al., 1998). Entretanto, mínimas condições de hipóxia tecidual, como as induzidas pela contração muscular (SILVA et al., 2005) e pelas alterações de perfusão dos tecidos induzidas pelo diabetes (LEE et al., 2003) são capazes de inibir a degradação do HIF-1 $\alpha$, o qual transloca ao núcleo onde ativa transcricionalmente genes alvos. Interessantemente, o gene do HIF-1 $\alpha$ é considerado um gene que se autorregula, de tal forma que o padrão de expressão do mRNA do HIF-1 $\alpha$ serve como parâmetro da sua atividade transcricional. Uma vez que em nosso estudo o tratamento com glimepirida não tenha alterado o mRNA do HIF-1 $\alpha$, podemos inferir com que este fator transcricional não está participando da regulação do Slc2a4 observada. Até o momento, não existe na literatura estudos de MEF2A, MEF2D e HIF-1 $\alpha$ em ratos obesos, tratados ou não com sulfoniluréias.

Em adição aos efeitos sobre a expressão do Slc2a4 e da proteína GLUT4, outros efeitos já atribuídos à glimepirida não podem ser excluídos, tais como aumento na metabolização oxidativa e estímulo na glicogeniogênese (MULLER; GEISEN, 1996). Entretanto, a observação de que as alterações de expressão do Slc2a4 e da proteína se correlacionaram positivamente com alterações de expressão dos componentes do KATP sugerem que pode haver uma relação causa-efeito entre estas variáveis, ou então que elas estejam sujeitas a fatores reguladores comuns.

Com o objetivo de esclarecer um pouco mais possíveis mecanismos envolvidos na regulação do Slc2a4 induzida pela glimepirida, estudamos células musculares L6 incubadas durante 24 horas com a droga. O perfil da regulação do Slc2a4 (redução) foi semelhante ao observado no músculo EDL, que é o tecido que deu origem a esta linhagem celular. Entretanto, o tratamento com glimepirida induziu aumento na expressão dos mRNAs SUR2A e KIR 6.2, indicando que nesta linhagem celular a regulação do KATP foi paralela à regulação do $S l c 2 a 4$. Interessantemente, neste modelo in vitro observamos que a glimepirida aumentou o mRNA de $\mathrm{NF \kappa B}$, o que em geral ocorre em paralelo à atividade transcricional deste fator. O NF-אB é um potente repressor da expressão do Slc2a4 (RUAN et al., 2002;

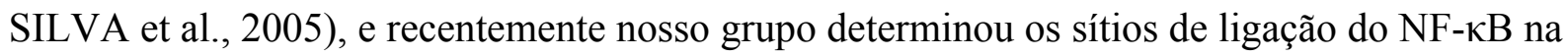

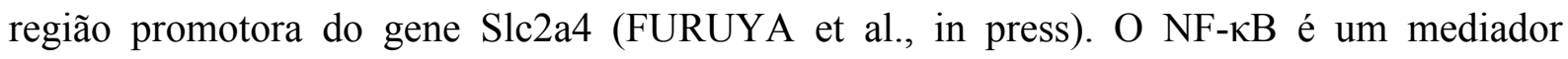
importante dos indutores de inflamação, e diminuição da atividade inflamatório é sabidamente um mecanismo que reduz a resistência à insulina (FURUYA et al., 2010). 
Na literatura, não há estudos de expressão do canal de KATP em músculo esquelético de ratos obesos, ou em células musculares tratadas ou não com sulfoniluréias, e nem uma possível relação com GLUT4. Os resultados do presente estudo permitem concluir que glimepirida aumenta expressão do gene $S l c 2 a 4$ em músculo sóleo de ratos resistentes à insulina, o que se correlaciona com aumento de mRNA de SUR2A/KIR6.2, sugerindo uma relação entre estas variáveis, ou a existência de fatores reguladores comuns. Um candidato importante a regulador comum destes genes é o NF- $\mathrm{kB}$, um importante mediador da resposta inflamatória, Estas regulações devem estar envolvidas no efeito sensibilizador da glimepirida sobre a sensibilidade à insulina in vivo. 


\section{CONCLUSÃO}

\section{No presente estudo, observou-se que:}

- o tratamento dos animais obesos com glimepirida induziu no músculo sóleo um aumento do Slc2a4, o qual se refletiu em aumento importante da proteína, o que deve contribuído para melhorar a captação de glicose neste tecido, e consequentemente contribuir para recuperar a homeostasia glicêmica.

- glimepirida aumentou a expressão de mRNA de SUR2a e KIR6.2 em sóleo, assim como aumentaram as proteínas SUR2A e KIR6.2. Estas observações indicam que a glimepirida deve alterar o KATP dos animais obesos, pelo menos no sóleo, podendo induzir alterações metabólicas que se relacionem com a melhora da homeostasia glicêmica.

- no modelo in vitro, glimepirida aumentou o mRNA de NF- $\mathrm{B}$, o que em geral ocorre em paralelo à atividade transcricional deste fator, sendo um mecanismo que reduz a resistência à insulina.

Com base nos resultados destacados acima, conclui-se que glimepirida aumenta expressão do gene Slc2a4 em músculo sóleo de ratos resistentes à insulina, o que se correlaciona com aumento de mRNA de SUR2A/KIR6.2, sugerindo uma relação entre estas variáveis, ou a existência de fatores reguladores comuns. Um candidato importante a regulador comum destes genes é o NF- $\kappa \mathrm{B}$, um importante mediador da resposta inflamatória, Estas regulações devem estar envolvidas no efeito sensibilizador da glimepirida sobre a sensibilidade à insulina in vivo. 


\section{REFERÊNCIAS*}

ASHCROFT, F. M. K (ATP) channels and insulin secretion: a key role in health and disease. Biochem. Soc. Trans., v. 34, pt. 2, p. 243-246, 2006.

ASHCROFT, F. M.; GRIBBLE, F.M. Sensitive K+ channels and insulin secretion: their role in health and disease. Diabetologia, v. 42, n. 8, p. 903-919, 1999.

ASHCROFT, F. M.; RORSMAN, P. Electrophysiology of the pancreatic beta-cell. Prog. Biophys. Mol. Biol., v. 54, p. 87-143, 1989.

BACKS, J.; OLSON, E. N. Control of cardiac growth by histone acetylation/deacetylation. Circ. Res., v. 98. p. 15-24, 2006.

BAHR, M.; VON HOLTEY, M.; MULLER G.; ECKEL, J. Direct stimulation of myocardial glucose transport and glucose transporter-1 (GLUT1) and GLUT4 protein. Circ. Res., v. 136, p. 2547-2553, 1995. Suppl. 6.

BAILEY, C. J.; GROSS, J. L.; PIETERS, A.; BASTIEN, A.; LIST, J. L. Effect of dapagliflozin in patients with type 2 diabetes who have inadequate glycaemic control with metformin: a randomised, double-blind, placebo-controlled trial. The Lancet, v. 375, p. 2223 2233, 2008.

BARROS, R. P.; MORANI, A.; MORISCOT, A.; MACHADO, U. F. Insulin resistance of pregnancy involves estrogen-induced repression of muscle GLUT4. Mol. Cell. Endocrinol., v. 295, p. 24-31, 2008.

BLACK, B. L.; OLSON, E. N. Transcriptional control of muscle development by myocyte enhancer factor-2 (MEF2) proteins. Annu. Rev. Cell. Dev. Biol., v. 14, p. 167-196, 1998.

BONORA, E.; NOGHETI, P.; ZANCARO, C.; CIGOLINI, M.; QUERENA, M.; CACCIATORI, V.; CORGNATI, A.; MUGGEO, M. Estimates of in vivo insulin action in man: comparison of insulin tolerance testes with euglicemic and hyperglycemic glucose clmap studies. J. Clin. Endocrinol. Metab., v. 68, p. 374-378, 1989.

BUSTIN, S. A. Absolute quantification of mRNA using real-time reverse transcription polymerase chain reaction assays. J. Mol. Endocrinol., v. 25, n. 2, p. 169-193, 2000.

BRIAVANOU, A. H.; DARNELL JR, J. E. Signal Transduction and the control of gene expression. Science, v. 295, p. 813-818, 2002.

BRYAN, J.; VILA-CARRILES, W. H.; ZHAO, G.; BABENKO, A. P.; BRYAN, L. A. Toward linking structure with function in atp-sensitive k channels. Diabets, v. 53, p. S104S112, 2004. Suppl. 3.

CAMERON, D. P.; CUTBUSH, L.; OPAT, F. Effect of monosodium glutamate-induced obesty in mice on carbohydrate metabolism and insulin secretion. Clin. Exp. Pharmacol. Phyiol., v. 5, p. 41-51, 1978.

*De acordo com:

ASSOCIAÇÃO BRASILEIRA DE NORMAS TÉCNICA. NBR 6023: informação e documentação: referências: elaboração. Rio de Janeiro, 2002. 
CAMPBELL, J. D.; SANSOM, M. S. P.; ASHCROFT, F. M. Potassium channel regulation. European Molecular Biology Organization, v. 4, n.11, p. 1038-1042, 2003.

CAMPS, M.; CATELlO, A.; MUNOZ, P.; MONFAR, M.; TESTAR, X.; PALACIN, M.; ZORZANO, A.; Effect of diabetes and fasting on GLUT4-(muscle/fat) glucose transporter expression in insulin-sensitive tissues. Biocem. J., v. 282, p. 765-772, 1992.

CORTRIGHT, R. N.; DOHM, G. L. Mecanism by which by insulin and muscle contraction stimulate glucose transport. Can. J. Appl. Physiol., v. 22, p. 519-530, 1997.

DAWSON, R; ANNAU Z. A behavioral assessment of arcuate nucleus damage after a single injection of monosodium glutamate. Neurobehav. Toxicol. Teratol., v. 5, p. 399-406, 1983.

DEFROZO, R. A.; JACOT, E.; JEQUIER, E.; MAEDER, E.; WAHREN, J.; FELBER, J. P. The efeects of insulino on the disposal of intravenous glucose. Results from indirect calorimetry and hepatic and femoral venous catheterization. Diabetes. v. 30, p. 1000-1007, 1981. Suppl. 12.

DEPRE, C.; YOUNG, M.; YING, J.; AHUJA, H.; HAN, Q.; GARZA, N.; DAVIES, P.; TAEGTMEYER, H. Streptozotocin-induced changes in cardiac gene expression in the absence of severe contractile dysfunction. J. Mol. Cell. Cardiol., v. 32, p. 985-996, 2000.

EL-REYANI, N. E.; BOZDOGAN, Ö, BACZKÓ, I.; LEPRÁN, I.; PAPP, J. G. Comparison of the efficacy of glibenclamide and glimepiride in riperfunsion-induced arrhythmias is rats. Eur. J. Pharmacol., v. 365, p. 187-192, 1999.

ERBET, B. L.; GLEADLE, J. M.; O’ROURKE, J.; BARTLETT, S. M.; POUTON, J.; RATCLIFFE, P. J. Isoenzime specific regulation of genes involved in energy metabolism by hypoxia: similarities with the regulation of erythropoietin. Biochem. J., v. 313, p. 809-814, 1996.

FERNANDES, L. C.; MARQUES DA COSTA, M. M.; CURI, R. Metabolism of glucose, glutamine and pyruvate in lymphocytes from walker 256 tumor-bearing rats. Braz. J. Med. Biol. Res., v. 27, p. 2539-2543, 1994.

FlaGG, T. P.; ENKVETCHAKUl, D.; KOSTER, J. C.; COLIN G. NICHOLS, C. G. Muscle KATP Channels: Recent Insights to Energy Sensing and Myoprotection. American Physiological Society, v. 1, p. 130-135, 2010.

FURUYA, D. T.; POLETTO, A. C.; FAVARO, R. R.; MARTINS, J. O.; ZORN, T. M.; MACHADO, U. F. Anti-inflammatory effect of atorvastatin ameliorates insulin resistance in monosodium glutamate-treated obese mice. Metabolism, v. 59, p. 395-399, 2009. Suppl. 3.

GARFIN, D. E. One dimensional gel eletrophoresis. Methods Enzimol., v. 182, p. 425-441, 1990.

GULli, G.; FERRANNINI, E.; STERN, M.; HAFFNER, S.; DEFRONZO, R.A.; The metabolic profile of NIDDM is fully established in glucose-tolerant offspring of two Mexican-American NIDDM parents. Diabetes, v. 41, p. 1575-1586, 1992. 
HICKMAN, I. J.; MACDONALD, G. A. Diabetes on the severity of liver disease. Am. J. Med., v. 120, n. 10, p. 829-834, 2007.

HIMMS-HAGEN, J. Brown adipose tissue thermogenesis and obesity. Prog. Lipd. Res., v. 28, p. 67-115, 1989. Suppl. 2.

HOMMELBERG, P. P.; PlAT, J.; LANGEN, R. C.; SCHOLS, A. M.; MENSINK, R. P. Fatty acid-induced NF-kappaB activation and insulin resistance in skeletal muscle are chain length dependent. Am. J. Physiol. Endocrinol. Metab., v. 269, p. E114-E120, 2009. Suppl. 1.

HUANG, S.; CZECH, M. P. The GLUT4 glucose transporter. Cell Metabolism., v. 4, n. 4, p. 237-252, 2007.

HWANG, L. E.; GU, J.; SCHAU, M.; BUNN, H. F. Regulation of hypoxia-inducible factor 1alfa in mediated by an O2-dependent degradation damain via the ubiquitin proteasome Pathway. Proc. Natl. Acad. Sci., v. 95, p. 7987-7992, 1998.

JANSON, C. G.; CHEN Y, LI Y.; LEIFER D. Functional regulatory regions of human transcription factor MEF2C. Brain. Res. Mol., v. 16, p. 70-82, 2001

JEANRENAUD, B. Hyperinsulinemia in obesity syndromes: its metabolic consequence and possible etiology. Metabolism, v. 27, s. 2, p.1881-1892, 1978.

JOOST, H. G.; THORENS, B. The extende GLUT-family of sugar/polyol transport facilitators: nomenclature, sequence characteristics, and potential function of its novel members. Mol. Membr. Biol., v. 18, n. 4, p. 247-256, 2001.

KECSKEMET, V.; BAGI, Z.; PACHER, P,; POZA, I.; KOCSIS, E.; KOLTAI, M. Z. New trends in the development of new antidiabetic drugs. Curr. Med. Chem., v. 9, p. 53-71, 2002.

KIZER, J. S.; NEMEROFF, C. B.; YOUNGBLOOD, W. W. Neurotoxic amino acids and structurally related analogs. Pharmacol. Rev., v. 29, p. 301-318, 1978.

KOVACS, M.; KINEMAN, R. D; SCHALLY, A. V.; FLERKO, B.; FROHMAN, L. A. Increase in mRNA concentrations of pituitary receptors for growth hormone-releasing hormone ans growth hormone secretagogeus after neonatal monosodium glutamate treatment. J. Neuroendocrinol., v. 12, p. 335-341, 2000.

KRAMER, W.; MULLER, G.; GEISEN, K. Characterization of the molecular mode of action of the sulfonylurea, glimepiride, at beta cell. Horm. Metab. Res., v. 28, p. 464-468, 1996.

LEE, M.; HWANG, J. T.; LEE, H. J.; KANG, I,; CHI, S. G.; KIM, S.S.; HA, J. AMP activated protein kinase activity is critical for hypoxia-inducible factor-1 transcriptional activity and its target gene expression under hypoxic conditions in DU145 cells. J. Biol. Chem., v. 278, p. 39653-39661, 2003.

LIMA, G. A.; ANHÊ, G, F.; GIANNOCCO, G.; NUNES, M. T,; CORREA-GIANELLA, M. L.; MACHADO, U. F. Contractile activity per se induces transcriptional activation of SLC2A4 gene in soleus muscle: involvement of MEF2D, HIF1- $\alpha$, and TR alpha 
transcriptional factors. Am. J. Physiol. Endocrinol. Metab., v. 296, n. 1, p. E132-E138, 2009.

LIU, M. L.; OLSON, A. L.; EDGINGTON, N. P.; MOYE-ROWLEY, W. S.; PESSIN, J. E. Mef2 binding site is essencial forc2c12 myotubes-especifoc expression of rat GLUT4/Muscle-adipose facilitative glucose transport gene. J. Biol. Chem., v. 269, p. 2851428521, 1994.

JOVÉ, M.; PlANAVILA, A.; LAGUNA, J. C.; VÁZQUEZ-CARRERA, M. Palmitate induced interleukin 6 production is mediated by protein kinase $\mathrm{C}$ and Nuclear Factor $\mathrm{kB}$ activation and leads to glucose transporter 4 down-regulation in skeletal muscle cells. Endocrinology, v. 146, n. 7, p. 3087-3095, 2005.

LIVAK, K. J.; SCHMITTGEN, T. D. Analysis of relative gene expression data using realtime quantitative pcr and the $2^{\text {-DDct }}$. Method. Methods, v. 25, p. 402-408, 2001.

MACHADO, U. F. Trasnportadores de glicose. Arq. Bras Endocrinol. Metab., v. 42, n. 6, p. 413-421, 1998.

MACHADO, U. F.; SHIMIZU, I. SAITO, M. Decreased glucose transporter (GLUT4) contente in insulin-sentive tissues of obese aurothioglucose - and monosodium glutamatetreated mice. Horm. Metab. Res., v. 25, p. 462-465, 1993.

MACHADO, U. F.; SHIMIZU, I.; SAITO, M. Reduced content and preserved translocation of glucose transporter (GLUT4) in White adipose tissue of obese mice. Physiol. Behavior, v. 55, n. 4, p. 621-625, 1994.

MACHADO, U. F.; NOGUEIRA, C. R.; CARPINELLI, A. R. Obesity is the major cause of alterations in insulin secretion and calcium fluxes by isolated islets from aged rats. Physiol. Behav., v. 52, p. 717-721, 1992.

MACHO, L.; JEZOVA, D.; ZORAD, S.; FICKOVA, M. Postnatal monosodium glutamate treatment results in attenuation of corticosterone metabolic rate in adult rats. Endocr. Regul., v. 33, p. 61-67, 1999. Suppl. 2.

MACHO, L.; FICKOVÁ, M.; JEZOVA, D.; ZORAD, S. Late effects of postnatal administration of monosodium glutamate on insulin action in adults rats. Phisiol. Res., v. 49, p. S79-S85, 2000. Suppl. I.

MAITER, D.; UNDERWOOD, L. E.; MARTIN, J. B.; KOENIG, J. I. Neonatal treatment with monosodium glutamate: effects of prolonged growth hormone $(\mathrm{GH})$-releasing hormone deficiency on pulsatile GH secreation and growth n female rats. Endocrinology, v. 128, p. 1100-1106, 1991. Suppl. 2.

MARCHETTI, P.; DOTTA, F.; LAURO, D.; PURRELLO, F. An overview of pancreatic beta-cell defects in human type 2 diabetes: implications for treatment. Regulatory Peptides, v. 146, n. 1-3, p. 4-11, 2008. 
MARETTE, A.; RICHARDSON, J. M.; RAMLAL, T.; BALON, T. W.; VRANIC, M.; PESSIN, J. E.; KLIP, A. Abundance, localization, and insulin-induced translocation of glucose transports in red and White muscle. Am. J. Physiol., v. 273, p. C443-C452, 1992.

MARMO, M. R.; NUNES, M.T; VOLPATO, C. T.; KETEKHUT, I. C.; HELL, N. S.; LIMA, F. B.; DOLNIKOFF, M. S. Reduced growth hormone mRNA levels in 28d-old MSG rats impair protein and lipid metabolism. Eur. J. Physiol., v. 427, p. R29, 1994.

MAXWELL, P. H.; WIESENER, M. S.; CHANG, G. W.; CLIFFORD, S. C.; VAUX, E. C.; COCKMAN, M. E.; WYKOFF, C. C.; PUGH, C. W.; MAHER, E. R.; RATCLIFFE, P. J. The tumor suppressor protein VHL targets hypoxia-inducible factors for oxygen-dependent proteolysis. Nature, v. 399, p. 271-275, 1999.

MEETOO, D.; MCGOVERN, P.; SAFADI, R. An epidemiological overview of diabetes across the world British. Journal of nursing., v. 16, n. 16, p. 1002-1007, 2007.

MORENO, H.; SERRANO, A. L.; SANTALUCIA, T.; GUMMÁ, A.; CANTO, C.; BRAND, N. J.; PALCÍN, M. SCHIAFFINO, S.; ZORZANO, A. Differential regulation of the muscle specific GLUT4 enhancer in regenerating and adult skeletal muscle. J. Biol. Chem., v. 278. p. 40557-40564, 2003.

MORI, R. C.; HIRABARA, S. M.; HIRATA, A. E.; OKAMOTO, M. M.; MACHADO, U. F. Glimepiride as insulin sensitizer: increased liver and muscle responses to insulin. Diabetes Obes. Metab., 2008.

MORTON, N. M.; PATERSON, J. M.; MASUZAKI, H.; HOLMES, M. C.; STAELS, B.; FIEVET, C.; WALKER, B. R.; FLIER, J. S.; MULLINS, J. J.; SECKL, J. R. Novel adipose tissue-mediated resistance to diet-induced visceral obesity in 11 beta-hydroxysteroid dehydrogenase type 1-deficient mice. Diabetes, v. 53, p. 931-938, 2004. Suppl. 4.

MORRIS, M. J.; TORTELLI, C. F.; FILIPPIS, A.; PROIETTO, J. Reduced BAT function as a mechanism for obesity in the hypophagic, neuropeptide $\mathrm{Y}$ deficient monosodium glutamatetreated rat. Regul. Peptide, v. 25, n. 75-76, p. 441-447, 1998.

MINAMI, K., MIKI T.; KADOWAKI, T.; SEINO, S. Roles of ATP-Sensitive K channels as metabolic sensors: studies of Kir6.x null mice. Diabets, v. 53, n. 3, 2004.

MITSUMOTO, Y.; KLIP, A. Developmental regulation of the subcellular distribution and glicosylation of GLUT1 and GLUT4 glucose transporters during myogenesis of L6 muscle cells. J. Biol. Chem., v. 267, n.7, p. 4957-4962, 1992.

MULLER, G.; GEISEN, K. Characterization of the molecular mode of action of the sulfonylurea, glimepiride, at adipocytes. Horm. Metab. Res., v. 28, n. 9, p. 469-487, 1996.

NAKAJIMA, H.; TOCHINO, Y.; FUJINO-KURIHARA, H.; YAMADA, K.; GOMI, M.; TAJIMA, K.; KANAYA, T.; MIYAZAKI, A.; MIYAGAWA, J.; HANAFUSA, T. Decreased incidence of diabetes mellitus by monosodium glutamate in the non-obese diabetic (NOD) mouse. Ress. Commum. Chem. Pathol. Pharmacol., v. 50, p. 251-257, 1985. Suppl. 2. 
NAKAI, T.; TAMAI, T.; TAKAI, H.; HAYASHI, S.; FUJIWARA, R.; MIYABO, S. Decreased ketonaemia in the monosodium glutamate-induced obese rats. Life Sci., v. 28, p. 2009-20013, 1986. Suppl. 22.

NAGASHIMA, K.; TAKAHASHI, A.; IKEDA, H.; HAMASAKI, A.; KUWAMURA, N.; YAMADA, Y.; SEINO, Y. Sulfonylurea and non-sulfonylurea hypoglycemic agents: pharmachological properties and tissue selectivity. Diabetes Res. Clin. Pract., v. 66, n. 1, p. S75-S78, 2004.

NEMEROFF, C. B.; KONKOL, R. J.; BISSETE, G.; YOUNGBLOOD, W.; MARTIN, J. B.; BRAZEAU, P.; RONE, M. S.; PRANGE, A. J.; BREESE, G. R.; KIZER, J. S. Analysis of the discruption in hypothalamic-pitutary regulation in rats treated enotally with monosodium Lglutamate (MSG): envidence for the involvement of tuberoinfundibular cholinergic and dopaminergic systems in neuroendocrine regulation. Endocrinology, v. 101, p. 613-622, 1997. Suppl. 2.

NEUFER, P. D.; CAREY, J. O.; DOHM, G. L. Transcriptional regulation of the gene for glucose transporter GLUT4 in skeletal muscle. Effects of diabetes and fasting. J. Biol. Chem., v. 268, p.13824-13829, 1993.

OLNEY, J. H. Brain lesions, obesity and other disturbances in mice treated with monosodium glutamate. Science, v. 164, p. 719-721, 1969.

PAIVA, D. C. P.; BERSUSA, A. A. S.; ESCUDER, M. M. L. Avaliação da assistência ao paciente com diabetes e/ou hipertensão pelo Programa Saúde da Família do Município de Francisco Morato, São Paulo, Brasil. Cad. Saúde Pública, Rio de Janeiro, v. 22, n. 2, p. 377 385, 2006.

de CARVALHO PAPA, P.; VARGAS, A. M.; SILVA, J. L. T., NUNES, M. T.; MACHADO, U. F. GLUT4 protein is differently modulated during development of obesity in monosodium glutamate-treated mice. Life Sciences, v. 71, p. 1917-1928, 2002.

PAPA, P. C.; SERAPHIM, P. M.; MACHADO, U. F. Loss of weght restores GLUT4 content in insulin-sensitive tissues of monosodium glutamate-treated mice. International Journal of Obesity, v. 21, p. 1065-1070, 1997.

PERKINS, N. D. Integrating cell-signalling pathways with NF- $\kappa \mathrm{B}$ and IKK function. Nat. Rev. Mol. Cell Biol., v. 8, p. 49-67, 2007.

PFAFFL, M. W. A new mathematical model for relative quantification in real-time RT-PCR. Nucleic Acids Research, v. 29, n. 9, p. 45, 2001.

PRATIPANAWATR, W.; PRATIPANAWATR, R.; CUSI, K.; BERRIA, R.; ADAMS, J. M.; JENKINSON, C. P.; MAEZONO, K.; DEFRONZO, R. A.; MANDARINO, L. J. Skeletal muscle insulin resistance in nomroglycemic subjects with a strong family history or type 2 diabetes is associated with decreased insulin-stimulated insulin receptor substrate- 1 tyrosine phosphrylation. Diabetes, v. 50; p. 2572-2578, 2001.

PRATO, S. D.; BIANCHI, C.; MARCHETTI, P. B-cell function and anti-diabetic pharmacotherapy. Diabetes/Metabolism Research and Reviews, v. 23, p. 518-527, 2007. 
PILZ, S.; MÄRZ, W. Free fatty acids as a cardiovascular risk factor. Clin. Chem. Lab. Med., v. 46, n. 4, p. 429-434, 2008.

RAPTIS, S. A.; DIMITRIADIS, G. D. Oral hypoglycemic agents: insulin secretagogues, alpha-glucosidase inhibitors and insulin sensitizers. Exp. Clin. Endocrinol. Diabets, v. 109, p. S265-S287, 2001. Suppl. 2.

REAVEN, G. M. Role of insulin resistance in human disease. Diabetes, v. 37, p. 1595-1607, 1998.

RICHARDSON, J. M.; BALOW, T. W.; TREADWAY, J. L.; PESSIN, J. E. Differential regulation of glucose transporter activity and expression in red white skeletal muscle. Diabetes. v. 266, n. 16, p. 12690-12694, 1991.

ROGERS, P.; WEBB, G. P. Estimation of body fat normal and obese mice. Br. J. Nutr., v. 43, s. 1, p. 83-86, 1980.

RUAN, H.; HACOHEN, N.; GOLUB, T. R.; VAN PARIS, L.; LODISH, H. F. Tumor necrosis factor- $\alpha$ supresses adipocyte-specific genes and activates expression of preadipocyte genes in 3T3-L1 adipocytes. Nuclear factor- $\kappa \mathrm{B}$ activation by TNF- $\alpha$ is obligatory. Diabetes, v. 51, p. 1319-1336, 2002.

SCHEEPERS, A.; JOOST, H. G.; SCHÜRMANN, A. The glucose transporter families SGLT and GLUT: molecular basis of normal and aberrant function. J. Parent. Ent. Nutrit., v. 28, n. 5, p. 365-372, 2004.

SEINO, S.; MIKI, T. Physiological and pathophysiological roles of ATP-sensitive K+ channels. Prog. Biophys. Mol. Biol., v. 81, n. 2, p. 133-176, 2003.

SILVA, J. L. T.; GIANOCCO, G.; FURUYA, D. T.; LIMA, G. A; MORAES, P. A. C.; NACHEF, S.; BORDIN, S.; BRITTO, L. R. G.; NUNES, M. T.; MACHADO, U. F. NF-kB, MEF2A, MEF2D and HIF1-a involvemet on insulin- and contraction-induced regulation of GLUT4 gene expression in soleous muscle. Mol. Cell. Endoc., v. 240, p. 82-93, 2005.

SKELLY, A. H. Type 2 Diabetes mellitus. Nursing Clinics of North America, v. 41, p. 531-547, 2006.

SMITH, A. J.; TANEJA, T. K.; MANKOURI, J.; SIVAPRASADARAO, A. Molecular cell biology of KATP channels: implications for neonatal diabetes. Expert Rev. Mol. Med., v. 9, n. 21, p. 1-17, 2007.

SOLBACH, T. F.; KFNIG, J.; FROMM, M. F.; ZOLK, O. ATP-Binding Cassette Transporters in the Heart. Trends Cardiovasc. Med., v. 16, n. 1, p. 7-15, 2006.

SPELLMAN, C. W. Islet cell dysfunction in progression to diabetes mellitus. J Am Osteopath Assoc., v. 107, p. S1-S5, 2007. Suppl. 3.

SPELLMAN, C. W. Aggressively managing type 2 diabetes mellitus, hyperlipidemia, and bone loss. J. Am. Osteopath Assoc., v. 5, n. 3, p. 20-27, 2008. 
THAI, M. V.; GURUSWAMY, S.; CAO, K. T.; PESSIN, J. E.; OLSON, A. L. Myocyte enhancer factor 2 (MEF2)-binding site is required for GLUT4 gene expression in transgenic mice. Regulation of MEF2 DNA binding activity in insulin- deficient diabetes. J. Biol. Chem., v. 273, p. 14285-14292, 1998.

THOMAS, P. M.; COTE, G. J.; WOHLIK, S.; HADDAD, B.; MATHEW, P. M.; RABL, W. Mutations in the sulfonylurea receptor gene in familial persistent hyperinsulinemic hypoglycemia of infancy. Science, v. 268, p. 426-429, 1995.

TIBALDI. J. Initiating and intensifying insulin therapy in type 2 diabetes mellitus. The American Journal of Medicine. v. 121, n. 6, p. 20-29, 2008.

TOKUYAMA, K.; HIMMS-HAGEN, J. Brown adipose tissue thermogenesis, torpor, and obesity of glutamate-treated mice. Am. J. Physiol., v. 251, p. 407-415, 1986.

VIRKAMAKI, A.; KORSHENINNIKOVA, E.; SEPALA-LINDROOS, A.; VEHKAVAARA, S.; GOTO, T.; HALAVAARA, J.; HAKKINEN, A. M.; YKI-JARVINEN, $\mathrm{H}$. Intramyocellular lipid is associated with resistance to vivo insulin actions on glucose uptake, antilipolysis, and early insulin signaling pathways in human skeletal muscle. Diabetes, v. 50, p. 2337-2345, 2001. Suppl. 10.

WANG, G. L.; SEMENZA, G. L. General involvement of hypoxia-inducible factor 1 in transcriptional response to hypoxia. Proc. Natl. Acad. Sci., v. 90, p. 4304-4308, 1993.

WANG, G. L.; SEMENZA, G. L. Purification and characterization of hypoxia-inducible factor 1. J.Biol. Chem., v. 270, p. 1230-1237, 1995.

WILD, S.; ROGLIC, G.; GREEN, A.; SICREE R.; KING, H. G. Prevalence of diabetes. estimates for the year 2000 and projections for 2030. Diabetes Care, v. 27, p. 1047-1053, 2004.

WILDING, J. P. H. The importance of free fatty acids in the development of Type 2 diabetes. Diabetic Medicine, v. 24, p. 934-945, 2007.

WORLD HEALTH ORGANIZATION. Definition and diagnosis of classification of diabetes mellitus and intermediate hyperglycemia. Report of a WHO/IDF consultation, 2006 .

YONEMITSU, S.; NISHIMURA, H.; SHINTANI, M.; INOUE, R.; YAMAMOTO, Y.; MASUZAKI, H.; OGAWA, Y.; HOSODA, K.; INOUE, G.; HAYASHI, T.; NAKAO, K. Troglitazone induces GLUT4 translocation in L6 myotubes. Diabetes, v. 50, p. 1093-1101, 2001.

ZORZANO, A.; PALACIN, M.; GUMÀ, A. Mechanisms regulating GLUT4 glucose transporter expression and glucose transport in skeletal muscle. Acta. Physiol. Scand., v. 183, p. 43-58, 2005. 


\section{APÊNDICE - Tabelas}

Tabela A1 - (Referente à figura 2) - Conteúdo de mRNA de SUR2A de músculo EDL de ratos controles e obesos, tratados ( $\mathrm{CG}$ e $\mathrm{MSG} / \mathrm{G})$ e não tratados (C e $\mathrm{MSG})$ com glimepirida, por 4 semanas.

\begin{tabular}{lc}
\hline GRUPO & mRNA $\left(\mathbf{2}^{\text {-DDCt }}\right)$ \\
\hline $\mathbf{C}(\mathbf{n}=\mathbf{1 2})$ & $1,032 \pm 0,036$ \\
$\mathbf{C G}(\mathbf{n}=\mathbf{7})$ & $0,945 \pm 0,102$ \\
$\mathbf{M S G}(\mathbf{n}=\mathbf{6})$ & $0,973 \pm 0,102$ \\
$\mathbf{M S G} / \mathbf{G}(\mathbf{n}=\mathbf{1 1})$ & $1,033 \pm 0,056$ \\
\hline
\end{tabular}

Resultados expressos como médias \pm EPM, comparados por ANOVA de 1 via para dados independentes, seguida do teste de Student Newman-Kewls.

Tabela A2 - (Referente à figura 2) - Conteúdo da proteína de SUR2A de músculo EDL de ratos controles e obesos, tratados (CG e $\mathrm{MSG} / \mathrm{G})$ e não tratados (C e $\mathrm{MSG}$ ) com glimepirida, por 4 semanas

\begin{tabular}{ll}
\hline GRUPO & PROTEÍNA (UA/g tecido) \\
\hline C $(\mathbf{n}=\mathbf{5})$ & $255,6 \pm 11,2$ \\
CG $(\mathbf{n}=\mathbf{5})$ & $281,8 \pm 18,9$ \\
MSG $(\mathbf{n}=\mathbf{5})$ & $268,2 \pm 18,7$ \\
MSG/G $(\mathbf{n}=\mathbf{6})$ & $240,5 \pm 16,1$
\end{tabular}

Resultados expressos como médias \pm EPM, comparados por ANOVA de 1 via para dados independentes, seguida do teste de Student Newman-Kewls. 
Tabela A3 - (Referente à figura 3) - Conteúdo de mRNA e proteína de KIR6.2 de músculo EDL de ratos controles e obesos, tratados (CG e $\mathrm{MSG} / \mathrm{G})$ e não tratados (C e MSG) com glimepirida, por 4 semanas.

\begin{tabular}{lll}
\hline GRUPO & mRNA $\left(\mathbf{2}^{\text {-DDCt }}\right)$ & PROTEÍNA (UA/g tecido) \\
\hline C & $1,041 \pm 0,053$ & $429,9 \pm 65,8$ \\
CG & $1,291 \pm 0,106^{* *}$ & $409,9 \pm 92,8$ \\
MSG & $0,860 \pm 0,077^{\wedge \wedge}$ & $491,5 \pm 28,8$ \\
MSG/G & $0,992 \pm 0,090^{\wedge}$ & $536,5 \pm 65$
\end{tabular}

Resultados expressos como médias \pm EPM, comparados por ANOVA de 1 via para dados independentes, seguida do teste de Student Newman-Kewls.

$* * \mathrm{p}<0,01$ vs. $\mathrm{C}, \wedge \mathrm{p}<0,01$ vs. $\mathrm{CG}$

Tabela A4 - (Referente à figura 4) - Conteúdo de mRNA de MEF2A de músculo EDL de ratos controles e obesos, tratados (CG e $\mathrm{MSG} / \mathrm{G})$ e não tratados (C e MSG) com glimepirida, por 4 semanas

\begin{tabular}{lc}
\hline GRUPO & mRNA $\left(\mathbf{2}^{- \text {-DDCt }}\right)$ \\
\hline C $(\mathbf{n}=\mathbf{1 2})$ & $0,954 \pm 0,157$ \\
CG $(\mathbf{n}=\mathbf{1 1})$ & $1,003 \pm 0,278$ \\
MSG (n= 12) & $1,047 \pm 0,173$ \\
MSG/G (n= 9) & $0,854 \pm 0,169$ \\
\hline
\end{tabular}

Resultados expressos como médias \pm EPM, comparados por ANOVA de 1 via para dados independentes, seguida do teste de Student Newman-Kewls. 
Tabela A5 - (Referente á figura 5) - Conteúdo de mRNA de MEF2D de músculo EDL de ratos controles e obesos, tratados (CG e $\mathrm{MSG} / \mathrm{G})$ e não tratados (C e $\mathrm{MSG}$ ) com glimepirida, por 4 semanas

\begin{tabular}{ll}
\hline GRUPO & mRNA $\left(\mathbf{2}^{\text {-DDCt }}\right)$ \\
\hline C $(\mathbf{n}=\mathbf{7})$ & $1,071 \pm 0,260$ \\
CG $(\mathbf{n}=\mathbf{8})$ & $0,749 \pm 0,073$ \\
$\mathbf{M S G}(\mathbf{n}=\mathbf{5})$ & $1,425 \pm 0,249$ \\
$\mathbf{M S G} / \mathbf{G}(\mathbf{n}=\mathbf{6})$ & $1,654 \pm 0,307$ \\
\hline
\end{tabular}

Tabela A6 - (Referente à figura 6) - Conteúdo de mRNA de HIF1- $\alpha$ de músculo EDL de ratos controles e obesos, tratados ( $\mathrm{CG}$ e $\mathrm{MSG} / \mathrm{G})$ e não tratados (C e $\mathrm{MSG}$ ) com glimepirida, por 4 semanas

\begin{tabular}{ll}
\hline GRUPO & mRNA $\left(\mathbf{2}^{\text {-DDCt }}\right)$ \\
\hline $\mathbf{C}(\mathbf{n}=\mathbf{8})$ & $0,375 \pm 0,049$ \\
$\mathbf{C G}(\mathbf{n}=\mathbf{9})$ & $0,361 \pm 0,099$ \\
$\mathbf{M S G}(\mathbf{n}=\mathbf{6})$ & $0,443 \pm 0,114$ \\
$\mathbf{M S G} / \mathbf{G}(\mathbf{n}=\mathbf{6})$ & $0,438 \pm 0,111$ \\
\hline
\end{tabular}

Resultados expressos como médias \pm EPM, comparados por ANOVA de 1 via para dados independentes, seguida do teste de Student Newman-Kewls. 
Tabela A7 - (Referente à figura 7) - Conteúdo de mRNA do Slc2a4 de músculo EDL e da proteína $(\mathrm{PM}+\mathrm{M})$ de GLUT4 de ratos controles e obesos, tratados (CG e MSG/G) e não tratados (C e MSG) com glimepirida, por 4 semanas.

GRUPO $\quad$ mRNA (2 $\left(^{\text {-DDCt }}\right) \quad$ PROTEÍNA (UA/g tecido)

\begin{tabular}{lcc}
\hline C & $1,043 \pm 0,09$ & $431,4 \pm 43,7$ \\
MG & $0,938 \pm 0,077$ & $394,7 \pm 86,9$ \\
MSG/G & $0,621 \pm 0,08^{* * \wedge}$ & $505,9 \pm 62,3$ \\
& $1,076 \pm 0,09 \# \#$ & $406,7 \pm 64,2$
\end{tabular}

Resultados expressos como médias \pm EPM, comparados por ANOVA de 1 via para dados independentes, seguida do teste de Student Newman-Kewls.

${ }^{* *} \mathrm{p}<0,01$ vs. $\mathrm{C} ; \wedge$ p $<0,05$ vs. CG; \#\# $\mathrm{p}<0,01$ vs. MSG

Tabela A8 - (Referente à figura 8) - Conteúdo de proteína GLUT4 nas frações de membranas plasmáticas (PM) e microssomais (M) de músculo EDL de ratos controles e obesos, tratados (CG e MSG/G) e não tratados (C e MSG) com glimepirida, por 4 semanas.

\begin{tabular}{lll}
\hline GRUPO & PM (UA/g tecido) & M (UA/g tecido) \\
\hline C $(\mathbf{n}=\mathbf{9})$ & $375,8 \pm 45,3$ & $55,6 \pm 7,3$ \\
CG $(\mathbf{n}=\mathbf{9})$ & $365 \pm 58,5$ & $38,7 \pm 9,5$ \\
MSG (n= 9) & $465,2 \pm 61,9$ & $40,6 \pm 6,6$ \\
MSG/G (n= 10) & $352,1 \pm 63,6$ & $54,5 \pm 8,1$ \\
\hline
\end{tabular}

Resultados expressos como médias \pm EPM, comparados por ANOVA de 1 via para dados independentes, seguida do teste de Student Newman-Kewls. 
Tabela A9 - (referente à figura 9) - Conteúdo de mRNA de SUR2A de músculo sóleo de ratos controles e obesos, tratados (CG e MSG/G) e não tratados (C e MSG) com glimepirida, por 4 semanas

\begin{tabular}{ll}
\hline GRUPO & mRNA $\left(2^{\text {-DDCt }}\right)$ \\
\hline C & $1,124 \pm 0,113$ \\
CG & $0,944 \pm 0,157$ \\
MSG & $1,101 \pm 0,192$ \\
MSG/G & $2,184 \pm 0,379 * * *^{*} \#$ \\
\hline
\end{tabular}

Resultados expressos como médias \pm EPM, comparados por ANOVA de 1 via para dados independentes, seguida do teste de Student Newman-Kewls.

** $\mathrm{p}<0,001$ vs. $\mathrm{C} ;{ }^{\wedge \wedge} \mathrm{p}<0,01$ vs. CG; \#\# $\mathrm{p}<0,01$ vs. MSG

Tabela A10 - (Referente à figura 10) - Conteúdo de mRNA de KIR6.2 e de proteína KIR6.2 (membranas plasmáticas) de músculo sóleo ratos controles e obesos, tratados (CG e $M S G / G)$ e não tratados (C e MSG) com glimepirida, por 4 semanas.

\begin{tabular}{|c|c|c|}
\hline GRUPO & mRNA $\left(2^{-D D C t}\right)$ & PROTEÍNA (UA/g tecido) \\
\hline $\mathbf{C}$ & $1 \pm 0,048$ & $249,45 \pm 41,4$ \\
\hline $\mathbf{C G}$ & $1,038 \pm 0,141$ & $166 \pm 16,5$ \\
\hline MSG & $1,126 \pm 0,153$ & $239,66 \pm 47,5$ \\
\hline MSG/G & $1,89 \pm 0,28^{* `} \# \#$ & $559,02 \pm 58,5^{* * * \cdots \wedge} \# \# \#$ \\
\hline
\end{tabular}

Resultados expressos como médias \pm EPM, comparados por ANOVA de 1 via para dados independentes, seguida do teste de Student Newman-Kewls.

A: ${ }^{*} \mathrm{p}<0,05$ vs. $\mathrm{C} ;{ }^{* * *} \mathrm{p}<0,001$ vs. $\mathrm{C} ;{ }^{\wedge} \mathrm{p}<0,05$ vs. $\mathrm{CG} ;{ }^{\wedge} \wedge \mathrm{p}<0,01$ vs. $\mathrm{CG}$; \#\# $\mathrm{p}<0,01$ vs. MSG; \#\#\# $\mathrm{p}<0,001$ vs. MSG 
Tabela A11 - (Referente à figura 11) - Conteúdo de mRNA de MEF2A de músculo sóleo de ratos controles e obesos, tratados (CG e $\mathrm{MSG} / \mathrm{G})$ e não tratados (C e $\mathrm{MSG}$ ) com glimepirida, por 4 semanas.

\begin{tabular}{lc}
\hline GRUPO & mRNA $\left(\mathbf{2}^{\text {-DDCt }}\right)$ \\
\hline $\mathbf{C}(\mathbf{n}=\mathbf{1 3})$ & $0,989 \pm 0,103$ \\
$\mathbf{C G}(\mathbf{n}=\mathbf{7})$ & $1,110 \pm 0,33$ \\
$\mathbf{M S G}(\mathbf{n}=\mathbf{9})$ & $1,150 \pm 0,194$ \\
$\mathbf{M S G} / \mathbf{G}(\mathbf{n}=\mathbf{1 1})$ & $1,504 \pm 0,266$ \\
\hline
\end{tabular}

Resultados expressos como médias \pm EPM, comparados por ANOVA de 1 via para dados independentes, seguida do teste de Student Newman-Kewls.

Tabela A12 - (Referente à figura 12) - Conteúdo de mRNA de MEF2D de músculo sóleo de ratos controles e obesos, tratados (CG e $\mathrm{MSG} / \mathrm{G})$ e não tratados (C e $\mathrm{MSG}$ ) com glimepirida, por 4 semanas.

\begin{tabular}{ll}
\hline GRUPO & mRNA $\left(\mathbf{2}^{\text {-DDCt }}\right)$ \\
\hline $\mathbf{C}(\mathbf{n}=\mathbf{8})$ & $1,253 \pm 0,1821$ \\
$\mathbf{C G}(\mathbf{n}=\mathbf{8})$ & $1,084 \pm 0,241$ \\
$\mathbf{M S G}(\mathbf{n}=\mathbf{8})$ & $1,248 \pm 0,242$ \\
$\mathbf{M S G} / \mathbf{G}(\mathbf{n}=\mathbf{1 0})$ & $1,488 \pm 0,269$ \\
\hline
\end{tabular}

Resultados expressos como médias \pm EPM, comparados por ANOVA de 1 via para dados independentes, seguida do teste de Student Newman-Kewls. 
Tabela A13 - (Referente à figura 13) - Conteúdo de mRNA de HIF1- $\alpha$ de músculo sóleo de ratos controles e obesos, tratados (CG e $\mathrm{MSG} / \mathrm{G})$ e não tratados (C e $\mathrm{MSG}$ ) com glimepirida, por 4 semanas.

\begin{tabular}{lc}
\hline GRUPO & mRNA $\left(\mathbf{2}^{-\mathbf{D D C t}}\right)$ \\
\hline $\mathbf{C}(\mathbf{n}=\mathbf{1 3})$ & $1,316 \pm 0,239$ \\
$\mathbf{C G}(\mathbf{n}=\mathbf{7})$ & $1,306 \pm 0,272$ \\
$\mathbf{M S G}(\mathbf{n}=\mathbf{9})$ & $1,897 \pm 0,218$ \\
MSG/G (n= 12) & $1,488 \pm 0,269$ \\
\hline
\end{tabular}

Resultados expressos como médias \pm EPM, comparados por ANOVA de 1 via para dados independentes, seguida do teste de Student Newman-Kewls.

Tabela A14 - (Referente à figura 14) - Conteúdo de mRNA Slc2a4 e de proteína GLUT4 de músculo sóleo de ratos controles e obesos, tratados (CG e $\mathrm{MSG} / \mathrm{G}$ ) e não tratados (C e MSG) com glimepirida, por 4 semanas.

\begin{tabular}{lll}
\hline GRUPO & mRNA $\left(\mathbf{2}^{\text {-DDCt }}\right)$ & PROTEÍNA (UA/g tecido) \\
\hline C & $0,9912 \pm 0,099$ & $466,29 \pm 68,78$ \\
CG & $1,166 \pm 0,214$ & $559,13 \pm 92,79$ \\
MSG & $1,219 \pm 0,23$ & $655,79 \pm 110,6$ \\
MSG/G & $1,981 \pm 0,384^{*}$ & $1310,99 \pm 143,87^{* * * \# \#}$ \\
\hline
\end{tabular}

Resultados expressos como médias \pm EPM, comparados por ANOVA de 1 via para dados independentes, seguida do teste de Student Newman-Kewls.

${ }^{*} \mathrm{p}<0,05$ vs. $C ;{ }^{* * *} \mathrm{p}<0,001$ vs. $\mathrm{C} ; \# \# \mathrm{p}<0,01$ vs. MSG. 
Tabela A15 - (Referente à figura 15) - Conteúdo de proteína GLUT4 nas frações de membranas plasmáticas (PM) e microssomais (M) de musculo SOLEO de ratos controles e obesos, tratados (CG e MSG/G) e não tratados (C e MSG) com glimepirida, por 4 semanas.

\begin{tabular}{|c|c|c|}
\hline GRUPO & PM (UA/g tecido) & M (UA/g tecido) \\
\hline$C(n=8)$ & $406,74 \pm 73,37$ & $59,55 \pm 8,76$ \\
\hline$C G(n=8)$ & $492,57 \pm 98,72$ & $63,56 \pm 9,67$ \\
\hline $\operatorname{MSG}(n=9)$ & $579,26 \pm 131,8$ & $76,54 \pm 5,76$ \\
\hline MSG/G $(n=9)$ & $1161,2 \pm 163,38 * * \# \#$ & $149,99 \pm 12,34 * * * \# \# \#$ \\
\hline
\end{tabular}

Resultados expressos como médias \pm EPM, comparados por ANOVA de 1 via para dados independentes, seguida do teste de Student Newman-Kewls.

$*^{* *} \mathrm{p}<0,01$ vs. $\mathrm{C} ; \# \# \mathrm{p}<0,01$ vs. $\mathrm{MSG} ; * * * \mathrm{p}<0,001$ vs. $\mathrm{C} ; \# \# \# \mathrm{p}<0,001$ vs. MSG

Tabela A16 - (Referente à figura 16) - Análise do mRNA de SUR2a em cultura de células musculares L6. Grupos: controle, controle + insulina, glimepirida e glimepirida + insulina por 24 horas.

\begin{tabular}{ll}
\hline GRUPO & mRNA $\left(\mathbf{2}^{-\mathrm{DDCt}}\right)$ \\
\hline Controle & $1,001 \pm 0,0191$ \\
Controle + Insulina & $0,848 \pm 0,037$ \\
Glimepirida & $1,181 \pm 0,057^{\wedge \wedge *}$ \\
Glimepirida + Insulina & $0,824 \pm 0,104 \# \#$ \\
\hline
\end{tabular}

Resultados expressos como médias \pm EPM, comparados por ANOVA de 1 via para dados independentes, seguida do teste de Student Newman-Kewls.

* $\mathrm{p}<0,01$ vs. Controle; ${ }^{\wedge \wedge} \mathrm{p}<0,001$ vs. Controle + Insulina; \#\# $\mathrm{p}<0,01$ vs. Glimepirida 
Tabela A17 - (Referente à figura 17) - Análise do mRNA de KIR6.2 em cultura de células musculares L6. Grupos: controle, controle + insulina, glimepirida e glimepirida + insulina por 24 horas.

\begin{tabular}{ll}
\hline GRUPO & mRNA $\left(\mathbf{2}^{\text {-DDCt}}\right)$ \\
\hline Controle & $0,964 \pm 0,066$ \\
Controle + Insulina & $0,692 \pm 0,084^{*}$ \\
Glimepirida & $1,507 \pm 0,113^{\wedge \wedge \wedge * * *}$ \\
Glimepirida + Insulina & $1,102 \pm 0,054 \# \# \wedge \wedge$ \\
\hline
\end{tabular}

Tabela A18 - (Referente à figura 18) - Análise do mRNA de Slc2a4 em cultura de células musculares L6. Grupos: controle, controle + insulina, glimepirida e glimepirida + insulina por 24 horas.

\begin{tabular}{ll}
\hline GRUPO & mRNA $\left(\mathbf{2}^{\text {-DDCt }}\right)$ \\
\hline Controle & $0,977 \pm 0,053$ \\
Controle + Insulina & $1,201 \pm 0,832$ \\
Glimepirida & $0,638 \pm 0,101^{* * \wedge \wedge \wedge}$ \\
Glimepirida + Insulina & $0,975 \pm 0,071 \# \#$ \\
\hline
\end{tabular}

Resultados expressos como médias \pm EPM, comparados por ANOVA de 1 via para dados independentes, seguida do teste de Student Newman-Kewls.

** $\mathrm{p}<0,001$ vs. Controle; ${ }^{\wedge \wedge \wedge} \mathrm{p}<0,001$ vs. Controle + Insulina; \#\# $\mathrm{p}<0,01$ vs. Glimepirida 
Tabela A19 - (Referente à figura 19) - Análise do mRNA de MEF2A em cultura de células musculares L6. Grupos: controle, controle + insulina, glimepirida e glimepirida + insulina por 24 horas.

\begin{tabular}{lc}
\hline GRUPO & mRNA $\left(\mathbf{2}^{\text {-DDCt }}\right)$ \\
\hline Controle & $0,914 \pm 0,113$ \\
Controle + Insulina & $0,944 \pm 0,157$ \\
Glimepirida & $1,121 \pm 0,192$ \\
Glimepirida + Insulina & $1,014 \pm 0,379$ \\
\hline
\end{tabular}

Resultados expressos como médias \pm EPM, comparados por ANOVA de 1 via para dados independentes, seguida do teste de Student Newman-Kewls.

Tabela A20 - (Referente à figura 20) - Análise do mRNA de MEF2D em cultura de células musculares L6. Grupos: controle, controle + insulina, glimepirida e glimepirida + insulina por 24 horas.

\begin{tabular}{ll}
\hline GRUPO & mRNA $\left(\mathbf{2}^{\text {-DDCt }}\right)$ \\
\hline Controle & $1,073 \pm 0,085$ \\
Controle + Insulina & $0,970 \pm 0,071$ \\
Glimepirida & $1,118 \pm 0,089$ \\
Glimepirida + Insulina & $0,788 \pm 0,106^{* * *} \# \#$ \\
\hline
\end{tabular}

Resultados expressos como médias \pm EPM, comparados por ANOVA de 1 via para dados independentes, seguida do teste de Student Newman-Kewls. 
Tabela A21 - (Referente à figura 21) - Análise do mRNA de HIF-1a em cultura de células musculares L6. Grupos: controle, controle + insulina, glimepirida e glimepirida + insulina por 24 horas.

\begin{tabular}{lc}
\hline GRUPO & mRNA $\left(2^{\text {-DDCt }}\right)$ \\
\hline Controle & $0,944 \pm 0,041$ \\
Controle + Insulina & $0,924 \pm 0,011$ \\
Glimepirida & $0,786 \pm 0,042$ \\
Glimepirida + Insulina & $0,975 \pm 0,071$
\end{tabular}

Resultados expressos como médias \pm EPM, comparados por ANOVA de 1 via para dados independentes, seguida do teste de Student Newman-Kewls.

Tabela A22 - (Referente à figura 22) - Análise do mRNA de NF-KB em cultura de células musculares L6. Grupos: controle, controle + insulina, glimepirida e glimepirida + insulina por 24 horas.

\begin{tabular}{ll}
\hline GRUPO & mRNA $\left(2^{- \text {DDCt }}\right)$ \\
\hline Controle & $1,085 \pm 0,071$ \\
Controle + Insulina & $0,758 \pm 0,076^{*}$ \\
Glimepirida & $1,439 \pm 0,0943^{* * \wedge \wedge}$ \\
Glimepirida + Insulina & $0,932 \pm 0,096 \# \#$ \\
\hline
\end{tabular}

Resultados expressos como médias \pm EPM, comparados por ANOVA de 1 via para dados independentes, seguida do teste de Student Newman-Kewls.

** $\mathrm{p}<0,001$ vs. $\mathrm{C} ;{ }^{\wedge \wedge} \mathrm{p}<0,01$ vs. $\mathrm{CG} ; \# \# \mathrm{p}<0,01$ vs. MSG 